\title{
BUILDING BLOCKS OF ELECTRIC VEHICLE DEPLOYMENT \\ A GUIDE FOR DEVELOPING COUNTRIES
}

May 2021

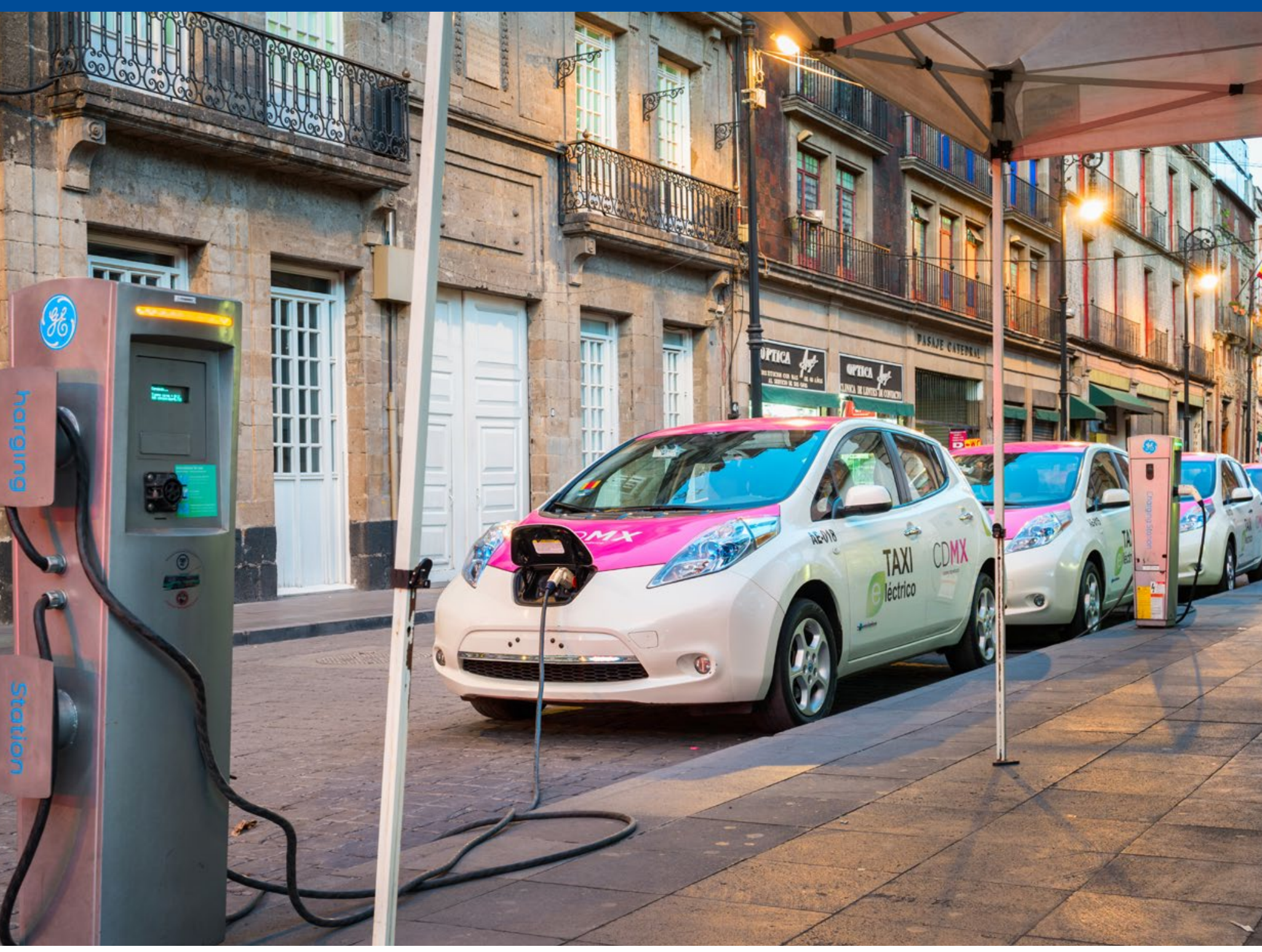




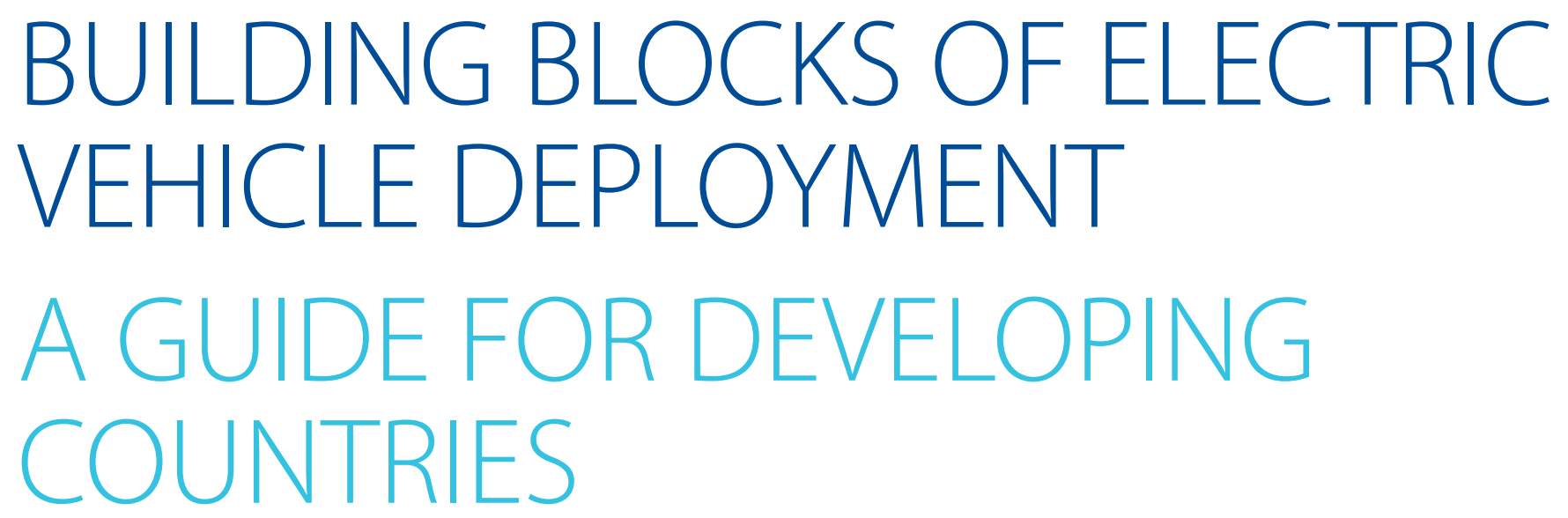

\section{Authors}

Alexandra Aznar, Scott Belding, Kaylyn Bopp, Kamyria Coney, Caley Johnson, Owen Zinaman National Renewable Energy Laboratory

May 2021

A product of the USAID-NREL Partnership

Contract No. IAG-17-2050 
Prepared by

\section{MNREL}

\section{NOTICE}

This work was authored, in part, by the National Renewable Energy Laboratory (NREL), operated by Alliance for Sustainable Energy, LLC, for the U.S. Department of Energy (DOE) under Contract No. DE-AC36-08G028308. Funding provided by the United States Agency for International Development (USAID) under Contract No. IAG-17-2050. The views expressed in this report do not necessarily represent the views of the DOE or the U.S. Government, or any agency thereof, including USAID.

This report is available at no cost from the National Renewable Energy Laboratory (NREL) at www.nrel.gov/publications.

U.S. Department of Energy (DOE) reports produced after 1991 and a growing number of pre-1991 documents are available free via www.OSTI.gov. 


\section{Acknowledgments}

The authors thank Sarah Lawson and Andrew Fang from the U.S. Agency for International Development (USAID) for their support of this work. We also wish to thank Garrett Fitzgerald (Smart Electric Power Association), Karen Glitman, Tyler Petersen, Kinshuk Chatterjee, and John Gartner (Center for Sustainable Energy), Paty Romero-Lankao, Cabell Hodge, and Abby Brown (National Renewable Energy Laboratory), Jeff Humber and Don McCubbin (USAID) for their detailed review comments, insights, and contributions to this report. The authors would like to thank and acknowledge Britton Marchese, Isabel McCan, Chris Schwing, and Liz Breazeale for their design and editorial support. 


\section{List of Acronyms}

BEV

DCFC

EU

EV

EVSE

GDP

GHG

IC-CPD

ICE

IEC

NREL

PHEV

TOU

USAID

V2G

VKT

ZEV battery electric vehicle

DC fast charging

European Union

electric vehicle

electric vehicle supply equipment

gross domestic product

greenhouse gas

in-cable control and protection device

internal combustion engine

International Electrotechnical Commission

National Renewable Energy Laboratory

plug-in hybrid electric vehicle

time of use

U.S. Agency for International Development

vehicle-to-grid

vehicle-kilometers traveled

zero-emission vehicle 


\section{Executive Summary}

Historically, the transportation sector has been powered overwhelmingly by petroleum-based products, but momentum for electric vehicles (EVs) is growing. Global auto manufacturers are pivoting away from traditional internal combustion vehicles, and the private sector, public sector, investors, and utilities are investing heavily in vehicle electrification. At the same time, national and subnational governments are pledging support for EV deployment and charging infrastructure investments and phasing in bans on new gasoline and diesel vehicles. Plummeting lithium-ion battery prices over the past decade have enabled EV market expansion, and battery costs are projected to continue falling. Auto manufacturers are increasing EV model availability to meet customer demand. Decarbonization of the power sector reduces the carbon and environmental impacts of EVs as they age. In other words, a confluence of factors is accelerating EV deployment worldwide, which amounts to a radical shift in the transportation sector, with significant implications for the power sector, transportation, and the environment.

This transformation does not happen on its own. Significant investment by numerous parties is needed to purchase EVs and to build out charging infrastructure. Political leadership plays an important role in launching any emerging technology, particularly one as disruptive as EVs. Utilities must adapt to and potentially flourish with the increased and altered electricity demand, while consumers need support in numerous forms to deploy EVs.

EVs can offer a myriad of benefits for customers and society. Yet limited experience in developing countries leave decision-makers grappling with how to most effectively direct resources and time to support EV deployment. Decision-makers in developing countries may be interested in learning about global best practices from other geographies. There are useful lessons that can be learned from successes and failures of countries in diverse geographies around the world.

This report lays out a framework for policymakers, regulators, and other decision-makers in developing countries for how to plan, implement, and scale EV deployment in their jurisdictions. The "building blocks" of EV deployment address technical, institutional, or economic topics that together underpin a safe, sustainable, and efficient transition to an electrified transport sector (Figure ES- 1). They include:

\section{- Targets and Incentives for EV and EV Supply Equipment (EVSE) Deployment}

- A number of complementary policy options need to be implemented in order to catalyze a robust EV market.

\section{- Data Management for EV Deployment}

- Data curation and management helps identify the potential benefits of vehicle electrification and enables well-designed strategies to scale EV deployment in a targeted manner.

\section{- Establishing a Network of Charging Infrastructure}

- EV market development hinges on the availability of charging infrastructure - a key requirement that can be met in a variety of ways. Different locations, charging needs, and equipment can lead to a variety of EVSE ownership and investment models that require a balance of public and private sector resources.

\section{- EVSE Standards and Communications Protocols}

- Establishing and enforcing a regulatory framework of charging standards, equipment certification, and building codes creates a compatible, reliable, and safe operating environment for EVs.

\section{- Grid Planning and Management}


- New EV loads on the electric grid present both challenges and opportunities. Long-term preparation and planning by utilities can ensure timely and cost-effective deployment of EVSE networks.

\section{- Electricity Tariff Design}

- Electricity tariffs specify how electricity consumers are charged for electricity (i.e., the fuel of EVs). Smart tariff design for EV charging can support utility cost recovery associated with hosting EVSE and can influence customer charging behavior to the benefit of the grid.

\section{- Workforce Development Strategies}

- EV deployment may create new jobs across multiple sectors, but workforce development strategies are required to lay the groundwork for thriving EV markets.

Each building block is explored in turn, providing decision-makers with a holistic, high-level understanding of and approach to EV deployment in developing countries.

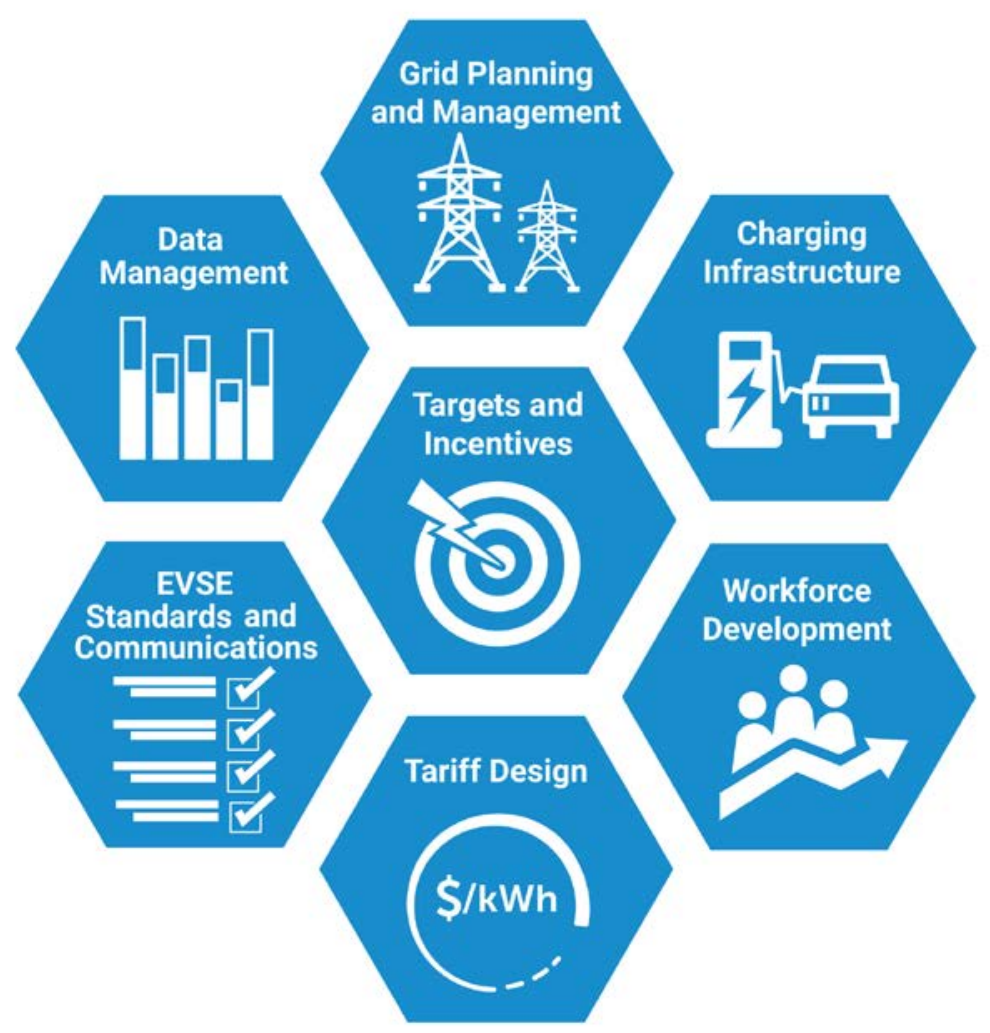

Figure ES-1. The building blocks of EV deployment 


\section{Table of Contents}

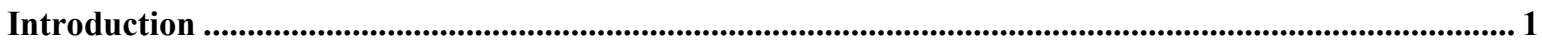

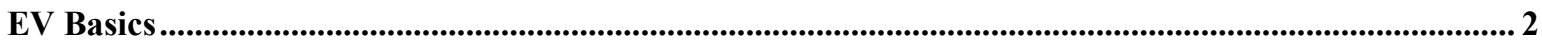

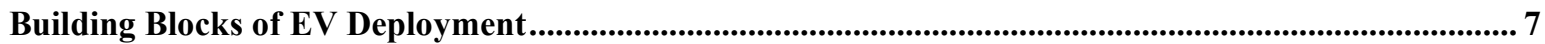

1 Targets and Incentives for EV and EVSE Deployment ..................................................................... 7

2 Data Collection and Management for EV Deployment.....................................................................16

3 Establishing a Network of Charging Infrastructure ...................................................................... 24

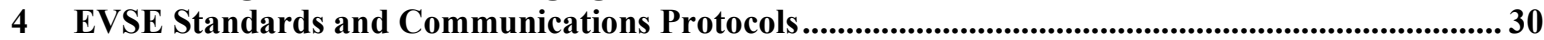

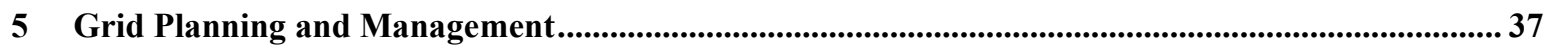

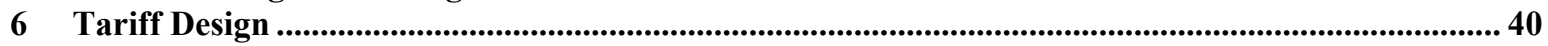

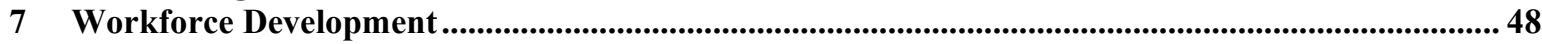

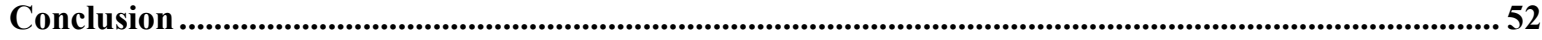

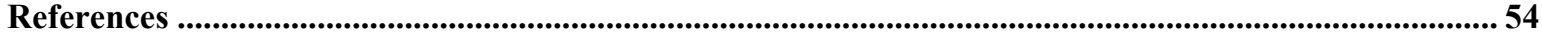




\section{List of Figures}

Figure ES- 1. The building blocks of EV deployment.............................................................. iv

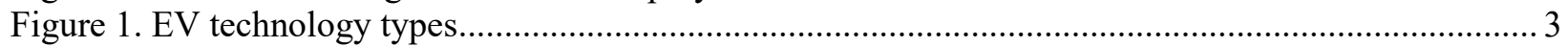

Figure 2. Passenger electric car sales and market share in selected countries, 2013-2019 ....................... 4

Figure 3. Illustrative examples of how jurisdictional goals may influence the EV application pursued ...... 5

Figure 4. Categories of EV and EVSE policy approaches ...............................................................

Figure 5. Vehicle tax costs of 4 years for privately owned vehicles based on $\mathrm{CO}_{2}$ emissions and vehicle type.

Figure 6. Correlation between energy use per capita in private passenger travel and urban density in

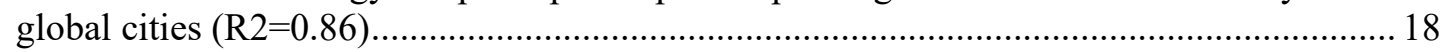

Figure 7. Delivery truck drive cycle data obtained from geolocating devices and stored in Fleet DNA ... 20

Figure 8. GHG emissions of various vehicles in Mexicali, Mexico, as they increase renewables, given their starting grid mix of $70 \%$ natural gas, $2.5 \%$ diesel, and $28 \%$ renewable........................ 21

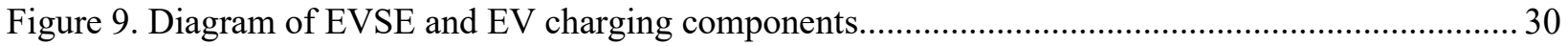

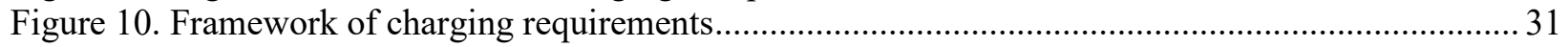

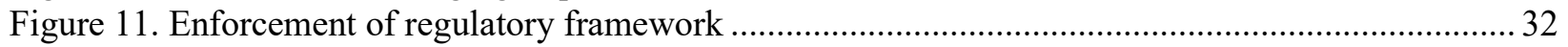

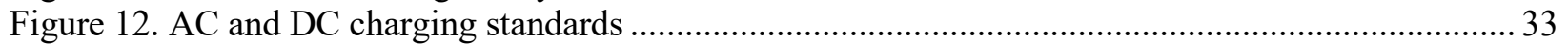

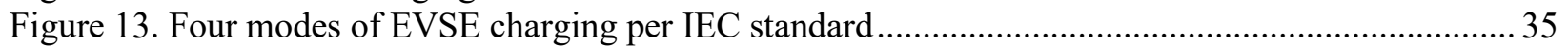

Figure 14. Interoperability protocols Illustration by Kaylyn Bopp. Adapted from (MJB\&A 2019)......... 36

Figure 15. Potential cost savings of grid investments due to optimized EV charge timing....................... 38

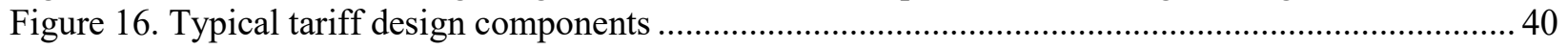

Figure 17. Utility load with EV charging before and after implementation of TOU energy charges......... 43

Figure 18. Examples of TOU EV energy charge at select U.S. utilities ...................................................4

Figure 19. Maturity of EVSE market and use of energy vs. demand charges .......................................... 45

Figure 20. Anticipated types of jobs in "electromobility value chain" ................................................... 51

\section{List of Tables}

Table 1. Benefits and Barriers to EV Deployment ................................................................................... 3

Table 2. Summary of EV and EVSE Targets and Subsidies in Select Countries .................................. 8

Table 3. Key ZEV Mandate Differences Between California, China, and EU ........................................ 14

Table 4. Summary of Key Transportation Data Valuable for Electrification Efforts ................................ 22

Table 5. Summary of Common Charging Infrastructure Characteristics by Location ..............................2 25

Table 6. List of Commonly Used Charging Connectors From IEC 62196 ............................................ 34

Table 7. Comparison of Cost Implications for Low and High Utilization Rate 50-kW DCFC Subject to

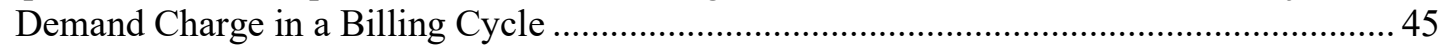

Table 8. EV and EVSE Workforce Needs and Considerations ........................................................... 49

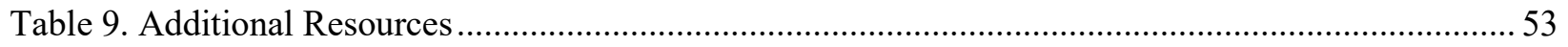




\section{Introduction}

\section{Electrifying vehicles can help countries reach decarbonization and mobility objectives for the transport sector.}

Countries can use electric transportation to help fulfill numerous goals, including greenhouse gas (GHG) emissions targets, local air quality goals, mobility objectives, energy security, and transportation resiliency. Vehicle electrification is a promising pathway to achieving clean energy transitions in the transport sector at scale. As vehicles electrify, the traditionally siloed electricity and transport sectors increasingly converge to create technical, institutional, and economic opportunities and challenges. To navigate this transition effectively, we propose the following foundational pillars or "building blocks" that undergird effective electric vehicle (EV) deployment. Jurisdictions with experience and mature EV markets offer useful lessons learned that may enable developing countries to leapfrog over common roadblocks. Nonetheless, developing countries face distinct challenges collectively, and individually, from developed countries that require careful consideration.

From our work around the world, the U.S. Agency for International Development (USAID) and National Renewable Energy Laboratory (NREL) have witnessed interest growing in EVs for a variety of reasons. Lao People's Democratic Republic (PDR), for example, looks toward EVs as a way to use their surplus of hydropower to displace expensive oil. Thailand and Pakistan seek economic development opportunities in EV manufacturing. Cities including Mexico City, Surat, India, and Kingston, Jamaica see the potential of bus electrification to improve local air quality and reduce traffic congestion. Many USAID partner countries in Southeast Asia are trying to understand how to reach ambitious EV deployment targets and implement EV and transportation plans. This pursuit is prompting questions about EV supply equipment (EVSE) standards, tariff design, and business models that affirm the importance of the building blocks outlined in this report.

\section{Effective EV deployment is aided by key building blocks.}

This report presents a series of building blocks for vehicle electrification. These building blocks can be understood as the key components of a broader framework for policymakers, regulators, and other decisionmakers to use as they plan, implement, and scale EV deployment in their jurisdictions. Each building block addresses a particular technical, institutional, or economic topic that implicates certain stakeholders across the power and transport sectors. Pursued together, they can help to underpin a safe, sustainable, and efficient transition to an electrified transport sector. While this report segments key issues into distinct building blocks to enhance reader understanding, in reality, these EV building blocks are closely integrated, and design decisions on a single aspect often have broader implications. Furthermore, the building blocks presented in this report are not intended to be pursued sequentially. Rather, effective EV deployment requires different decision-makers and agencies - such as environment, transportation, and energy ministries, local transit authorities, utilities, land use planners, code and standard officials, consumer advocates, and the private sector (e.g., vehicle dealerships, charging network companies) - to work in parallel on different issues while taking into account unique socioeconomic and institutional realities that vary by jurisdiction. There are also significant risks to prioritizing some building blocks over others (e.g., lack of engagement from key actors). The building blocks of vehicle electrification reflect this nonlinear, iterative, intersectional dynamic.

This report is intended to inform policymakers and regulators in developing countries with an interest in electrifying transport. It lays out a framework for policymakers, regulators, and other decision-makers for how to plan, implement, and scale EV deployment in their jurisdictions. It does not present a detailed and comprehensive analysis or literature review of each topic, although it does connect the reader to resources for additional information. Instead, this report presents a holistic and actionable framework for decision-makers to understand where to begin and how to proceed in achieving their EV deployment objectives, outlining the key considerations and dimensions of each building block. Where possible, this report explores examples from developing countries, and where those do not exist, it highlights relevant examples from developed countries. After a brief background section on EV technology, this report explores the seven building blocks for vehicle electrification, including:

- Targets and Incentives for EV and EVSE Deployment

- Data Management for EV Deployment

- Establishing a Network of Charging Infrastructure 
- EVSE Standards and Communications Protocols

- Grid Planning and Management

- Electricity Tariff Design

- Workforce Development Strategies.

\section{EV Basics}

\section{EVs come in several forms and offer energy, performance, and environmental benefits, but barriers to deployment remain.}

EVs take many forms (e.g., passenger vehicles, truck, buses, and two-wheelers) and use different technologies (e.g., hybrid electric, plug-in hybrid electric, battery electric). Figure 1 captures the spectrum of EV types.

Compared to conventional vehicles that use internal combustion engines (ICEs), EVs offer several benefits. They are more efficient ${ }^{1}$ and emit fewer GHGs and air pollutants. With better low-end torque for acceleration, heavy loads, and hill climbs, EVs have superior (and quieter) performance. Because of their simpler mechanics and greater efficiency, fuel and maintenance costs are lower than conventional ICE vehicles. Nonetheless, EVs face numerous barriers to deployment in most markets today. First and foremost, without significant incentives, EVs currently have higher upfront costs compared to ICEs. As well, the EV market currently lacks the typical vehicle options that customers may be used to. Furthermore, consumers do not in general have a high degree of familiarity with EVs. Additionally, the way EVs charge differs from the way ICE vehicles are refueled-in some cases charging can be more convenient (e.g., charging at home does not require a dedicated trip), but in other cases charging can be less convenient because the speed of refueling EVs typically takes longer than ICE vehicles. Moreover, the ranges of EVs are sensitive to temperature and usage patterns, so charging needs may differ across geographies and climates. Table 1 summarizes some of these common benefits and barriers to EV deployment.

\footnotetext{
${ }^{1}$ On an energy basis (i.e., per unit input of energy).
} 


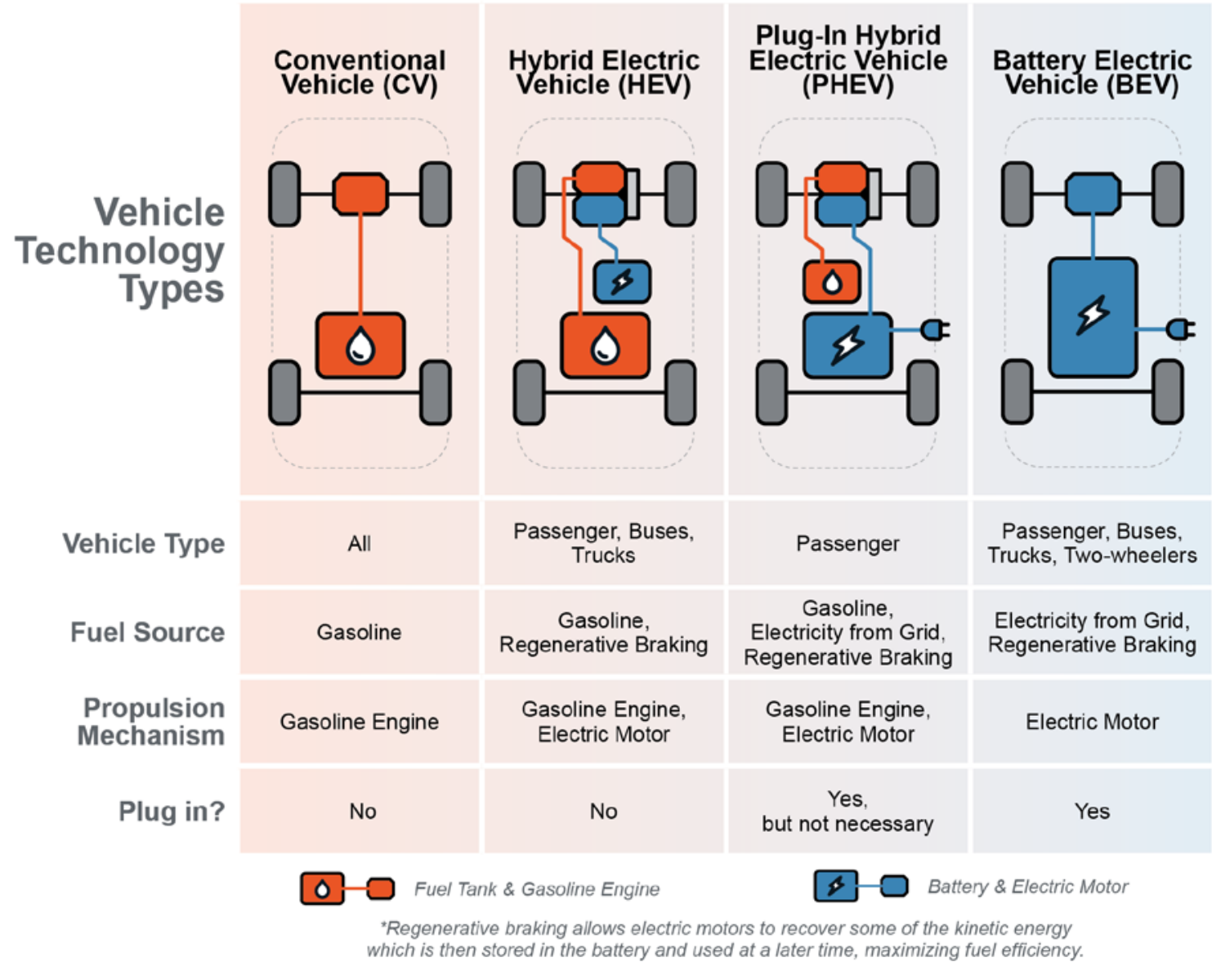

Figure 1. EV technology types

Source:(NREL 2020)

Table 1. Benefits and Barriers to EV Deployment

\begin{tabular}{|c|c|}
\hline Benefits of EVs & Barriers to EV Deployment \\
\hline $\begin{array}{l}\text { - 3-4 times more efficient per unit of input } \\
\text { energy } \\
\text { - Lower fuel and maintenance costs } \\
\text { - Reduced or displaced criteria air pollutant } \\
\text { and } \mathrm{CO}_{2} \text { emissions } \\
\text { - Better low-end torque for acceleration, } \\
\text { heavy loads, and hill climbs } \\
\text { - Ouiet operation. }\end{array}$ & $\begin{array}{l}\text { - } \quad \text { Higher upfront costs (before incentives) } \\
\text { - } \quad \text { Reduced range and charging convenience } \\
\text { - } \quad \text { Range sensitivity to temperature and } \\
\text { - } \quad \text { Lowage patterns } \\
\text { - Consumers unfamiliar with technology. }\end{array}$ \\
\hline
\end{tabular}

Globally, deployment of EVs is accelerating, but they still represent a small fraction of vehicle sales in most countries (with the exception of Norway ${ }^{2}$; see Figure 2). To date, the majority of EVs have been deployed in China (IEA 2020b).

\footnotetext{
${ }^{2}$ EV sales represent $56 \%$ of total vehicle sales in Norway as of 2019 (IEA 2020b).
} 


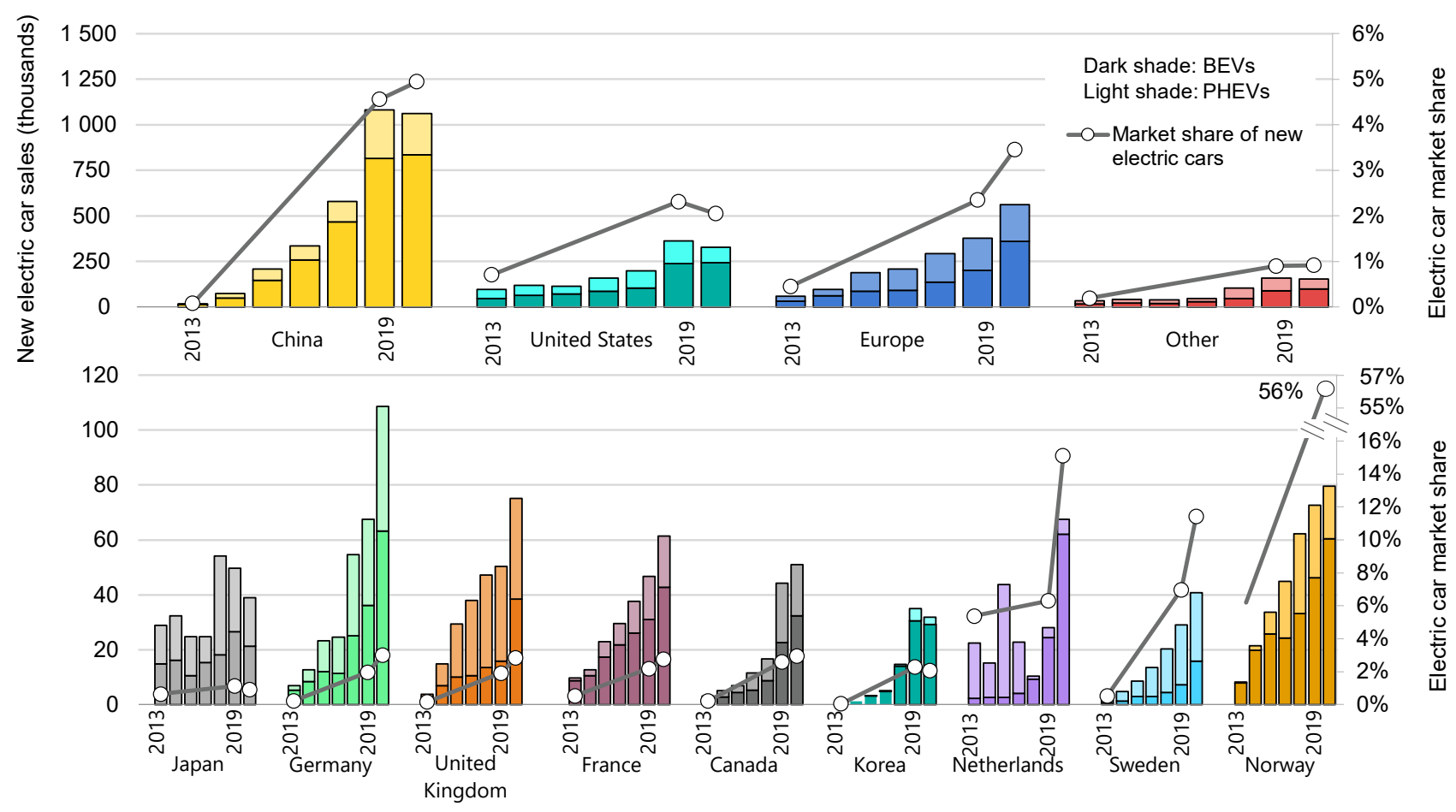

Figure 2. Passenger electric car sales and market share in selected countries, 2013-2019

Source: (IEA 2020b)

EVs offer benefits for consumers and society, but their ascendance is not guaranteed. Policymakers, regulators, and other decision-makers can unlock their potential through strategic and holistic planning, preparation, and execution. This report aims to inspire ideas and guide next steps for decision-makers to accelerate EV market development.

\section{Some preconditions make a transition to EVs easier to achieve.}

There are several starting conditions that a jurisdiction may have that will aid in the development of EV markets. These include:

1. Existing government goals, targets, and objectives that can be achieved through EV deployment. These might include local emissions reduction, GHG reductions, petroleum usage and/or import reduction, energy security, reduction in vehicle kilometers traveled, encouraging access to mobility, resilience to natural disasters, and reducing the total cost of ownership for vehicle consumers. ${ }^{3}$ These goals may motivate stakeholders to pursue EVs as a potential means of achievement. Jurisdictional and stakeholder goals and local conditions/opportunities inform: (1) the types of EVs that might be prioritized, and (2) the approaches that may be appropriate to develop markets for those vehicle types. Figure 3 illustrates which vehicle types tend to be most effective at delivering the benefits for various goals. For example, if policymakers want to improve urban air quality, that goal might best be achieved through prioritizing electrification of buses (which operate disproportionately in urban centers) and motorcycles (which often lack emissions control devices and therefore pollute more than light-duty vehicles). Or, if policymakers want to expand mobility access, they may focus on electrifying technologies or services with lower price points, such as micro-transit or buses, rather than higher-cost, privately owned light-duty vehicles.

\footnotetext{
${ }^{3}$ Oftentimes, these goals overlap.
} 
Goals

Improve Urban Air Quality

Reduce GHGs

Reduce Petroleum Use (for energy security or trade balance)

Achieve Lifecycle Cost Savings

Support Economic Development

Reduce Traffic Congestion

Enhance Transport System Resilience to Natural Disasters

Expand Mobility Access

\section{Prioritized EV Applications}
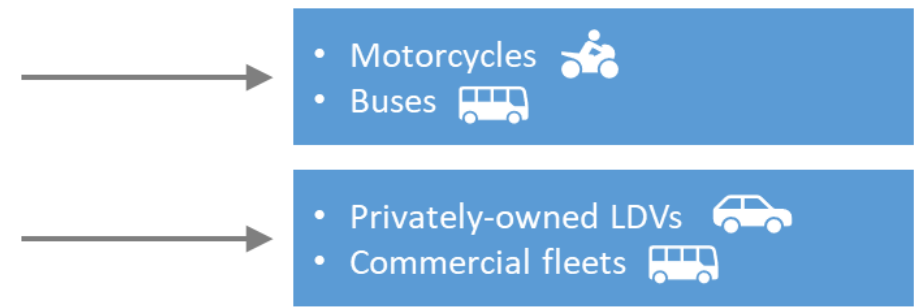

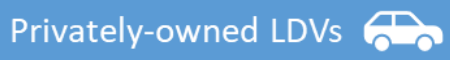

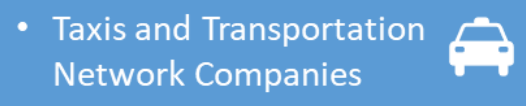

Privately-owned LDVs

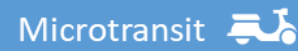

Motorcycles

- Buses स⿴囗十

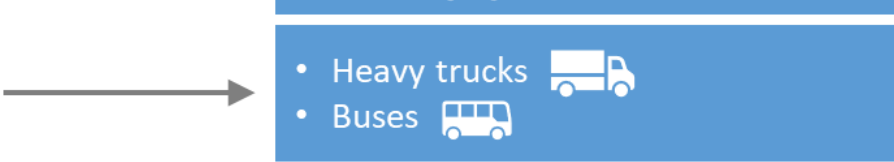

Microtransit こృ

- Buses स्स

Figure 3. Illustrative examples of how jurisdictional goals may influence the EV application pursued

2. Types of existing mobility applications. Electric mobility can have numerous applications, including fleets (e.g., mass transit, taxis, delivery trucks), personal vehicles (e.g., cars, motorcycles), ridesharing vehicles (i.e., shared mobility), and off-road vehicles (e.g., at airports, ports, other unique places and applications). Assessing the applications of transportation at play in a given jurisdiction informs opportunities for vehicle electrification. For example, a city with high transit bus use may be a good candidate for bus electrification over other EV applications. Developing countries often have different vehicle needs (e.g., two-and-three wheelers) and much lower levels of vehicle ownership and government transportation budgets than developed countries, influencing the type of mobility application or vehicle that will lead the EV market in these countries.

3. Local EV “champions" who wish to accelerate EV adoption. Such champions often include fleet managers, vehicle dealerships, charging network owners, vehicle manufacturers, and electric utilities. All of these entities can view EVs as a way to decrease costs, increase their market share, and/or expand their revenue streams. Other powerful champions include groups that see EVs as a way to achieve their environmental, economic, or mobility-related goals, including civil society organizations, energy ministries, and regulators.

4. The nature of existing transportation system. Vehicle electrification is constrained by characteristics of land use and the built environment. Clear land-use regulations determine how urban spaces are ordered and served by different transport modes (e.g., micro-mobility, public transport, freight), foundational knowledge upon which to build vehicle electrification strategies. In many developing countries, 
uncoordinated urban growth has led to expansive and fragmented urban spaces that affect travel distances and times, realities that influence how decision-makers consider the possibilities and priorities for vehicle electrification. Certain characteristics of the built transportation environment lend themselves to lowercost and more convenient opportunities to incentivize EVs beyond fleet applications. First and foremost, locations suitable for convenient charging vary by jurisdiction. To date, experience in the developed world suggests that most light-duty EV owners in established markets prefer to charge at home (EERE 2021), so countries where single-family homes and residential garages are present may be primed to adopt light-duty vehicles more quickly. Countries or cities with more multifamily dwellings and fewer garages will need to rely more heavily on shared charging infrastructure. Workplace charging can be just as convenient to commuters, so countries where commercial buildings with large parking lots are present can also be viewed as a desirable starting condition for EV market development. Home charging and (to a lesser extent) workplace charging require less expensive equipment than public fast charging and allow for more flexibility to enable charge timing that is more compatible with the power system's load. In a different vein, parking availability and cost — often controlled by local governments — is a valuable asset that can be leveraged to incentivize EVs. Locations with difficult parking can provide a huge EV purchase incentive for a relatively low cost by installing EVSE in locations that are difficult to park in, and only allowing EVs to park in the area by the EVSE. Similarly, the presence of pay-for-access (i.e., toll) roads or driving (e.g., high-occupancy vehicle) lanes represent another opportunity for local governments to offer highly valued incentives for a relatively low cost because waiving toll fees has been found to be a particularly powerful way to incentivize individuals to purchase EVs (Narassimhan and Johnson 2018). Finally, an import tariff or vehicle registration tax scheme that can be adjusted to make EVs less expensive can be a valuable prerequisite to EV market development.

\section{Box 1. EV Deployment Strategies in Mexico}

Mexico's federal government, as well as the capital, Mexico City, has developed EV incentives grounded in the realities of the existing transportation and built environment. For example, Mexico's federal income tax law exempts EVs and hybrids from sales or import fees (Secretária de Hacienda y Credito Público 2014). Mexico City is spurring EV market growth with a multipronged approach, including: (1) exclusion of EVs and hybrids from vehicle verification proceedings (i.e., these vehicles can circulate daily), (2) EcoTag program that permits EVs to use urban toll roads (at lower cost), (3) preferential parking, and (4) exemptions to the requirement for public and private transit operators to renew their fleet every decade if they operate EVs (Jose Antonio Tellez Martine and Vazquez 2018; Aleatica 2017). For additional details on EV incentives, see Targets and Incentives for EV and EVSE Deployment.

There is no "one-size-fits-all" solution set for transportation electrification, but the preconditions outlined previously may shape the EV applications and approaches a jurisdiction takes and facilitate smoother and faster EV market development. 


\section{Building Blocks of EV Deployment}

\section{Targets and Incentives for EV and EVSE Deployment}

\section{There are a variety of targets and incentives that can be considered to accelerate EV market development.}

There are several categories of policies to support adoption of EVs and deployment of charging infrastructure. The type of benefits a government seeks from EV deployment and its existing EV goals, targets, and objectives (see Introduction) influence the prioritization and selection of policies, targets, and incentives. Policy approaches can also address equity concerns related to EV deployment in two main ways: (1) expanding access to EVs and EVSE, and (2) allocating the costs of EV and EVSE incentives fairly so as to not disproportionally burden lowincome or otherwise marginalized groups (see Tariff Design). Policy approaches for EV and EVSE deployment alone do not guarantee an EV market; they are strengthened by the presence of other EV building blocks. Key policy approaches include:

EV and EVSE Targets: EV deployment targets set a vision and concrete objective for EV market development in a given jurisdiction (Cui, Hall, and Lutsey 2020). EV targets can be understood as a policy goal, rather than a specific policy instrument. Though not a prerequisite for market development, EV targets can offer a useful longterm vision to policy and regulatory authorities, as well as industry, who are planning to take actions to increase EV adoption. EV targets are typically specified on a sales and/or cumulative stock basis for different types of vehicles. EVSE targets primarily focus on publicly available charging stations to incentivize EV infrastructure readiness and meet demands of EV owners.

Purchase Incentives: Purchase incentives are a category of policy instrument used to reduce upfront purchase costs of EVs. They are a form of subsidy designed to increase EV adoption. In practice, the most easily managed purchase incentives can take the form of reduced import duties, registration fees, or sales taxes. Other purchase incentives include cash grants, rebates, tax incentives, and/or lowinterest financing. They typically feature eligibility criteria based on aspects such as: EV technology type, cumulative sales of specific EV models, program expenditure caps, and other elements. In addition, creating "soft costs" benefits (i.e., indirect financial or behavioral incentives) can also be an effective tool. These include free access to toll roads, highoccupancy vehicle lanes, and traffic-limited zones of given cities, which can serve as an incentive for EV adoption. EVSE subsidies involve financial support for charging infrastructure deployment and installment. See Table 2 for EV and EVSE targets and subsidies in select countries.

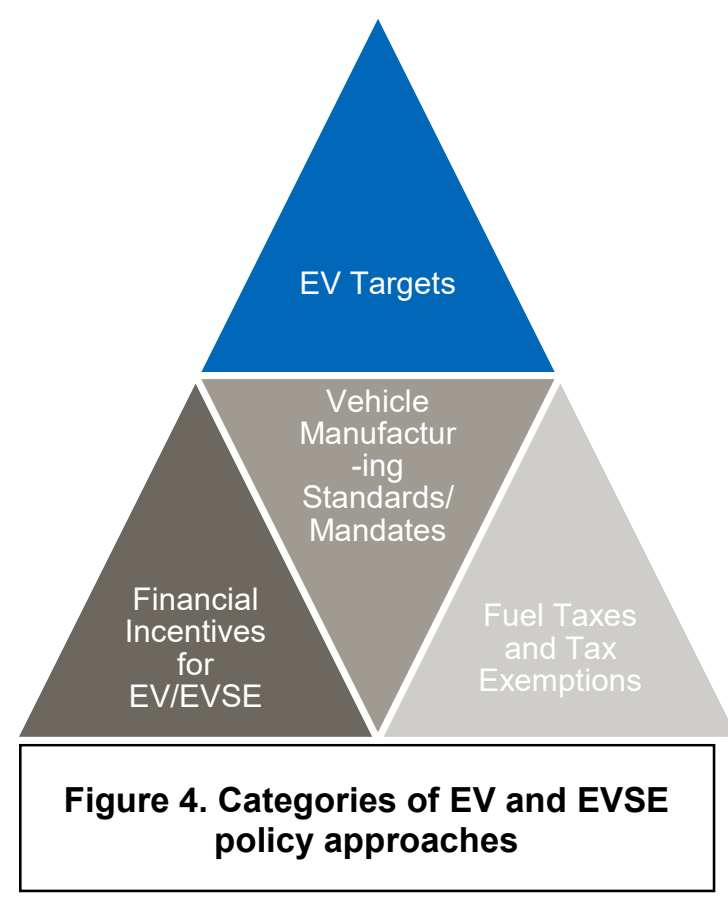


Table 2. Summary of EV and EVSE Targets and Subsidies in Select Countries

\begin{tabular}{|c|c|c|}
\hline Country & EV and EVSE Targets & Incentives \\
\hline Chile & $\begin{array}{l}\text { 2019: install } 150 \text { publicly accessible charging stations } \\
\text { 2022: tenfold increase of EVs from } 2017-2022\end{array}$ & $\begin{array}{l}\text { EV: financing schemes for renewable taxis } \\
\text { (electric and hybrid vehicles) }\end{array}$ \\
\hline China & 2020: 5 million EVs & $\begin{array}{l}\text { EV: purchase tax exemption (10\%) and up to } \\
\text { CNY 22,500 (USD } 3,200) \text { for battery EVs } \\
\text { (BEVs) }(300 \mathrm{~km}-400 \mathrm{~km}) \\
\text { EVSE: the City of Beijing-up to CNY } 200,000 \\
\text { (USD 28,300) per station for operators. }\end{array}$ \\
\hline $\begin{array}{l}\text { European } \\
\text { Union (EU) }\end{array}$ & $\begin{array}{l}\text { 2020, 2025, and 2030: } 1 \text { charger per } 10 \text { electric cars. } \\
\text { 2025: } 1 \text { million charging points and } 13 \text { million zero- and } \\
\text { low-emission vehicles }\end{array}$ & $\begin{array}{l}\text { EV: up to EUR } 7,000 \text { (USD 7,900) for BEVs in } \\
\text { France; up to EUR 6,000 (USD 6,800) for BEVs } \\
\text { in Germany; BEVs are exempt from the annual } \\
\text { vehicle tax for } 5 \text { years in Italy. }\end{array}$ \\
\hline India & $\begin{array}{l}\text { 2020-21: } 498 \text { publicly accessible chargers in government } \\
\text { offices; } 68 \text { publicly accessible chargers across the } \\
\text { country; } 1,500 \text { additional publicly accessible chargers in } \\
\text { and around major metro rail systems and government } \\
\text { offices. } \\
2030: 30 \% \text { EV sales }\end{array}$ & $\begin{array}{l}\text { EV: up to INR 300,000 (USD 4,000) for plug-in } \\
\text { hybrid EV (PHEV) and BEV } \\
\text { EVSE: FAME II: INR } 10 \text { billion (USD } 130 \text { million) } \\
\text { to deploy networks of charging stations, with } \\
\text { incentives that range from } 50 \%-100 \% \text { of the } \\
\text { cost of a charger based on its location and } \\
\text { access }\end{array}$ \\
\hline Japan & $\begin{array}{l}\text { 2030: } 20 \%-30 \% \text { sales in BEVs and PHEVs } \\
\text { 2050: } 100 \% \text { sales of HEV, PHEV, BEV, and fuel cell } \\
\text { electric vehicles (FCEV) }\end{array}$ & $\begin{array}{l}\text { EV: Up to JPY } 400,000 \text { (USD 3,700) for BEV } \\
\text { (>400 km) } \\
\text { EVSE: provide between half to two-thirds of the } \\
\text { costs (depending on location and charger type). } \\
\text { These subsidies totaled JPY } 1.1 \text { billion (USD } 10 \\
\text { million). }\end{array}$ \\
\hline Pakistan & $\begin{array}{l}\text { 2030: } 30 \% \text { sales of EVs } \\
\text { 2040: } 90 \% \text { sales of EVs } \\
\text { 2040: one DC fast charger per } 3 \times 3 \mathrm{~km} \text { area in all major } \\
\text { cities and along major motorways every } 15 \mathrm{~km} \text {. }\end{array}$ & $\begin{array}{l}\text { EVSE: lower electricity tariffs for a general sales } \\
\text { tax rate of } 1 \% .\end{array}$ \\
\hline $\begin{array}{l}\text { United } \\
\text { States }\end{array}$ & 2025: 3.3 million EVs in 11 states combined & $\begin{array}{l}\text { EV: tax credit up to USD } 7,500 \text { (PHEV and BEV) } \\
\text { EVSE: up to } 30 \% \text { of the installation cost of new } \\
\text { EVSE (limited to USD 1,000) through fiscal year } \\
2020 \text {. }\end{array}$ \\
\hline
\end{tabular}

See “Global Outlook EV 2020" for additional EVSE targets and subsidies (IEA 2020b). 


\section{Box 2. National Electric Vehicle Policy Announcement in Pakistan}

In November 2019, Pakistan's Ministry of Climate Change drafted the National Electric Vehicle Policy, which serves as an example of a robust policy approach, combining numerous EV sales targets, purchase incentives, EVSE investments, and manufacturing standards, including:

- Target: $90 \%$ market share in passenger vehicles, heavy trucks, two- and three-wheelers, and buses by 2040 , with 2030 targets of $30 \%$ for the first two groups of vehicles and $50 \%$ for the latter two

- Lower electricity tariffs for EV charging stations

- EVs taxed at $1 \%$ instead of $17 \%$, and EV trucks exempted from registration fees.

- EV components have reduced customs duty and sales tax.

- EV manufacturing machinery has no taxes or import duties.

- Commitments to install DC fast chargers

- Reduced import duty on charging equipment

- Toll tax reduced $50 \%$

- Low-interest financing to EV manufacturers from the State Bank of Pakistan (Uddin 2020).

When discussing the National Electric Vehicle Policy, the Adviser to Prime Minister for Commerce and Investment, Abdul Razak Dawood, led a high-level meeting to consult stakeholders on approaches to policy implementation. Stakeholders included the Adviser on Industries and Production, the Federal Minister for Science and Technology, and Advisers to Prime Minister on Climate Change and Institutional Reforms and Austerity. In addition, the Economic Coordination Committee of the Cabinet created a working group to draft incentive proposals for the National Electric Vehicle Policy. The working group included the Minister of Planning \& Development, Minister of Science and Technology, Special Assistant to the Prime Minister (SAPM) on Austerity and Institutional Reforms, Deputy Chairman Planning Commission, SAPM on Commerce (Chairman), SAPM on Petroleum, Secretaries Industry and Climate Change (Kundi 2020).

See “Global Outlook EV 2020” for additional EVSE targets and subsidies (IEA 2020b).

Vehicle Manufacturing Standards/Mandates: Vehicle manufacturing standards require automotive manufacturers to ensure the vehicles they produce meet specific requirements, including minimum fuel economy levels and GHG emission intensity levels. These manufacturing standards typically apply to manufacturers of ICE vehicles. The manufacturing and sale of EVs, however, is often used to comply with these standards by increasing fleet-wide fuel economy and decreasing fleet-wide GHG intensity. In 2017, China wrote the first nationwide zeroemission vehicle (ZEV) mandate into their fuel economy standards (Kodjak 2017). This rule requires vehicle manufacturers to produce or import a certain number of ZEVs. It gives long-range ZEVs greater credit than shortrange counterparts and allows any credits in excess of the ZEV mandate to apply toward compliance with fuel overall economy standards. Both the Chinese rule and similar fuel economy standards in the United States and Europe (Lutsey 2017) do not account for energy used or emissions from powerplants. ZEVs are further incentivized by multipliers that inflate the implied fuel savings. Such distortions are generally scheduled to be phased out when EVs reach substantial market share.

Fossil Fuel Taxes: Fossil fuel taxes (excise taxes) are collected at the time of vehicle refueling for gasolinefueled vehicles and are often used to fund road construction and repair. EVs do not directly use gasoline or diesel, and thus are not required to pay fuel taxes. For some EV owners, this can be viewed as an incentive to purchase EVs over conventional vehicles, in addition to the already cheaper cost of electricity as a transportation fuel relative to gasoline or diesel. However, many governments are devising ways to make up for lost revenues as their vehicles shift away from fossil fuels. These include taxes on energy consumption (per-joule) regardless of fuel, kilometer-based fees, vehicle fees and decals, toll roads, carbon taxes, and more (Dender 2019; Schroeder 2015). 
Of these, taxes on energy consumption and carbon tend to favor electric vehicles since they generally are more efficient and emit less carbon. Vehicle fees and toll roads can also be adjusted to favor electric vehicles if desired.

\section{EV targets can help guide the design of policy instruments to support market development and send important investment messages to industry.}

EV targets are goals set by governments aiming to increase EV market development. In practice, EV targets often exist within national or local climate mitigation plans. However, EV targets can also be developed independently. While targets are not a prerequisite for market development, they can be used as a guiding tenet for policymakers who are planning to roll out specific policy instruments to increase EV adoption. Put differently, EV targets are not necessarily policy instruments in and of themselves capable of scaling EV adoption, but rather a goal that might guide the design of specific policy actions. They represent a long-term vision for policymakers to strive toward. By indicating a government's seriousness about EVs, EV targets signal opportunities to invest for the private sector. In general, EV targets are stated using two different metrics:

EV Sales Target. Defined as an absolute number of EV sales or percentage of total car sales that are EVs specified over a defined period of time. Sales targets can be set by governments at any level, from national to provincial to state or local. While oftentimes sales targets focus on light-duty passenger vehicles, they can also include other EV types, including trucks, commercial vehicles, and vans, among others. One key design dimension of EV sales targets is eligibility, ${ }^{4}$ with decision-makers needing to decide which specific EV technologies (e.g., EVs, PHEVs, FCEVs, etc.) and applications (e.g., light-duty, buses, trucks, etc.) should count toward target achievement. To aid in designing EV sales targets, it is helpful for countries to collect and review historical data on vehicle sales. In some cases, governments may already collect this data. In other cases, new data collection processes may need to be established. In any case, this data can be used as a guide to design EV sale targets in a specific country. Various countries have announced EV sales targets. For example, South Korea is aiming to ensure that every third light-duty vehicle sold in the country by 2030 is an EV (Randall 2019).

EV Stock Target. EV stock targets are defined aspirations for the total number of registered vehicles on the road that are electric. Similar to EV sales targets, EV stock targets require consideration of eligible technologies (BEVs, FCEVs, ZEVs, etc.), vehicle applications (e.g., light-duty vehicles, buses, etc.), and timeframes for target achievement. In order to implement stock targets, government agencies and ministries that register vehicles need to collect data on the vehicle technology and make this data available for decision-makers. Various countries have made EV stock target announcements. For instance, Malaysia's Electric Mobility Blueprint includes an EV stock target of 100,000 electric light-duty passenger EVs by 2030 (Amir 2019).

\section{Box 3. ICE Phase-Out Targets and Retrofitting Petrol Vehicles}

Some countries and jurisdictions have announced targets to phase out ICE vehicles in the coming decades. These targets include goals to ensure there are no new sales of ICE and diesel cars. They typically also include some form of $100 \%$ EV sales targets and $100 \%$ EV or ZEV stock target. Denmark, for instance, aims to achieve this ICE phase-out goal by 2030 , and has established both a 2030 EV stock target of 1.0 million light-duty passenger EVs and a $100 \%$ sales target for light-duty passenger ZEVs by 2035 . The combination of a technology-prescriptive (EV) 2030 stock target with a technology-neutrality (ZEV) 2035 sales target provides a strong market signal while also enabling the Danish car market with flexibility for compliance. In other countries, such as Japan, national governments aim to achieve ICE phase-out targets purely through 100\% EV sales. The Government of Japan announced a long-term goal of $100 \%$ sales of passenger HEVs, PHEVs, BEVs, and FCEVs by the end of 2050. This target was established within Japan's automotive industry strategy to promote open innovation in the next generation of electrification technology with all EVs produced by Japanese automakers (IEA 2020b).

Retrofitting petrol-using vehicles can be an alternative for countries that are unable to phase out their current ICE automobile population. This alternative takes existing ICE vehicles and converts them to an EV or a HEV. Though research is limited, India has a few retrofitting companies that specialize in converting various ICE vehicles, such as trucks, bikes, cars, and three wheelers to EVs (Chaudhary 2020).

\footnotetext{
${ }^{4}$ This also applies to EV stock targets.
} 


\section{Well-designed financial incentives increase EV adoption by addressing upfront and lifetime vehicle costs for consumers while minimizing the impact on government budgets.}

Often the purchase price of EVs is generally higher than their conventional counterparts. In this case, many countries have found that incentives are helpful to encourage the adoption of EVs. Many of these policies are designed to recoup associated costs to minimize the impact on government budget through specific policy design dimensions (e.g., vehicle type eligibility, incentive caps, tax reduction type and amount, etc.) These incentives can be developed and funded by different levels of government (e.g., federal and local) and include:

Purchase Incentives: Purchase incentives are used to encourage consumers to buy EVs instead of conventional vehicles by offsetting the capital costs of EVs. Globally, EV purchase incentives have many design dimensions, including vehicle type eligibility, funding amount based on vehicle type and features, and financial incentive caps. For example, China has three EV purchase incentives for passenger EVs: for a BEV if the electric range is between $300 \mathrm{~km}$ and $400 \mathrm{~km}$, for a BEV electric range at or above $400 \mathrm{~km}$, and for a PHEV if the range is at or above $50 \mathrm{~km}$ (IEA 2020b). Similarly, India, as part of its National Electric Mobility Mission Plan 2020, proposed purchase incentives for state or city transport entities to purchase battery electric buses (Government of India 2012)..$^{5}$

Alternatively (or in addition to), countries use tax credits as another type of financial incentive to reduce the cost of EVs for consumer. For example, the United States implemented a federal tax credit of up to USD 7,500 for passenger light-duty PHEVs and BEVs with a minimum battery capacity of $5 \mathrm{kWh}$. This tax credit begins to phase out gradually when each individual vehicle manufacturer sells 200,000 EVs (IEA 2020b). In 2018, Tesla surpassed this threshold, triggering the federal tax credit phase-out for the new purchase of a Tesla. The federal tax credit phase-out began in the second quarter of 2019 with a 50\% reduction from full credit (i.e., USD 3,750) and then a $25 \%$ reduction from full credit the following quarter (i.e., USD 1,875); as of the time of this writing, Tesla vehicles are no longer eligible for the U.S. federal tax credit (U.S. Department of Energy 2020). Depending on the tax code of a particular country, however, tax credits can favor the wealthy, since low-income people may not have sufficient tax burden to take advantage of tax credits.

Soft-Cost Incentives: Soft-cost incentives are indirect financial benefits that reduce total cost of ownership for EVs. Distinct from purchase incentives, they can include favorable benefits such as free or priority parking, reduction or elimination of vehicle registration fees, and special access to toll roads or high-occupancy vehicle lanes for EV owners. For example, in an effort to reduce reliance on purchase incentives but maintain support for EV deployment, China has begun emphasizing EV soft-cost incentives. Some provinces (e.g., Shanghai) are waiving typical drivers' license plate fee for EV drivers, saving them nearly RMB 100,000 (USD 15,900) (IEA 2020b). In other Chinese cities, EVs are exempted from certain regulations, including traffic control measures that limit the number of cars permitted on the roads during certain periods. Similarly, multiple states in the United States (i.e., California, Colorado, Florida, and New York) allow EVs to use high-occupancy vehicle lanes.

\footnotetext{
5 These include Rs. 5-20 Lakhs (6,725-26,900 USD) for HEV buses, Rs. 18-34 Lakhs (24,210-45,730 USD) for PHEV buses and Rs. 20-37 Lakhs (26,900-49,765 USD) for battery electric buses
} 
Disincentives for conventional vehicle use: While direct and soft-cost financial incentives provide a "carrot" for adopting EVs, governments can also use a "stick" to discourage use of conventional vehicles. Two common ways of doing so are through fuel taxes and emissions taxes. Fuel taxes ${ }^{6}$ are type of excise tax that is imposed on the sale of fuel. The Organization for Cooperation and Economic Development countries have a range of fuel tax prices, with the United States at the second lowest price of $\$ 0.56$ per gallon and Netherlands at the highest price of $\$ 3.36$ per gallon. When consumers purchase fuel-efficient vehicles, they pay less fuel taxes due to their improved vehicle performance and they are able to use less gasoline per miles traveled. Fuel taxes are eliminated or unnecessary for EV owners, as the vehicles are refueled through electricity.

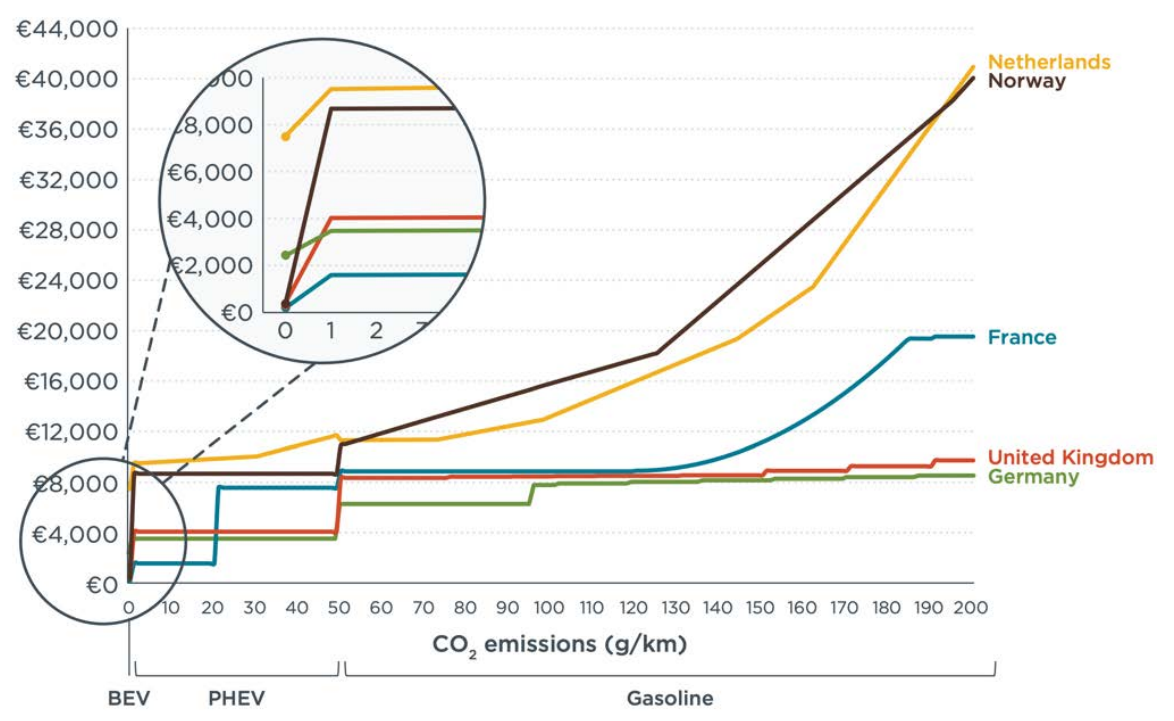

Figure 5. Vehicle tax costs of 4 years for privately owned vehicles based on $\mathrm{CO}_{2}$ emissions and vehicle type

In addition, vehicle emissions taxes are common in European countries; over 18 European countries have $\mathrm{CO}_{2}$ emission taxes. The $\mathrm{CO}_{2}$ emission taxes are based on the vehicle and $\mathrm{CO}_{2}$ emitted $(\mathrm{g} / \mathrm{km})$. Figure 2 shows the comparison of five European countries' vehicle tax costs of 4 years for privately owned vehicles based on $\mathrm{CO}_{2}$ emissions and vehicles (i.e., BEV, PHEV, and gasoline).

\section{Standards and mandates increase the supply of EVs by requiring vehicle manufacturers to develop more fuel-efficient, low-emissions products.}

EV standards and mandates support EV targets by requiring vehicle manufacturers to produce more EVs and/or fuel-efficient vehicles. They include:

Fuel Economy Standards and GHG Emission Standards: Fuel economy standards incentivize vehicle manufacturers to develop and produce vehicles that are able to travel further using less fuel, thereby reducing gasoline/diesel consumption and GHG emissions. Because EVs use no gasoline, they can greatly improve the average fuel economy (in km per L gasoline) of the manufacturer's fleet. Most standards count electric energy as 0 gallons gasoline, but others translate it to $\mathrm{L}$ of gasoline equivalent (which still provides a large boost to fuel economy). GHG emissions standards incentivize vehicle manufacturers to develop and produce vehicles that emit fewer $\mathrm{CO}_{2}$ emissions. ${ }^{7}$

For example, the National Highway Traffic Safety Administration and the Environmental Protection Agency in the United States regulate two vehicle fuel economy and GHG standards: (1) the Corporate Average Fuel Economy, which focuses on decreasing overall miles per gallon (mpg) of new passenger vehicles; and (2) the GHG emissions standard, which focuses on grams of emitted carbon dioxide, or the $\mathrm{CO}_{2}$-equivalent for GHG, per miles traveled in cars and trucks. In 2020, the National Highway Traffic Administration and Environmental Protection Agency issued the Safer Affordable Fuel-Efficient Vehicles Rule to amend and establish new carbon dioxide and fuel economy standards. This rule requires vehicle manufacturers to:

- Improve fuel efficiency by $1.5 \%$ annually for model years 2021 through 2026

\footnotetext{
${ }^{6}$ In the United States, fuel or gasoline taxes are used to fund infrastructure projects on roadways and other transportation projects.

${ }^{7}$ Typically measured in grams/kilometer.
} 
- Continue compliance of strict pollution standards under the Clean Air Act for passenger cars and light trucks from model years 2017 through 2026

- Meet a 40.4 mpg overall industry average required fuel economy by May 2026 (EPA, NHTSA 2020).

Through its New European Driving Cycle regulations, the EU established GHG emission standards that require a $15 \%$ reduction of $\mathrm{CO}_{2}$ emissions (in grams of per kilometer $(\mathrm{g} / \mathrm{km})$ by 2025 and $37.5 \%$ reduction of $\mathrm{CO}_{2}$ emissions $(\mathrm{g} / \mathrm{km})$ by 2030 based on a 2021 baseline $^{8}$ (ICCT 2019).

ZEV Mandate: A ZEV mandate requires vehicle manufacturers to incorporate more ZEVs in the market. ZEV type or eligibility is one of the program's design dimension, as the term for ZEV can vary by region. ZEV is generally defined as a vehicle or car that does not produce tailpipe exhaust. Because they do not produce tailpipe emissions, EVs (of various types) are considered ZEVs and can help vehicle manufacturers meet their ZEV requirements. In Chinese regulations, ZEVs are called new-energy vehicles; low-emission vehicle, or zero-low emission vehicles in EU regulations; and ZEVs in U.S. regulations (ICCT 2019).

The design dimensions of the ZEV mandate include vehicle manufacturer volume size based on sales, ZEV eligibility based on vehicle type, credit requirements and credit value based on vehicle type, and mandate penalties. Within a ZEV program, vehicle manufacturers are assigned ZEV credit requirement that are earned by selling ZEVs (i.e., the number of credits are based on ZEV type). Based on the credit requirement, a certain percentage of sales must be ZEVs. For example, if the credit requirement is $7 \%$ and the vehicle manufacturer plans to sell 100,000 vehicles in a year, then they must have at least 7,000 ZEV credits to fulfill the program requirement. Jurisdictions that have implemented this mandate (e.g., California, China, the EU) share similar program characteristics with varying ZEV program design dimensions. See Table 3 for the key differences between California's ZEV Mandate, China's new-energy vehicle mandate, and the EU's Voluntary ZEV Targets.

${ }^{8}$ The 2021 baseline for new cars is $95 \mathrm{~g} / \mathrm{km}$. Thus, new cars in the EU require an average target value of $81 \mathrm{~g} / \mathrm{km} \mathrm{by} 2025$ and $59 \mathrm{~g} / \mathrm{km}$ by 2030 . 
Table 3. Key ZEV Mandate Differences Between California, China, and EU

\begin{tabular}{|c|c|c|c|}
\hline & California & China & $\mathbf{E U}$ \\
\hline $\begin{array}{l}\text { Regulated } \\
\text { vehicle } \\
\text { manufacturers }\end{array}$ & $\begin{array}{l}\text { Vehicle sales greater } \\
\text { than } 20,000 \text { units }\end{array}$ & $\begin{array}{l}\text { Vehicle sales greater than } 30,000 \\
\text { units }\end{array}$ & $\begin{array}{l}\text { All vehicle } \\
\text { manufacturers have the } \\
\text { option to comply or } \\
\text { not }\end{array}$ \\
\hline ZEV eligibility & $\begin{array}{l}\text { BEVs, FCEVs, and } \\
\text { conditional PHEVs* }\end{array}$ & $\begin{array}{l}\text { BEVs with range of } 100 \mathrm{~km} \\
\text { FCEVs with range of } 300 \mathrm{~km} \\
\text { PHEVs with range of } 50 \mathrm{~km}\end{array}$ & $\begin{array}{l}\text { All vehicles that } \\
\text { produce } 50 \mathrm{~g} / \mathrm{km} \text { or } \\
\text { lower of } \mathrm{CO}_{2} \\
\text { emissions }\end{array}$ \\
\hline $\begin{array}{l}\text { Percentage } \\
\text { credit } \\
\text { requirements }\end{array}$ & $\begin{array}{l}\text { 2019: } 7 \% \\
\text { 2020: } 9.5 \% \\
\text { 2025: } 22 \%\end{array}$ & $\begin{array}{l}\text { 2019: } 10 \% \\
\text { 2020: } 12 \% \\
\text { 2021-2023: } 14 \%-18 \%\end{array}$ & $\begin{array}{l}\text { 2025-2029: } 15 \% \\
2030: 35 \%\end{array}$ \\
\hline $\begin{array}{l}\text { Percentage of } \\
\text { credits per } \\
\text { vehicle sold } \\
\end{array}$ & Up to 4 credits & Up to 6 credits & Up to 1.05 credits \\
\hline Penalty & $\begin{array}{l}\$ 5,000 \text { per ZEV } \\
\text { credit deficit }\end{array}$ & $\begin{array}{l}\text { Government will not approve new } \\
\text { vehicles that do not meet fuel } \\
\text { consumption standards until the } \\
\text { ZEV deficits are fully offset. }\end{array}$ & None \\
\hline
\end{tabular}

* PHEVs must comply with California's "super ultra-low emission vehicle" emission standards.

Source: (Rokadiya and Yang 2019; Hardman, Jenn, Axsen et al. 2018)

\section{Consumer education and awareness drive end-use EV adoption and are key aspects of EV market transformation.}

While many government agencies and ministries are incorporating and implementing EV targets and incentives to increase EV adoption, it is crucial to communicate, educate, and establish awareness of EV technologies, policies, and incentives to consumers. Developing local communication programs or joining global programs can provide a platform to promote EVs to consumers and communities. Currently, there are 15 countries that participate in the Electric Vehicle Initiative, which was established under the Clean Energy Ministerial as a multi-government policy forum to accelerate the adoption of EVs globally (IEA 2021). ${ }^{9}$ Global programs, like the Electric Vehicle Initiative, provide a platform for public sector stakeholders to gain knowledge and resources about best practices and lessons learned for EV adoption through workshops and webinars. Resources developed can be implemented into local communication programs, discussed at public events and workshops, and shared through social media marketing. Clear, tailored consumer education and awareness initiatives encourage EV adoption beyond early adopters and help mainstream the technology.

\footnotetext{
${ }^{9}$ Fifteen countries are currently participating in the Electric Vehicle Initiative: Canada, Chile, China, Finland, France, Germany, India, Japan, the Netherlands, New Zealand, Norway, Poland, Portugal, Sweden, and the United Kingdom.
} 


\section{Box 4. Summary of Key Target and Incentive Guidance for Decision Makers}

- Set EV and EVSE targets, as these commitments can focus and guide government and private sector deployment strategies.

- Consider EV and EVSE purchase incentives to help defray the capital costs of these important investments.

- Consider soft-cost incentives, such as free parking or reduced registration fees, that reduce total cost of ownership for EVs.

- Pair EV incentives with disincentives for ICE use, such as fuel or GHG taxes.

- Increase the supply of EVs through standards and mandates that require manufacturers to develop more fuel-efficient, low-emissions products such as EVs.

- Develop consumer education and awareness programs to build end-user demand for EVs. 


\section{Data Collection and Management for EV Deployment}

Data curation and management helps identify the potential benefits of vehicle electrification and enables well-designed strategies to scale EV deployment in a targeted manner.

There are measurable attributes of a transportation system that can help to indicate: (1) the best way to improve general transportation efficiency and quality for a given region, (2) the potential benefits of a transition to electric mobility for various types of vehicles/applications, and (3) the most effective instruments and approaches for transitioning to electric mobility. These attributes are often quantified by the key data sets listed in this section, which we organize into two categories ${ }^{10}$ :

Foundational Data: Multipurpose data useful for defining the fundamentals of a transportation system.

- Transportation fuel use

- Vehicle stock

- Vehicle kilometers traveled.

Specialized Data: Useful for identifying the potential benefits of electrification, the best vehicles to electrify, and the best instruments to use when pursuing electrification.

- Mode of travel

- Access to home charging

- Gasoline prices

- Electricity tariffs

- Drive cycle profiles

- Geospatial data

- Electricity generation mix.

\section{Foundational Data}

Transportation Fuel Use data can be used for multiple purposes. When divided by population, it becomes a basic metric for how energy efficient a transportation system is. It can also be an input to numerous quantitative models to help estimate the emissions coming from the transportation sector, and therefore the air quality impacts of vehicle electrification. Fuel is often imported, making the quantity of fuel used important in macroeconomic and energy security-related calculations, as well as resiliency-related decisions. It can also be converted to energy equivalents in order to estimate the increased electricity demand that electrifying transportation would add to the power system under various deployment scenarios. Fuel use is tracked in most countries because it is typically taxed. Therefore, some version of this data can usually be located at relevant ministries related to tax revenue collection or imports. However, it is often processed and made readily available by Ministries of Energy.

Vehicle Stock data generally includes the make, model, vehicle type, and model year of every vehicle registered in a country. Vehicle age and average lifespan can be determined by comparing the model year of vehicles to the registration snapshot year. This data is invaluable when determining how many vehicles might be replaced with comparable and available EVs. It also aids any fleet-specific strategies by informing decision-makers how many fleet-specific vehicles are in the country. Vehicle stock data is typically collected through a vehicle registration system that is coordinated with registration tax/fee collection. Therefore, relevant ministries related to tax revenue collection or vehicle registration may be a good place to begin searching for this data. ${ }^{11}$ In addition, commercial banks are sometimes good sources of vehicle stock data, as they collect this data in order to assess the wealth of their clientele when evaluating eligibility for loans. The credit agency Experian and the data company IHS Markit

\footnotetext{
${ }^{10}$ The data descriptions below are aimed at the national level but are just as useful for regional and local transportation systems.

${ }^{11}$ Oftentimes, government-owned vehicles do not pay taxes or need to be registered with the same government agencies as privately owned vehicles; as a result, they may be missing from some vehicle stock databases.
} 
have compiled international databases of vehicle registrations that can be accessed for a fee. Vehicle stock can also be derived from import data by making assumptions for vehicle life (Johnson, Koebrich, and Singer 2019).

Vehicle-Kilometers Traveled (VKT) data is another data type that can be used for multiple purposes. This metric reports the kilometers that motorized vehicles travel on an annual basis. It is typically a good indicator of the amount and type of infrastructure used to support the VKT, with high VKT countries having more road lanes and parking spaces per capita, but possibly less mass transit and pedestrian infrastructure. When divided by population data, the per-capita VKT reflects how "motorized" a country's transportation system is. When VKT is divided by fuel consumption, it can reveal the average fuel economy of various vehicle categories in a country. Per-capita VKT is a metric that often correlates to the per-capita gross domestic product (GDP) of a country (Ecola et al. 2014), which means VKT can be usefully extrapolated into the future using GDP and population projections (which are typically quite common) (Johnson, Koebrich, and Singer 2019). If VKT data is collected, it is typically tracked by a Ministry of Transportation in order to inform transportation infrastructure planning processes and maintenance decisions. This data usually originates as traffic counts on given roads and is aggregated up to regional or national levels. In some cases, VKT data may not be aggregated and will require processing and analysis to become more broadly applicable (Climate Technology Centre and Network 2018). 


\section{Box 5. Technical Insight: How to Fill Gaps in Foundational Data}

The data sources for the three foundational data sets can be more difficult to obtain in developing countries. Fortunately, there are methods to fill in missing data in such instances. Data gaps can be interpolated through simple algebra if one knows vehicle efficiency, the VKT per fuel used, annual km traveled per vehicle (VKT/vehicle stock), fuel use per vehicle, and other metrics involving two of the pillar data sets in an equation. An example of this is estimating fuel use based on VKT and average fuel economy based on the equation Fuel Economy $=\mathrm{VKT} /$ Fuel Consumption. Missing data can be estimated by using proxy data from other countries with economic, cultural, and geographic similarities. For example, one can estimate the per capita transport energy based on population density by aligning them on the line of best fit, shown in Figure 6. Another example is using a country's per-capita GDP to estimate its per-capita VKT, based upon the historic relationship between the two explored in Ecola et al. 2014. For detailed case studies that involved filling data gaps, see Jamaica (Johnson, Koebrich, and Singer 2019), Tonga (Climate Technology Centre and Network 2018), Guam (Johnson 2013), and U.S. Virgin Islands (Johnson 2011). Note that there is currently no central database of fundamental data for developing countries; such a database would greatly improve the ease and reliability of using proxy data.

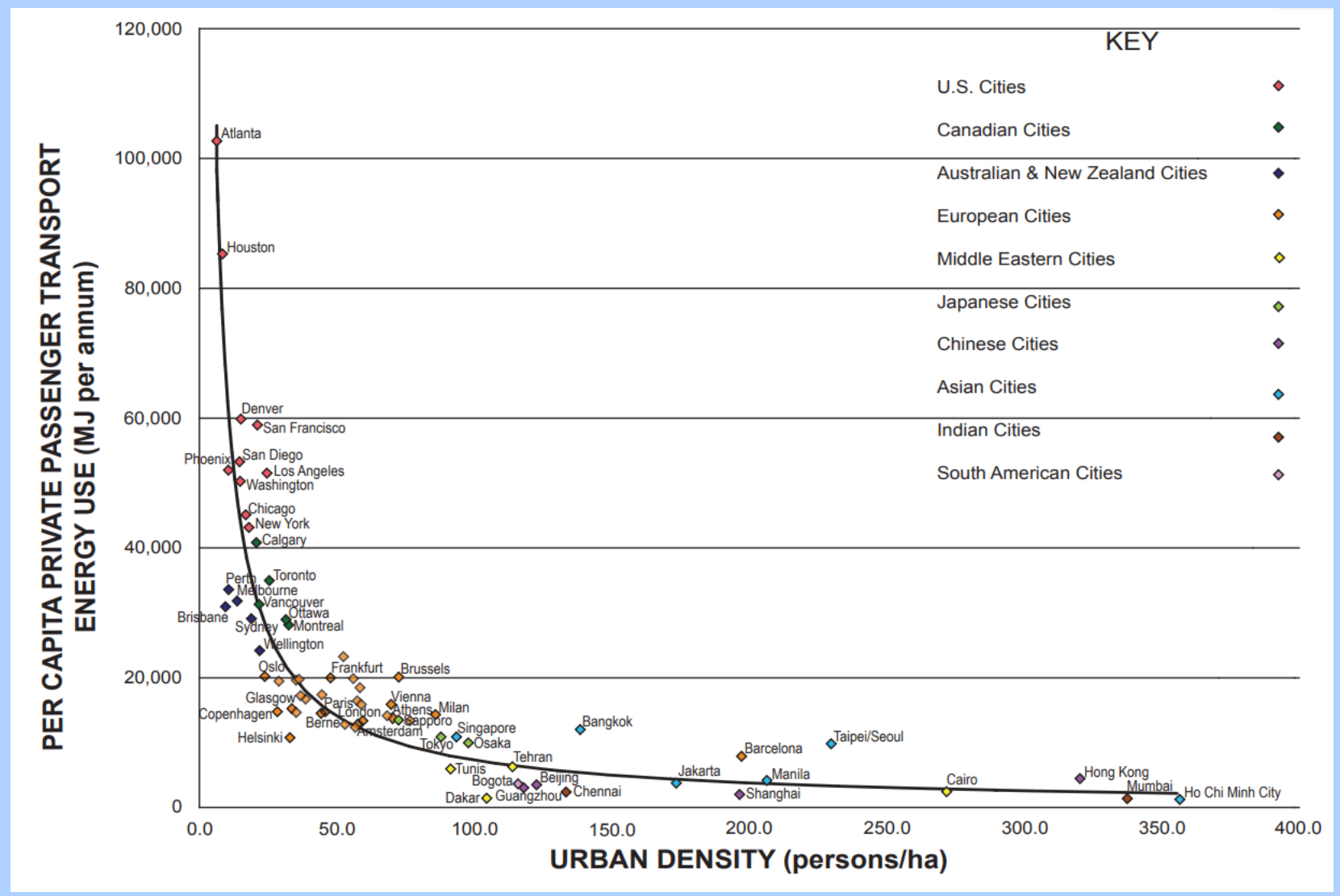

Figure 6. Correlation between energy use per capita in private passenger travel and urban density in global cities ( $R 2=0.86)$

Source: (Newman and Kenworthy 2015)

\section{Specialized Data}

Mode of Travel data often describes trips that are made by walking, biking, scooter, microtransit, mass transit, taxi, transportation network companies, carpools, and more. It can be used to determine how to allocate resources in order to support the most travelers in the most economical or environmentally friendly way. It may be useful to break this data down by age, gender, income, and trip type to enable resource allocation in an equitable manner. Mode of travel data is usually created through surveys conducted by governments, for instance as part of a national census process. Examples where this data is collected include India's National Census, the Mexican 2015 
Intercensal Survey, ${ }^{12}$ New Zealand Household Travel Survey (New Zealand Ministry of Transport 2018), Chilean Household Travel Survey (Salas 2018), South African Household Transportation Survey (Lars Kamer 2019), and the Jamaican Census. ${ }^{13}$ Many developing countries have not conducted such a survey. For these countries, extrapolations can be made from other countries with similar population density and per-capita income levels since the means of travel is generally related to these. Mode of travel data for numerous countries is available for a fee on Statista. ${ }^{14}$

Access to Home Charging data is an important indicator for how convenient it will be for EV owners to recharge. Globally, $50 \%-80 \%$ of charging events (amongst early adopters) have occurred at home (Hardman, Jenn, Tal et al. 2018), and a lack of home charging availability is often found to be a barrier to EV adoption (Funke et al. 2019). However, to the best of our knowledge, no countries have robust data sets on capability to charge at home, so this must often be approximated by other data. The best approximation is the number of houses with garages and car ports, such as the data collected through the American Housing Survey. ${ }^{15}$ Another potential approach is to utilize data on the share of buildings that are detached and semi-detached houses as a proxy. The efficacy of this approach is supported by U.S. data, where the share of housing units with garage or carport (66\%) is close to the share of detached houses (62\%) (Funke et al. 2019). This data is often ascertained through property titles/registrations and may be available through a Ministry of Housing or equivalent. Another potential source of information is databases of property titles and real estate listings, which are often compiled through private companies offering online real estate search services. Such databases can have a variety of property details that serve as good proxies for home charging capability in a number of developing countries.

Gasoline price data can be useful for assessing the likelihood that EVs will have favorable economics in a given country. Gasoline prices are positively correlated with EV purchase rates in the United States (Narassimhan and Johnson 2018), and it is reasonable to assume that, when controlling for other factors, this correlation will likely stand globally. Therefore, it is helpful to understand average gasoline prices when decision-makers are determining which jurisdictions within their country to pursue market development activities for EVs. Gasoline price data is also useful when determining if EV purchase incentives are needed to catalyze a market, and what magnitude. Many Ministries of Energy track retail prices for gasoline and diesel. Many of them get aggregated in (IEA 2020a). For locations where prices are not tracked, petroleum excise taxes can enable a comparison between areas. This is because the major regional differences in gasoline retail prices come from fuel taxes. These tax rates may be available from the Ministry of Revenue at the national, state, and/or local levels as applicable. ${ }^{16}$

Comparisons can be made to most Organisation for Economic Co-operation and Development countries based on a data set compiled by the Organisation for Economic Co-operation and Development and distilled by NREL (Brooker et al. 2015).

Electricity Tariffs are an important factor in EV life cycle cost comparisons. While not significantly correlated with EV purchase rates among consumers in the United States (Narassimhan and Johnson 2018), electricity tariffs nonetheless have significant impact on operational costs. Lower energy prices (per kWh) help the upfront investment in EVs pay back more quickly. In addition, some rate structures can influence what equipment can be used economically, when it can be used economically, and what impact it will have on the grid. See Tariff Design for more information on the detailed relationships between electricity tariffs and EV adoption. Tariffs are typically available from the utility, and simplified versions for some countries are available in (IEA 2020a).

Drive Cycle Profile data define the distances driven, stops and starts, acceleration patterns, and geographical travel patterns of specific vehicles. These profiles, along with climate data that can impact battery range, are used to determine which vehicles would best be replaced by EVs, what the most appropriate equipment is (in terms of vehicle range and optimal EVSE placement), and what the economic payback of EV investment may be. Drive cycle profiles can be tracked with common telematics and geolocating devices such as Geotab or Trip Recorder 747 ProS that simply plug into the on-board diagnostics port or auxiliary power outlet of a vehicle. The data can then be analyzed through models such as NREL's FASTSim (Brooker et al. 2015) or by analytic services such as

\footnotetext{
12 INEGI. 2015. “Intercensal Survey 2015.” http://en.www.inegi.org.mx/programas/intercensal/2015/.

132011 Census of Population and Housing. Table 1.11: Total Population 3 Years Old and Over by Usual Mode of Transportation by Parish. Statistical Institute of Jamaica.

${ }^{14}$ Statista. Home page. www.statista.com.

${ }^{15}$ U.S. Census Bureau. "American Housing Survey." https://www.census.gov/programs-surveys/ahs.html

${ }^{16}$ It is important to account for all levels of taxation.
} 
ezEV (Sawatch Labs 2020). There are drive cycle trends that can be discerned from fleet types and functions. In such cases, the drive cycles stored in the FleetDNA database (NREL 2019) are useful. Figure 7 is an example of two drive cycle attributes (daily distance traveled and total number of stops) for two types of vehicles (warehouse delivery in purple and food delivery in green). Simplified drive cycle data for nonfleet vehicles is also derived from navigation devices and smart phones. Such data (which is anonymized for privacy purposes) can be made available to transportation planners and other customers. Inrix and Waze are two examples of companies that harvest and offer this data in many countries.

Daily Total Number of Stops and Distance Traveled by Vocation for Delivery Trucks

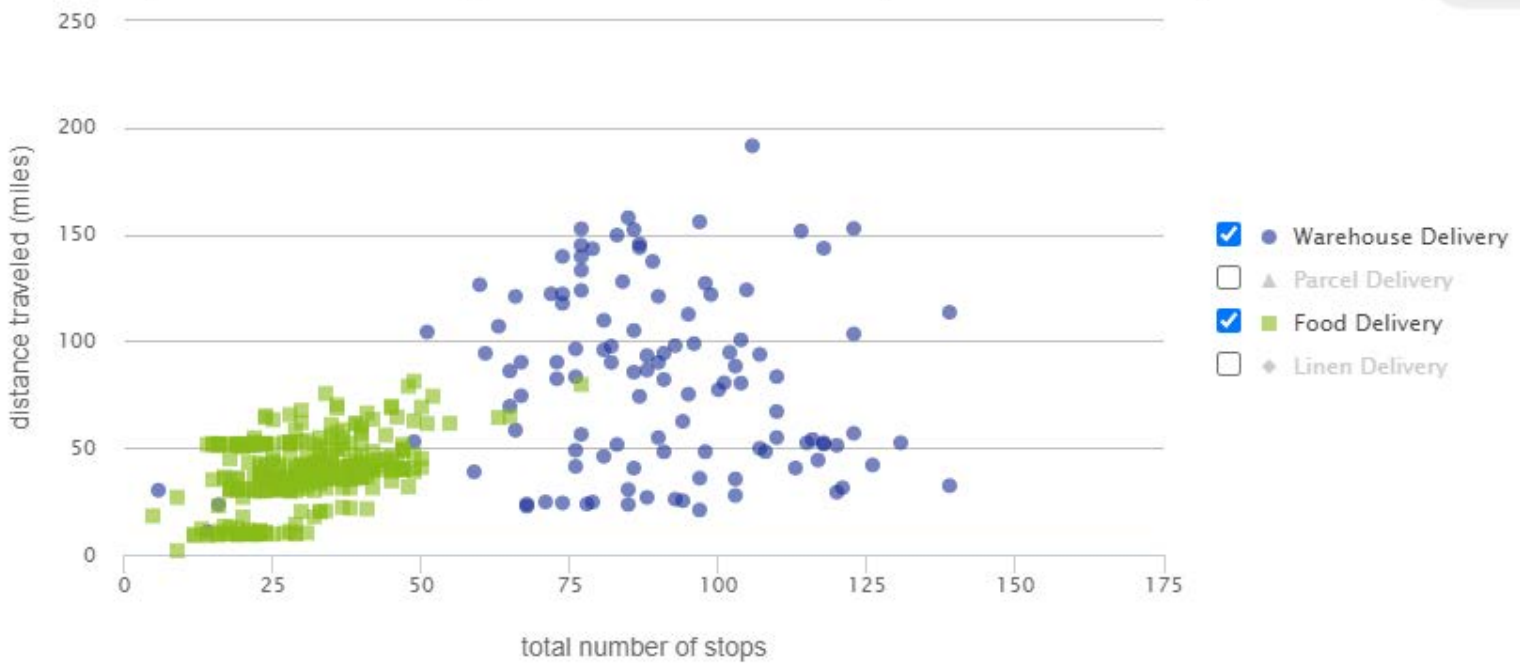

Figure 7. Delivery truck drive cycle data obtained from geolocating devices and stored in Fleet DNA ${ }^{17}$

Note: This data helps delivery truck owners determine the necessary battery size and charging infrastructure.

Geospatial Data. In addition to drive cycle analyses, a number of GIS data files can be valuable when planning where to locate new EV charging infrastructure. Residential and commercial zoning can be helpful to showcase commuting patterns within a city and identify potential EVSE hosts. Traffic volume maps help planners estimate how many EVs could potentially drive along given road segments. Various demographic data files can inform planners as to the areas with populations most likely to adopt EVs and underserved communities in need of transportation services. Utility feeder maps, ideally tied to feeder capacity data, can help ensure that high-powered chargers are installed in locations where the grid can best handle their additional load (though this does not always coincide with optimal commuting patterns). These GIS data files are most likely to be housed in local governments, planning boards, transportation authorities, and electric utilities.

Electricity generation mix is data that shows what portion of the electricity is generated by various fuels. This is critical data to have when determining the emissions-related benefits of EV adoption in a given area, as shown in Figure 8. This figure compares representative powertrains (two conventional vehicles on top, HEV in the middle, PHEV, then BEV on bottom). It shows that the emissions of BEVs are strongly tied to generation mix, PHEVs tied more loosely to it (depending on how much of the driving is done in electric mode), and conventional vehicles are not impacted at all by the grid mix. Another reason it is important to know the percentage of electricity that is generated by variable renewable resources is to enable effective management of EV charging loads to reduce negative impacts on grid operations and time EV charging to absorb excess renewable generation (Fitzgerald, Nelder, and Newcomb 2017). This data is usually available from the utility. In countries with numerous utilities, it is often available in aggregated form from the utility regulating body, the Ministry of Energy or Ministry of Environment.

\footnotetext{
${ }^{17}$ Fleet DNA is a clearinghouse of commercial fleet vehicle operating data. See https://www.nrel.gov/transportation/fleettestfleet-dna.html for more information.
} 


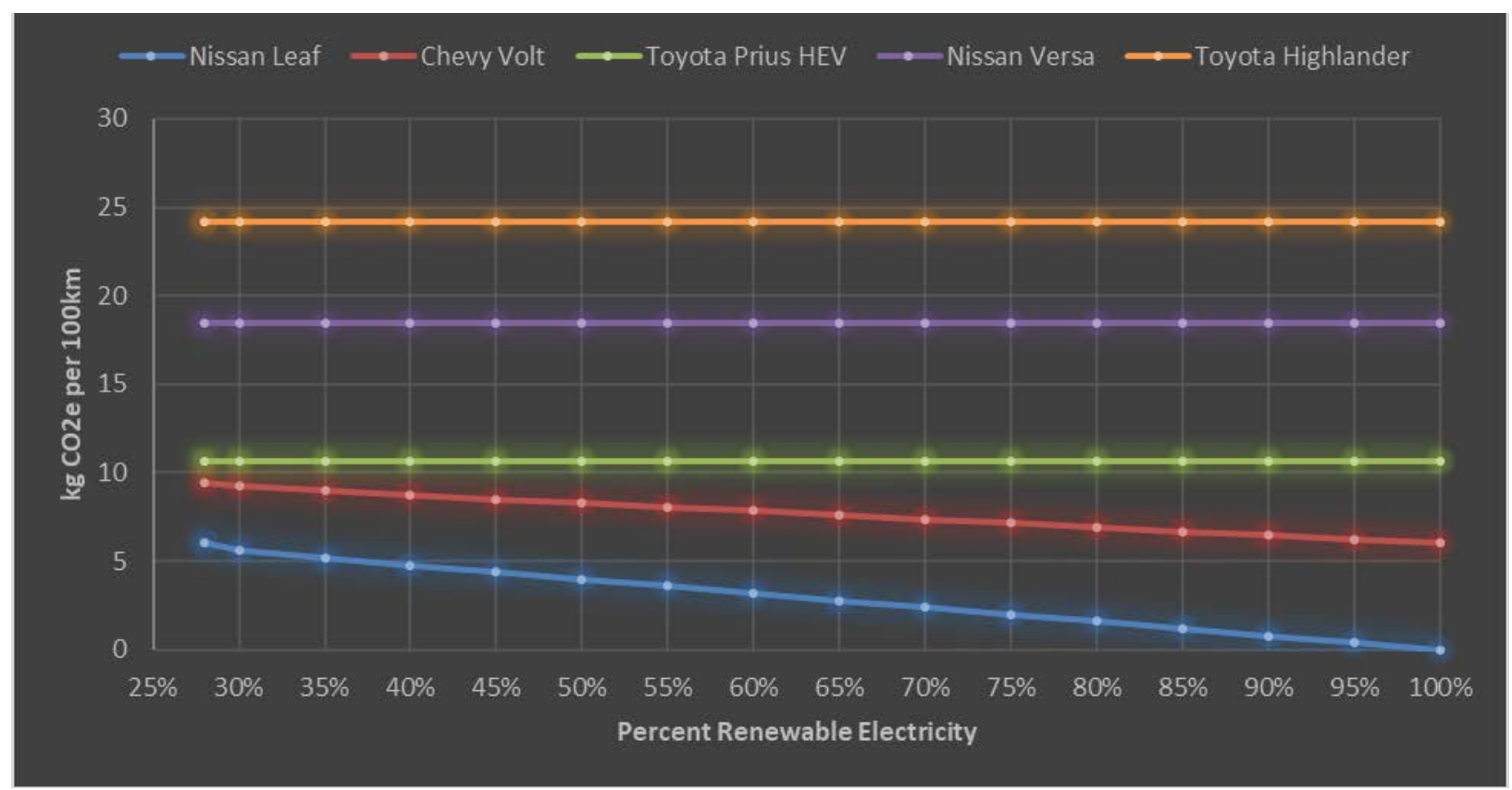

Figure 8. GHG emissions of various vehicles in Mexicali, Mexico, as they increase renewables, given their starting grid mix of $70 \%$ natural gas, $2.5 \%$ diesel, and $28 \%$ renewable

Note: The vehicle models serve as representative powertrains for (from top to bottom) a gasoline SUV then four hatchbacks - gasoline, HEV, PHEV, and BEV.

Source: (Johnson et al. 2020)

\section{Data Summary and Collection}

A variety of data can assess the benefits of and facilitate the strategic adoption of EVs. The most useful and most likely to be found or derived in developing countries is listed in Table 4 . The lines highlighted in blue are foundational data, meaning that it is multipurpose data useful for defining the fundamentals of a transportation system. 
Table 4. Summary of Key Transportation Data Valuable for Electrification Efforts

\begin{tabular}{|c|c|c|c|c|}
\hline Data Set & Purpose/Use & Source & $\begin{array}{l}\text { Probable } \\
\text { Keeper* }\end{array}$ & Alternatives \\
\hline $\begin{array}{l}\text { Transport- } \\
\text { ation fuel use }\end{array}$ & $\begin{array}{l}\text { Defines potential } \\
\text { economic and } \\
\text { environmental benefits of } \\
\text { EVs }\end{array}$ & Fuel taxes & $\begin{array}{l}\text { Ministry of } \\
\text { Energy }\end{array}$ & $\begin{array}{l}\text { Calculate from } \\
\text { VKT and fuel } \\
\text { economy }\end{array}$ \\
\hline Vehicle stock & $\begin{array}{l}\text { Helps prioritize vehicles } \\
\text { to electrify }\end{array}$ & $\begin{array}{l}\text { Vehicle } \\
\text { registration }\end{array}$ & $\begin{array}{l}\text { Ministry of } \\
\text { Transportation }\end{array}$ & $\begin{array}{l}\text { Calculate from } \\
\text { vehicle imports and } \\
\text { expected life }\end{array}$ \\
\hline VKT & $\begin{array}{l}\text { Helps compare } \\
\text { electrification with other } \\
\text { strategies of increasing } \\
\text { transport efficiency }\end{array}$ & Traffic counts & $\begin{array}{l}\text { Ministry of } \\
\text { Transportation }\end{array}$ & $\begin{array}{l}\text { Extrapolate from } \\
\text { another country/city } \\
\text { based on population } \\
\text { density or GDP }\end{array}$ \\
\hline $\begin{array}{l}\text { Mode of } \\
\text { travel }\end{array}$ & $\begin{array}{l}\text { Prioritizes vehicles to } \\
\text { electrify and compares } \\
\text { with other strategies of } \\
\text { increasing transport } \\
\text { efficiency }\end{array}$ & $\begin{array}{l}\text { Transportation } \\
\text { survey }\end{array}$ & $\begin{array}{l}\text { Ministry of } \\
\text { Transportation }\end{array}$ & $\begin{array}{l}\text { Extrapolate from } \\
\text { another country/city } \\
\text { based on population } \\
\text { density }\end{array}$ \\
\hline $\begin{array}{l}\text { Access to } \\
\text { home } \\
\text { charging }\end{array}$ & $\begin{array}{l}\text { Indicates how convenient } \\
\text { charging will be for } \\
\text { population }\end{array}$ & $\begin{array}{l}\text { Housing } \\
\text { survey or real } \\
\text { estate } \\
\text { databases }\end{array}$ & $\begin{array}{l}\text { Ministry of } \\
\text { Housing, } \\
\text { private real } \\
\text { estate websites }\end{array}$ & $\begin{array}{l}\text { Proxies such as } \\
\text { detached house type }\end{array}$ \\
\hline $\begin{array}{l}\text { Gasoline } \\
\text { price }\end{array}$ & $\begin{array}{l}\text { Indicates potential } \\
\text { economic benefits of EVs }\end{array}$ & Retail prices & $\begin{array}{l}\text { Ministry of } \\
\text { Energy }\end{array}$ & $\begin{array}{l}\text { Transportation fuel } \\
\text { excise taxes }\end{array}$ \\
\hline $\begin{array}{l}\text { Electricity } \\
\text { tariffs }\end{array}$ & $\begin{array}{l}\text { Indicates potential } \\
\text { economic benefits of } \\
\text { EVs, charging equipment, } \\
\text { and impact on utility }\end{array}$ & Posted tariffs & Utility & $\begin{array}{l}\text { Ministry of Energy, } \\
\text { IEA }\end{array}$ \\
\hline $\begin{array}{l}\text { Drive cycle } \\
\text { profiles }\end{array}$ & $\begin{array}{l}\text { Helps determine which } \\
\text { vehicles are suitable for } \\
\text { EVs and what equipment } \\
\text { is needed }\end{array}$ & $\begin{array}{l}\text { Telematics } \\
\text { and } \\
\text { geolocating } \\
\text { devices }\end{array}$ & $\begin{array}{l}\text { Fleet } \\
\text { managers }\end{array}$ & Fleet DNA \\
\hline $\begin{array}{l}\text { Geospatial } \\
\text { data }\end{array}$ & $\begin{array}{l}\text { Helps determine where } \\
\text { EVSEs should be located }\end{array}$ & $\begin{array}{l}\text { Local } \\
\text { governments }\end{array}$ & $\begin{array}{l}\text { Local } \\
\text { governments }\end{array}$ & None \\
\hline $\begin{array}{l}\text { Electricity } \\
\text { generation } \\
\text { fuel mix }\end{array}$ & $\begin{array}{l}\text { Defines potential } \\
\text { economic and } \\
\text { environmental benefits of } \\
\text { EVs }\end{array}$ & Electric utility & Electric utility & $\begin{array}{l}\text { Regulator of utility } \\
\text { or Ministry of } \\
\text { Energy }\end{array}$ \\
\hline
\end{tabular}

*Names have been generalized as "ministries" even though they have a wide variety of names. 
The data described above can be collected by a variety of stakeholders, depending on the organizations within a given country, but the collecting entity should have the following attributes. First, it should have ties with as many of the data sources as possible and have the trust of the sources of the data. Many developing countries can be short on easily searchable databases and require personal connections to find hidden data sets - sometimes in paper copy. Second, they should have the technical capacity to clean the data, check for validity, and fill in gaps in fundamental data. Third, they should have the appropriate resources to host large data sets in a searchable format, ideally online. Finally, they should be a permanent fixture in the given country. Therefore, the best candidates to collect and house the data are ministries within the national government - most likely the Ministry of Transportation or Ministry of Energy. 


\section{Establishing a Network of Charging Infrastructure}

\section{EV market development hinges on the availability of charging infrastructure, a key requirement that can be met in a variety of ways.}

Just as gasoline-powered vehicles demand an extensive network of petrol stations, so too do EVs require a widespread and reliable method of refueling. The apparatus of electric refueling is EVSE. One of the most important attributes of any EVSE is the level of power it provides when charging an EV. There are three major types of EVSE, each with different power characteristics.

- Level 1 (L1) charging uses AC to deliver power using common household electricity standards. This results in low power loads $(1-2 \mathrm{~kW})$ and relatively longer EV charge times $(\approx 4 \mathrm{mi} / 6.4 \mathrm{~km}$ of light-duty vehicle range per hour of charging) (Bennett et al. 2019).

- Level 2 (L2) charging uses AC to deliver power using a specialized connection of higher voltage. These deliver between $6.6 \mathrm{~kW}$ and $19 \mathrm{~kW}$ of power, and charging rates of $\approx 25 \mathrm{mi} / 40 \mathrm{~km}$ of light-duty vehicle range per hour of charging, but many current EV models have an onboard limitation ("power acceptance rate") that restricts charging to roughly half that rate in order to manage temperature and optimize battery life (Bennett et al. 2019; Nicholas and Hall 2018) .

- DC Fast Charging (DCFC) uses DC to provide high power levels (i.e., 50-400 kW) using specialized charging equipment. Multiple DCFC standards exist, but all provide rapid charging $(\approx 180 \mathrm{mi} / 290 \mathrm{~km}$ of lightduty vehicle range per hour of charging). Another key consideration for DCFC is that not all vehicles can or should be fast-charged. Some vehicles lack the proper connectors (see EVSE Standards and Communications Protocols), and the high power level of these EVSE can reduce the lifetime of some EV batteries (Rogge, Wollny, and Sauer 2015; Shirk and Wishart 2015; Pillai et al. 2018).

EVs can be driven for many different purposes, and so the spectrum of refueling needs is equally broad. This section summarizes the refueling demands that are met by various charging locations and types of EVSE (see Table 5), and the business models that can support such EVSE investment.

\section{Demands for EV refueling vary by location and influence equipment choices. Residential Charging}

Privately owned vehicles spend the majority of their time parked at home, which is why countries such as the United States experience and predict more home charging than any other EVSE location (Engel et al. 2018). Residential electricity prices typically enable a significantly lower cost of charging compared to public charging options (see below), and this home charging has the added benefit of being significantly more convenient for customers. However, some conditions that support home charging in the United States may not apply in other countries. Home charging is easiest for single-family homes with dedicated parking spaces and access to electricity. Dense urban environments and other factors that encourage multifamily housing will reduce the viability of home charging for these residents without reliable access to a parking space and nearby electrical outlet. Compared to EV deployment patterns in developed countries, many developing countries or regions with lower access to home charging will need to rely more heavily on other EVSE locations.

\section{Workplace Charging}

For personal vehicle commuters, vehicles spend several hours per (week)day parked at work, leading to a sizeable opportunity for EVSE usage at the workplace. This scenario eliminates many of the constraints of home charging, since a workplace typically has multiple dedicated parking spaces and a single set of decision-makers on EVSE investment. For firms that assume the costs of charging, the value proposition for this EVSE investment may be less straightforward, because the direct benefits go to the business's employees and visitors, and not the business itself, though in many regions workplace charging is linked to indirect benefits such as attracting and retaining employees. Some businesses contract a private EVSE developer to having employees and visitors pay for charging services, instead of the business taking on those costs.

\section{Public Charging}

Certain highly trafficked or transport-critical public locations lead to EVSE investment opportunities for utilities, private firms, or governments who are interested in supporting EV deployment. Key transit corridors are high- 
value locations in which EVSE can ease "range anxiety" 18 and enable further EV deployment, while shopping centers, movie theaters, and city centers are examples of public attractions that commonly lead to lengthy parking times. Public charging may also be used by commuters for travel to work. While the revenues from these public charging investments can be uncertain (due to less regular or predictable usage than other location types), customers are often willing to pay more for the convenience of public charging, which can lead to a strong value proposition for EVSE investors in the private sector.

\section{Fleet Charging}

Fleets of vehicles are unique because, unlike workplace or public charging, the owner of the fleet's EVSE is the same entity as the operator of the fleet's EVs. This removes uncertainty surrounding the value proposition of EV/EVSE investment and makes cost-benefit analyses more straightforward. Fleets possess the additional benefit of having highly scheduled and predictable usage patterns, unlike personal driving habits. This means that fleet EVs are easier to plan for in terms of grid investment and cost recovery. However, because fleet vehicles spend so much more time in operation than other EVs with less strenuous duty cycles, the refueling needs of fleets may require higher upfront investment in DCFC charging stations or dedicated L2 charging stations for each vehicle. These costs are offset by savings on fuel and maintenance, which accrue more rapidly in these high-usage contexts. Fleet charging stations are typically not available to the public.

Table 5. Summary of Common Charging Infrastructure Characteristics by Location

\begin{tabular}{|l|l|l|l|l|}
\hline \multicolumn{1}{|c|}{$\begin{array}{c}\text { EVSE } \\
\text { Location }\end{array}$} & $\begin{array}{c}\text { EVSE } \\
\text { Type }\end{array}$ & $\begin{array}{c}\text { EV User } \\
\text { and EVSE } \\
\text { Owner }\end{array}$ & \multicolumn{1}{|c|}{ Benefits } & \multicolumn{1}{|c|}{ Drawbacks } \\
\hline Home & L1, L2 & Same & $\begin{array}{l}\text { Inexpensive electricity; } \\
\text { convenient }\end{array}$ & $\begin{array}{l}\text { Not available in every } \\
\text { housing situation; not viable } \\
\text { for long journeys }\end{array}$ \\
\hline Workplace & L1, L2 & Different & $\begin{array}{l}\text { Predictable charging needs; } \\
\text { can save costs if behind } \\
\text { same meter as workplace }\end{array}$ & $\begin{array}{l}\text { Workplace must make } \\
\text { investment decision; } \\
\text { convenient during working } \\
\text { hours only }\end{array}$ \\
\hline Public & L1, L2, & Different & $\begin{array}{l}\text { Meets charging needs for } \\
\text { vacations, leisure activities, } \\
\text { and EV users without other } \\
\text { charging access }\end{array}$ & $\begin{array}{l}\text { Charging costs to EV user } \\
\text { can be relatively higher than } \\
\text { other EVSE locations; less } \\
\text { predictable demand }\end{array}$ \\
\hline Fleet & L2, DCFC & Same & $\begin{array}{l}\text { Predictable charging needs; } \\
\text { high potential for efficient } \\
\text { electrification and fleet fuel } \\
\text { cost savings }\end{array}$ & $\begin{array}{l}\text { High upfront cost; requires } \\
\text { extensive planning }\end{array}$ \\
\hline
\end{tabular}

Different locations, charging needs, and equipment lead to a variety of EVSE ownership and investment models, which require a balance of public and private sector resources.

\section{Public and Private Sector Perspectives}

In many countries and contexts, private firms will be leaders in the investment and deployment of EVSE because of the inherent business opportunities within electrified transport. EV users will desire charging services, which private firms can provide for an acceptable price. By definition, following these incentives leads the private sector to deploy EVSE in situations where charging is sufficiently profitable, and to avoid deploying EVSE in

\footnotetext{
${ }^{18}$ Range anxiety is the feeling that an EV's stored electricity is insufficient to meet the distance requirements of a trip and may leave the driver stranded if they are unable to refuel.
} 
unprofitable (or insufficiently profitable) situations. Private firms therefore will not make EVSE investments in communities or transportation corridors with few EV users or EV users unable to pay the price of charging. As a result, the charging network that arises from EVSE deployment led purely by the private sector may not match a country or city's goals for electrified transportation. The government, or public sector, can choose to fill these gaps by incentivizing or subsidizing EVSE deployment in situations that may not be highly profitable to begin with, but that allow the overall EV market to grow larger, more quickly, and more equitably.

\section{Residential Charging}

Charging infrastructure in a single-family home is one of the most straightforward and common arrangements. The private sector is less directly involved as the homeowner covers the necessary hardware and installation costs, then captures the benefits of refueling their EV in a convenient location at a low residential electricity rate. These systems are almost always Level 1 or Level 2 chargers because the light-usage duty cycle of personal EVs usually ensures long vehicle dwell times (the time a vehicle spends immobilized at a stop). However, the housing stock in many countries contains many multifamily homes and/or homes with a lack of plug-ready parking spaces. In these contexts, focusing on residential EVSE deployment may not reach large segments of the population who could adopt EVs but require other charging options. Residential charging becomes even more complex in rental units, where the landlord-tenant problem creates split incentives for the landlord, who must pay the costs of improvement, and the tenant, who receives the benefits. In these cases, the landlord may view EVSE as a renovation.

\section{Workplace Charging}

Workplace charging infrastructure may be subject to a similar split incentive as rental housing, if the business decides to invest in a benefit for its employees and assume responsibility for the maintenance and security of its EVSE. Businesses can decrease these cost burdens by placing the EVSE behind the same meter as the office's electricity, which can help reduce the relative cost of utility demand charges (see Tariff Design) for the EVSE. As previously mentioned, businesses may also contract with private sector EVSE developers, to whom the employees and visitors would pay money for charging services. Workplace charging business models may also benefit from the reliability of commuter employee travel patterns. This reliability helps enable managed charging programs (see Grid Planning and Management) that can reduce demand charges by spreading EVSE energy consumption over time. Long dwell times for parked employees typically require only Level 1 or 2 workplace charging systems.

\section{Public Charging}

While public EVSE installations do not enjoy the extremely reliable user base of residential, workplace, or fleet charging infrastructure, charging locations such as highways, commuter corridors, or shopping centers can be key enablers of EV deployment. In addition, public charging may be the only option for an EV driver who does not have home access to charging or a workplace environment that supports reliable EVSE access. The potential value and convenience of charging stations in these public locations, for both easing range anxiety and enabling longer trips, can justify the higher charging prices required to offset the higher average installation costs of public EVSE due to distance from existing electrical infrastructure (Smith and Castellano 2015). With such a range of locations, Level 1, Level 2, and DCFC units are all potentially viable for public applications. Transportation corridor EVSE intended for longer intercity travel is likely to be DCFC, while EVSE intended for public convenience or shorter intracity travel could be Level 1, Level 2, or DCFC, depending on the anticipated EV dwell time and anticipated customer needs at the charging location.

The variety of potential stakeholders, project partners, and desired recharging services leads to many possibilities for ownership, investment, and operation of public EVSE (U.S. Department of Energy Clean Cities 2012). The list of possibilities is long. To begin with, there are multiple methods of revenue collection. ${ }^{19}$ The host site of a charging station has numerous options as well. The host may purchase, install, and operate the EVSE itself, which allows the host to retain all revenues. However, it is often more efficient or desirable for the host site to partner with other firms to cover these responsibilities and share revenues. Some hosts may want to own charging equipment while also having a customized payment structure for the EVSE based on time of use or the user (e.g.,

${ }^{19} \mathrm{EV}$ drivers may pay a combined fee for parking and charging, pay a monthly or annual fee for a charging service subscription, hold an account with a charging company, or pay directly for energy or charging time with a credit card or hard currency. 
charge more during business hours while letting government vehicles charge without a fee). It is possible for private sector partners to manage this transaction structure and collection. Other hosts may not want to be responsible for installation and maintenance. They can provide the EVSE site while contracting with a third party to install and operate the charging station. These are only a few examples of the many possibilities for deploying and maintaining public EV charging infrastructure. Host site capabilities and the local availability of partner organizations or policy incentives will determine the options available for a given EVSE location.

Finally, public EVSE installations must consider the role of the utility and potential grid upgrade costs. A common issue is for a private company to choose an otherwise financially attractive location for EVSE that requires electrical infrastructure upgrades to avoid overloading the distribution and/or transmission systems. Depending on the individual setting, the EVSE owner or the utility may be obligated to pay these upgrade costs, which are often expensive and lengthy ( $>1$ year) procedures. Project planning and utility coordination are therefore key for charging infrastructure deployment, as grid upgrade costs can alter both project economics and construction time (see Grid Planning and Management)

\section{Fleet Charging}

Ownership and investment models for fleet charging have many considerations, but fleets can proceed without the complication of split incentives. In this case, the fleet (whether privately or publicly owned) makes both the investment in EVSE and receives the benefits of EV charging services, most notably in the form of fuel cost savings. Fleets have many vehicles with high-usage duty cycles, which both increases the magnitude of fuel cost savings and limits the time available for refueling. The ability to eliminate a large portion of fuel costs, combined with this time constraint, leads many fleets to consider DCFC units or dedicated Level 2 units for each vehicle despite the associated cost premium. Fleet managers must also consider electricity rate structure, since the value of an EV fleet can be maximized by ensuring that the vehicles recharge using the least expensive rate available (see Tariff Design). The layout of the charging depot itself is also important for facilitating effective recharging of very high-usage fleets (e.g., buses). An EV refuels more slowly than an ICE vehicle, so coordinating the timing and sequence of recharging an EV fleet can be more difficult than similar planning for ICE fleets.

For fleets with predictable routes, such as transit buses or waste management vehicles, on-route charging is an option as well. Placing charging stations along an EV's route can extend those routes and ease the scheduling issues of depot charging. However, the dispersed nature of on-route charging often requires a greater number of charging stations than charging only at the supply depot, and on-route charging may require more extensive planning to address the construction and installation considerations at each location. For public transit or other fleets with defined routes, catenary lines are an established alternative for vehicle electrification. These overhead lines are an often-overlooked method of electrifying transportation in a cost-effective and energy-efficient manner and are most commonly deployed for rail or bus lines. Electric buses served by catenary lines may additionally benefit from a small, short-range battery to extend their range beyond the catenary line itself.

Because of the high usage of fleet vehicles, fleet managers are typically familiar with fuel expenses and the value proposition of EV investment (i.e., higher upfront cost and lower operational expenses). EVSE will therefore be deployed similarly for fleets owned by the private and public sectors. In addition, fleet vehicles usually provide services or transportation in a highly equitable manner. Buses, for example, are a low-cost transportation option for people unable to afford their own vehicle. As a result, fleet electrification is an effective strategy for equitable transportation electrification overall.

\section{Battery Swap}

A less-proven business model focuses on speedy refueling through a charging station that hosts many fully charged batteries. The company invests in charging stations and enough batteries to ensure availability for users. EV drivers can then swap their empty battery for a full one, for a fee. This model could be an elegant solution to range anxiety and long refueling times, but the idea must overcome several obstacles in order to be successful. EV manufacturers must commit to producing models with easily swappable batteries, which can be a major design and intellectual property sacrifice. Drivers of freshly purchased EVs may also be reluctant to exchange their brand-new battery for ones of uncertain age and quality. The most prominent battery swap business to date, in Israel, went bankrupt in 2013 (Noel and Savacool 2016). However, with reductions in battery cost, sufficient industry commitments, and improvement in battery performance, swapping may be a viable business model. Battery swapping for two- and three-wheel vehicles is a promising growth area, especially in South and East 
Asian countries, as shown by the success of companies like Taiwan's Gogoro, India's Ola, and others (P\&S Intelligence 2020). Battery swapping for buses is also a promising growth area because batteries are generally more accessible in buses, the space is more standardized, and the batteries could be swapped between numerous fleet vehicles without a change in ownership. This type of EVSE deployment often promotes equitable EV market growth as well, as two-wheelers, three-wheelers, and buses are relatively available and affordable modes of transport.

\section{Equity Considerations}

The categories for EVSE business models, described previously, include equity considerations that are connected to the balance of public and private sector resources committed to EVSE deployment. While every context is different, three overall categories of equity can be applied to EVSE deployment: access, type, and price.

Access describes the population for whom EVSE is convenient to use. As an example, if EV owners are mostly wealthy people who own single-family homes in wealthy neighborhoods (a global trend for early EV adopters), then the most profitable EVSE locations are in these same neighborhoods or the EV owners' workplaces. The private sector is unlikely to deploy EVSE elsewhere because it will not return a sufficient profit. This inequity may cause potential lower-income EV consumers, or potential EV consumers in mixed-income neighborhoods, to decide against using EVs due to the lack of accessible charging infrastructure at home and work. To avoid this lower rate of EV adoption, public sector resources may be used for EVSE deployment to give marginal EV buyers confidence that they can access charging services.

Type relates to the diversity of EV models (truck, car, three-wheel, two-wheel, etc.) and the potential variety of charging and connector standards (see EVSE Standards and Communications Protocols). If EVs of a certain type are more highly adopted than others and can only be charged by a certain type of plug, then the most profitable EVSE will provide this popular charging service and not others. For example, if early EV adopters in a country mostly purchase four-wheeled personal vehicles, and these four-wheel cars require a differently shaped plug than two- or three-wheel EVs, the most profitable EVSE to deploy will only provide charging services to four-wheel cars. This can lead to limited EVSE networks for other vehicles that result in lower levels of two- or three-wheel EV adoption. This gap may be filled by public sector investment, or by setting charging and connector standards that allow many types of EVs to charge using the same equipment (again, see EVSE Standards and Communications Protocols).

Price is an equity consideration for EVSE in less-utilized locations. If a charging station is not servicing enough EVs to be profitable, one way to increase its revenues is by increasing the price of charging. This tactic may be successful from the perspective of a private firm who receives these increased revenues; however, at the same time, it can prevent lower-income EV drivers from affording the charging service. For example, a travel route may be popular only during certain seasons due to tourist demand, leading to low average usage across the entire year. In this situation, a private firm could demand high charging prices to meet its revenue requirements, which tourists are able to pay, but year-round residents are not. Inequity therefore arises as the tourist EV market grows, but these residents are discouraged from adopting EVs due to the cost of refueling. If the EVSE in these situations provides crucial network coverage to prevent range anxiety or supports travel patterns that help grow the EV market, public sector policies or subsidies can fill this gap by supporting affordable charging prices.

\section{Determining the optimal amount of EV charging infrastructure is complex; however, well-executed individual projects can add up to an effective system.}

Range anxiety and the overall accessibility of charging are primary concerns for potential EV adopters, and these factors drive EVSE deployment. At the same time, EVSE investors and developers are incentivized to seek the optimal location and highest demand for charging services, a selection process that can slow the pace of EVSE deployment. Governments may have justifiable concerns on the topic of "perfect" EVSE deployment — enough charging infrastructure to support the number of EVs on the road by keeping drivers secure and satisfied, but not so much as to incur unnecessary installation and grid upgrade costs by overbuilding. Optimizing EVSE deployment on this large scale is a complex exercise, and there are modeling tools available that can estimate these needs through consideration of the types of EVs to be served, charger type, population density, and other factors (Wood et al. 2017; Bedir et al. 2018; AFDC 2020). 
While this macro-planning approach has value for large-scale benchmarks and policymaker strategy, what matters most for successful EVSE deployment is that each project is carefully planned and executed based on real-world data (see Data Collection and Management). Private sector EVSE investors, national and state policymakers, and utilities should all coordinate to ensure that large-scale EVSE strategies can be realistically implemented. In countries or regions with few resources, even low-expense data collection and project tracking can significantly improve the stability of overall EVSE deployment. Considering the elements of these building blocks - the location, installation, users, costs, and benefits for a particular location-will result in effective instances of EVSE deployment that sum up to create an efficient network of charging infrastructure. An example approach in India demonstrates the balanced consideration of these interrelated factors (Pillai 2018). 


\section{EVSE Standards and Communications Protocols}

\section{Establishing a regulatory framework of charging standards, equipment certification, and building codes creates a consistent, reliable, and safe operating environment for EVs.}

Increasingly advanced EV and EVSE technologies are entering the market at a rapid pace. Due to the highly interrelated nature of EV charging technology, it is important to establish a consistent regulatory framework. An effective means of doing this is for policy makers to adopt and enforce internationally or nationally appropriate EV and EVSE codes and standards. This ensures interoperability between different types of EVs and EVSE and establishes a safe and reliable operating environment for consumers and installers. Government selection, adoption, and enforcement of codes and standards can provide consumers with confidence in the long-term viability of EV charging technologies. This in turn may increase investment in these technologies and lower the risk of it becoming obsolete in the near future. These efforts support the development of a robust network of charging infrastructure that underpin successful EVSE deployment and increased EV adoption.

A regulatory framework governs the connection from:

\section{The EV to EVSE}

2. The EVSE to the grid.

Generally, the connection from the EV to the EVSE is governed by charging standards, and the connection between the EVSE to the grid is governed by installation codes. The terminology describing the regulatory framework of EV charging can be inconsistent. Therefore, we use three different terms, defined below, to encompass the three key elements that make up the regulatory framework outlined in Figure 9.

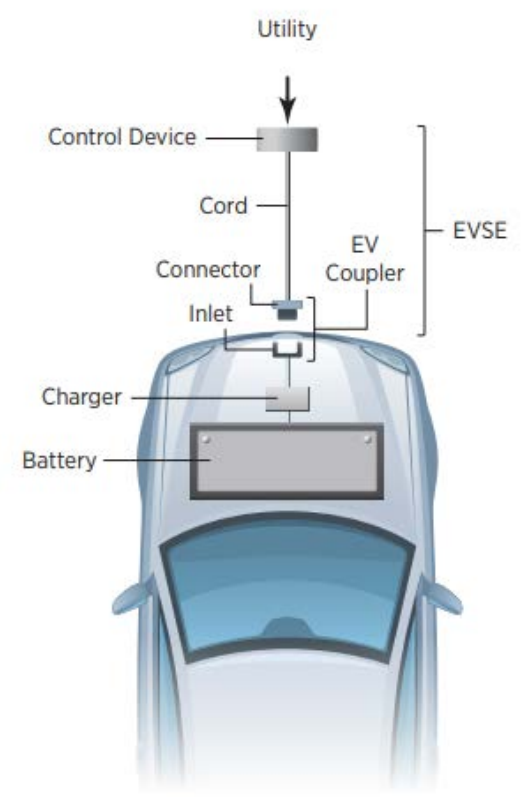

1. Charging Standard: a document that outlines specifications for manufacturers to design and build an EVSE with a connector that is compatible with the vehicle charging inlet. ${ }^{20}$ Charging standards provide the specifications for a common charging connector and inlet designs (Figure 9), as well as the basic safety requirements and charging limitations. EVSE are classified into levels based on the rate which the EV batteries are charged ${ }^{21}$ and in some cases there are different charging standards for each level. Charging standards are generally developed by national or international nongovernmental standards developing organizations (such as the International Electrotechnical Commission or IEC) consisting of members representing manufacturers, consumers, technical experts, and government ministries. In some cases, charging standards can also be developed by governments as is the case in China.

Figure 9. Diagram of EVSE and EV charging components

Image from Dean Armstrong, NREL https://afdc.energy.gov/files/Ddfs/5I227

\footnotetext{
${ }^{20}$ The charging coupler includes the EVSE connector and the EV inlet. The EVSE connector is the nozzle and cord that provides power from the EVSE to the EV. The EV inlet is where the vehicle receives this power.

${ }^{21}$ The three most common levels are Level 1 (120-volt), Level 2 (240- or 208-volt) and DCFC (480-volt). See Establishing a Network of Charging Infrastructure for more information on charging levels.
} 
2. Equipment Certification: ensures that once manufactured, the EVSE is in compliance with the charging standard design and reassures the public they are effective and safe for use. Equipment certifications are granted by independent equipment testing laboratories such as Underwriters Laboratory and Electrical Testing Laboratories. These laboratories conduct rigorous performance, safety, and quality testing before certifying that a particular product complies with a given standard.

Governments often formally approve and recognize equipment testing laboratories and subsequently require their certification for installed products in internationally or nationally adopted installation codes.

3. Installation Codes: establish both electrical requirements for a safe and reliable interconnection with the utility grid as well as construction requirements for buildings that may house EVSE. An example of an installation code focusing on safe electrical interconnection is the U.S. National Fire Protection Association's National Electric Code, where Section 625 specifically outlines the proper electrical installation requirements for an EVSE. An example of an installation code focusing on building construction requirements is the International Code Council's International Building Code. ${ }^{22}$ Installation codes often refer back to charging standards and equipment Regulatory Framework certifications.

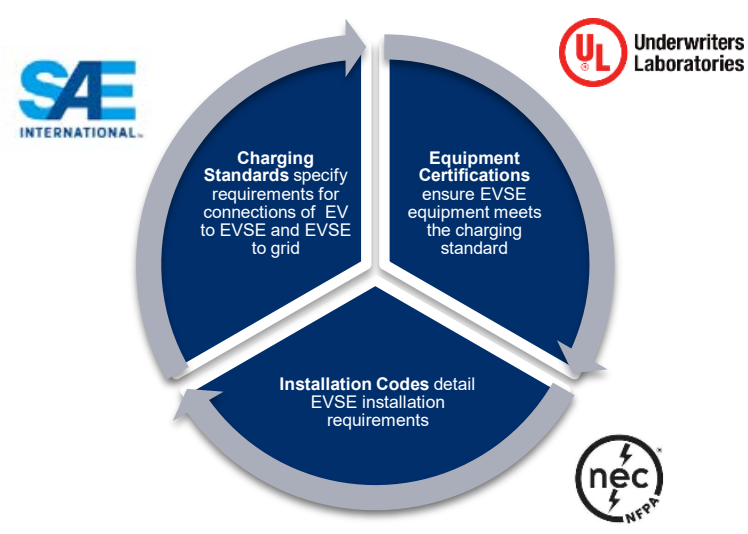

Figure 10. Framework of charging requirements Source: Kaylyn Bopp, NREL

\section{Box 6. EV Codes and Standards Development in Lao PDR}

The Lao PDR is interested in increasing EV adoption in order to take advantage of the country's large supply of domestically produced hydro-electric power and reduce the need for oil imports for their transportation sector. As part of this effort, the government recently passed the "Strategy on Clean Energy Use and Promotion in the Transportation Sector, Development Plan 2025, Strategy 2030, and Vision 2050." This strategy was developed by the Lao government's EV Working Group, which included representatives from the private sector, the local utility (Électricité du Laos), Ministry of Energy and Mines, Ministry of Public Work and Transport, Ministry of Finance, and Ministry of Trade and Industries. The working group conducted research on locally appropriate EVSE business models, technical standards, and EVSE tariff designs with capacity building and technical support from the USAID-NREL Advanced Energy Partnership for Asia. Special consideration was given to selecting financially sustainable business models and regionally appropriate EV charging standards.

\section{The regulatory framework governing EV and EVSE technical requirements must be thoughtfully reviewed and consistently enforced.}

By design, a regulatory framework comprising charging standards, equipment certifications, and installation codes strategically reference one another to mutually reinforce each other's authority (Figure 10). Policymakers play a pivotal role in supporting this framework by selecting and adopting charging standards that are appropriate for their region, formally recognizing equipment testing laboratories that consumers can trust to verify the safety of new technology and adopting or updating installation codes to remove barriers to EVSE installations. Because

\footnotetext{
${ }^{22}$ While the International Building Code does not have specific EVSE provisions, it does include requirements concerning circuitry, power systems, and power supply that apply to EVSE installation. To facilitate the future addition of EVSE to buildings, existing codes for building construction can be amended to include specific EVSE requirements that require new buildings have the necessary electrical capacity and prewiring to allow future owners to more easily install an EVSE without extensive retrofit work. These requirements are often known as "EV Make-Ready" or "EV Capable" requirements.
} 
the elements of the regulatory framework work best as a collective, policymakers can consider designing and reviewing this regulatory framework holistically.

Wherever possible, the regulatory framework should be enforced to ensure compliance. Distributing this enforcement amongst several entities may help to disperse this responsibility. Typically, government ministries are primarily responsible for the review, selection, and adoption of charging standards and installation codes. They should also formally recognize one or multiple equipment certification laboratories and require electricians to be licensed in their field and educated on current installation codes. Ideally, all EVSE equipment (imported or manufactured within the country) should be certified by the recognized equipment testing laboratory to be in accordance with the selected standard and installed by a certified electrician. The local authorities having jurisdiction ${ }^{23}$ should verify that the equipment meets the standard and was installed in compliance with the code before operation begins. Figure 11 provides an example of how different entities may enforce compliance at each stage of the regulatory framework.

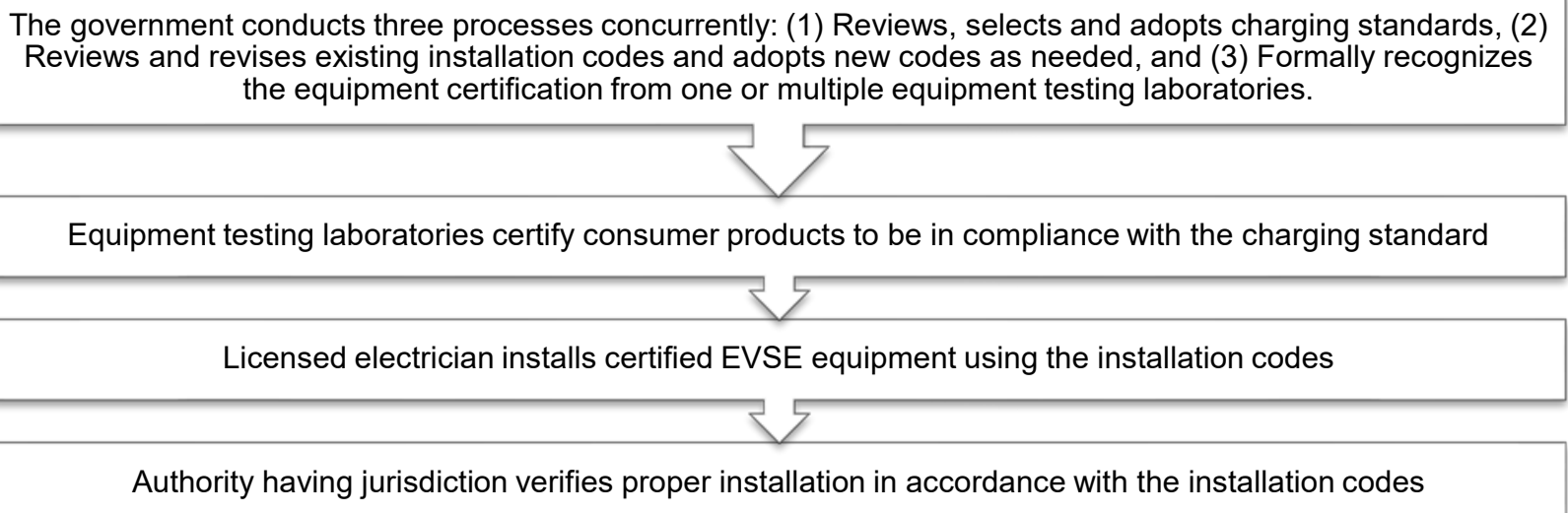

Figure 11. Enforcement of regulatory framework

\section{Reviewing current codes and standards will help policymakers understand whether they serve to help or hinder EVSE deployment and adoption.}

It is important for policymakers to conduct a thorough review of their existing regulatory framework before making changes or additions. Special consideration should be given to reviewing the requirements relating to electrical infrastructure, building design, and construction to examine whether they can currently accommodate safe EVSE installations as existing codes may unintentionally prevent or deter EVSE installations. Once reviewed, codes can be modified or adopted to account for current and future advances in technology. When considering which charging standard to adopt, policymakers should review which of the existing charging standards are common in their geographic region, which EV manufacturers have sales or distribution in the area, and which charging standard those vehicles use. Adopting a charging standard that is used in nearby countries can ease EV travel between countries and increase the number of EV models available for purchase. The specific charging standards, equipment certifications, and installation codes listed in this report are not intended to be an all-inclusive list, but rather an introduction to those that are especially relevant to the subject of EV charging and those that are most common in existing markets.

\footnotetext{
${ }^{23}$ The authority having jurisdiction can vary by location but generally has locally granted authority and the necessary expertise to confirm proper installation and safe operations. In practice, an authority having jurisdiction may include a local fire marshal, electrical inspector, labor or health ministry, and building inspectors, among others.
} 


\section{Relevant Installation Codes}

National Fire Protection Association's National Electric Code: Article 625

The National Electric Code has been adopted in North America and certain South American countries. It details specific requirements for the installation of electricity circuits and electrical equipment in homes and commercial buildings. Article 625 of the code covers specific requirements for the installation of EVSE including branch circuits, overcurrent protection, conductor gauge and length, and loss primary service.

International Code Council: International Building Code and International Residential Code

The International Building Code has been adopted in the United States and is the basis for similar codes adopted in the Middle East and Caribbean (ICC 2015). It details specific requirements for the installation of electricity circuits and electrical equipment in commercial and residential. This code includes requirements concerning circuitry, power systems, and power supply that apply to EVSE installation.

\section{Relevant Charging Standards}

Although there are a number of different charging standards developed for the charging connector, a select number of them have become commonplace in recent years. Some of these standards detail provisions for only AC charging (typically Level 2) or only DCFC, while others allow for both. EV owners typically desire the ability to charge using both AC and DC power and EVs increasingly have the capability to do both. ${ }^{24}$

It is important to note that power from the electrical grid is transmitted using AC electricity, whereas EV batteries are charged using DC power. This difference necessitates the conversion of electricity from $\mathrm{AC}$ to $\mathrm{DC}$ power at some point in the charging process. Depending on the level of EVSE, the electricity from the grid is converted from AC to DC in different places. With Level 2 charging, this happens inside the vehicle when the vehicle's internal power converter converts AC electricity to DC. With DCFC, a power converter inside the EVSE converts AC electricity into DC electricity before being delivered directly to the vehicle. AC or DC power may be delivered to the vehicle using different charging connectors. Figure 12 helps to explain AC and DC charging standards in EVSE and

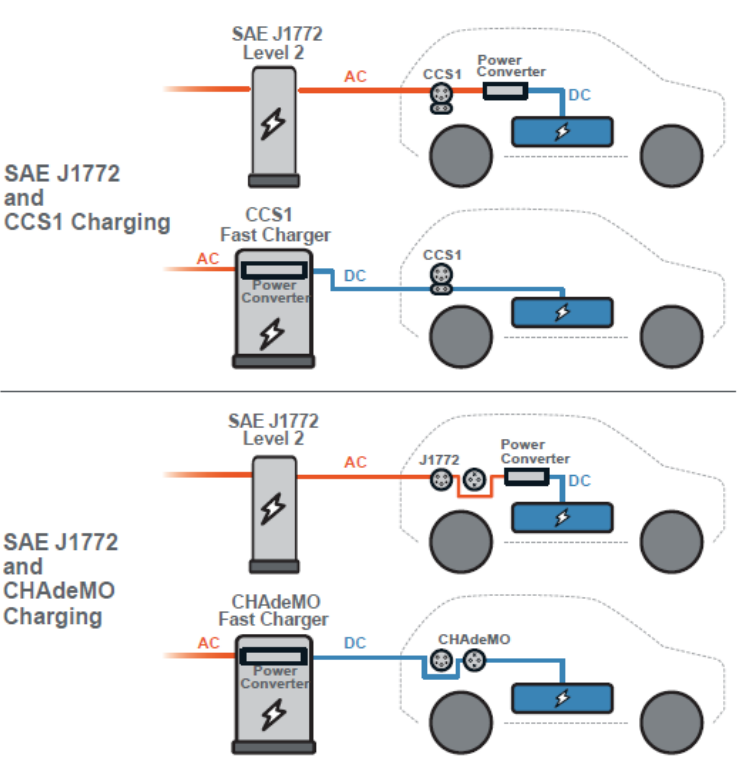

Figure 12. AC and DC charging standards EVs with different charging standards.

\section{IEC 62196 Standard}

This standard defines the electrical specifications and design of several configurations of charging connectors developed by different manufacturers. A selection of the most commonly used Level 1 , Level 2, and DCFC connectors listed in the IEC 62196 are described in Figure 11. It is important to note that countries generally select either Type 1 or Type 2 for the Level 1 and Level 2 charging standard and include additional charging standards for DC fast charging to supplement these. Selecting a defined set of charging connectors helps to standardize the inlets in the EVs available for purchase, as well as the charging connectors for the EVSE that are installed.

\footnotetext{
${ }^{24}$ PHEVs generally do not include DC connectors and can only charge using Level 1 or Level 2 AC EVSE.
} 


\begin{tabular}{|c|c|}
\hline \multicolumn{2}{|r|}{ Table 6. List of Commonly Used Charging Connectors From IEC 62196} \\
\hline \multicolumn{2}{|c|}{ Level 1 and Level 2 Couplers (AC Charging) } \\
\hline Type 1 & $\begin{array}{l}\text { Also known as the SAE J1772 connector. Type } 1 \text { can be used for Level } 1 \text { and Level } 2 \\
\text { charging. This connector is most common in North America and Japan. }\end{array}$ \\
\hline 2 & $\begin{array}{l}\text { Also known as the "Mennekes" connector. Type } 2 \text { can be used for Level } 1 \text { and Level } \\
2 \text { charging. This connector is most common in the EU. }\end{array}$ \\
\hline $\mathrm{GB} / \mathrm{T}(\mathrm{AC})$ & A connector designed by and used exclusively in China. \\
\hline \multicolumn{2}{|c|}{ DCFC Couplers (DC Charging) } \\
\hline & $\begin{array}{l}\text { Combined Charging System } 1 \text { (CCS1): A charging connector that can be used for } \\
\text { DCFC only. This connector type is an extension of the SAE J1772 connector } \\
\text { (detailed above). This charging standard is most common in North America. }\end{array}$ \\
\hline CCS2 & $\begin{array}{l}\text { Combined Charging System } 2 \text { (CCS2): A charging connector that can be used for } \\
\text { Level 1, Level 2, or DCFC. This connector type was originally developed in } \\
\text { Germany. This charging standard is most common in the EU and India. }\end{array}$ \\
\hline $\begin{array}{l}\text { CHAdeMO } \\
\text { (0) }\end{array}$ & $\begin{array}{l}\text { CHAdeMO: A charging connector that can only be used for DCFC. This connector } \\
\text { type was developed by a group of Japanese automakers and occurs primarily in } \\
\text { Japanese EVs sold to the United States and Japan. }\end{array}$ \\
\hline $\mathrm{GB} / \mathrm{T}(\mathrm{DC})$ & GB/T: A connector designed by and used exclusively in China. \\
\hline \multicolumn{2}{|c|}{ AC Level 2 and DCFC } \\
\hline Tesla & $\begin{array}{l}\text { Tesla: A charging connector that can be used for both DCFC and Level } 1 \text { and Level } \\
\text { 2. Proprietary to Tesla vehicles. Used in all Tesla markets except China and Europe. }\end{array}$ \\
\hline
\end{tabular}

Coupler images adapted from (EnelX JuiceBlog 2019)

IEC 61851 Standard

This standard defines four modes of EVSE and categorizes each by the operating voltage, the power (i.e., $\mathrm{kW}$ ) delivered to the $\mathrm{EV}$, and the presence or absence of fault and protection features. These fault and protection features maintain a safe operating environment for the vehicle battery and grid infrastructure and may be provided through an in-cable control and protection device (IC-CPD) or be built into permanently installed EVSE units. Permanently installed EVSE units may also support external communication to the EV owner or grid management via an internet connection. External communication enables additional EVSE features such as power management and fleet oversight. The IEC 61851 standard differentiates the locations of fault and protection features and the presence of external communication in Modes 1-4, which can be seen in Figure 13. 

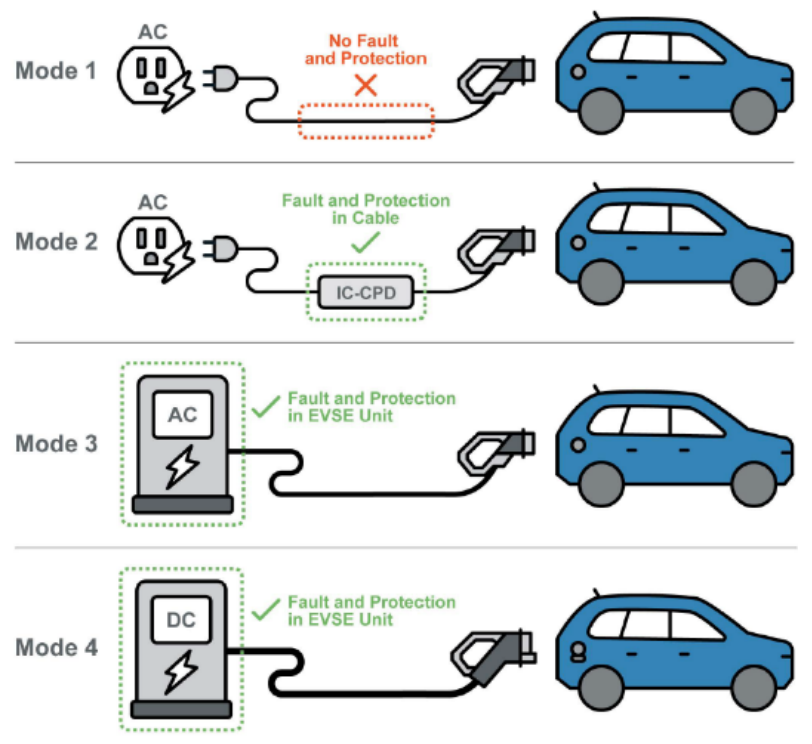

Figure 13. Four modes of EVSE charging per IEC standard
Mode 1: Charging an EV from a standard electrical outlet with a portable extension cord that lacks an IC-CPD. This mode has been banned in some countries due to the lack of fault and protection features.

Mode 2: Charging an EV from a standard electrical outlet using a portable EVSE cable with an IC-CPD. Includes fault and protection features.

Mode 3: Charging an EV from permanently installed AC EVSE in either a residential or public setting. Includes the fault protection features normally provided by an IC-CPD but within the EVSE unit. Also includes external communication features.

Mode 4: Charging an EV from a permanently installed DC EVSE in a public setting. Includes

the fault protection features normally provided by an IC-CPD but within the EVSE unit. Also includes external communication features.

\section{Having interoperable and open standards-based public EVSE infrastructure is critical to the success of the EV market.}

Communication and interoperability protocols allow EVSE to operate as a system and provide services to customers, making vehicle charging more accessible and convenient. Charging networks are businesses that remotely manage the operations and payment collection of numerous EVSE located at different sites. They do this by using EVSE that are connected to the internet or cellular service (via Wi-Fi or wired network). Once connected, EVSE can then offer cloud-based services that benefit the site host and customer (utilization monitoring, diverse payment options, app or web-based station locators, real-time status availability reports, and station usage reporting). In many countries, there exists multiple charging networks, encouraging competition, diversification, and increased EVSE deployment. In such cases, EV drivers will likely use different charging networks to charge their vehicle, which may require the driver to open multiple user accounts in order to pay for charging at each network they use. Alternately, if there are certain network interoperability communication protocols in place, an EV driver may have one user account that can be used to pay at different charging networks (i.e., analogous to network roaming with a mobile phone).

In the scenario in which a charging network goes out of business, by selecting EVSE with hardware that uses certain open standards-based communication and interoperability protocols, the EVSE can be easily switched to a different charging network without expensive equipment upgrades.

There are two main areas where interoperability protocols exist:

1. Charger and Network Interoperability protocols allow EVSE owner-operators to switch charging networks without having to purchase a new EVSE or make expensive equipment upgrades.

2. Network to Network Interoperability protocols allow drivers with a membership to one charging network to access other networks without having to become a member.

\section{Relevant Interoperability Protocols}

\section{Open Charge Point Protocol}

Open Charge Point Protocol-compliant EVSE physically separates the hardware aspects of the EVSE from the network and software components. In this way, the EVSE is designed to be interoperable with any charging 
network. This allows EVSE owners to operate EVSE purchased from different manufacturers and switch from one network to another without replacing or upgrading the EVSE. This helps to prevent stranded EVSE assets by allowing any network the ability to operate the equipment in the event that a site host decides to switch charging networks, or the existing provider no longer offers charging. (AFDC 2018)

\section{Open Charge Point Interface}

A network communications standard that forms bilateral data sharing agreements between two or more charging networks to facilitate network "roaming" for drivers. The Open Charge Point Interface also standardizes terminology and the types of data attributes collected and reported to other networks and data aggregators.

(MJB\&A 2019)

\section{Open InterCharge Protocol}

A network communications standard that forms a central hub-based data sharing agreement among multiple charging networks to facilitate network roaming for drivers.

\section{$\underline{\text { International Organization for Standardization } 15118}$}

An open payment and communication standard that allows for secure and automatic payment from a driver's account once a driver plugs the EVSE into the EV. This standard is common in Europe.

EVSE technical standards and communications protocols are a fundamental pillar of EV market development that ensure the interoperability between EVs and EVSE and establish safe and reliable operating environments for users. Proper review, adoption, and enforcement will safeguard consumers and EVSE investments from becoming technologically obsolete leading to successful EVSE deployment and increased EV adoption.

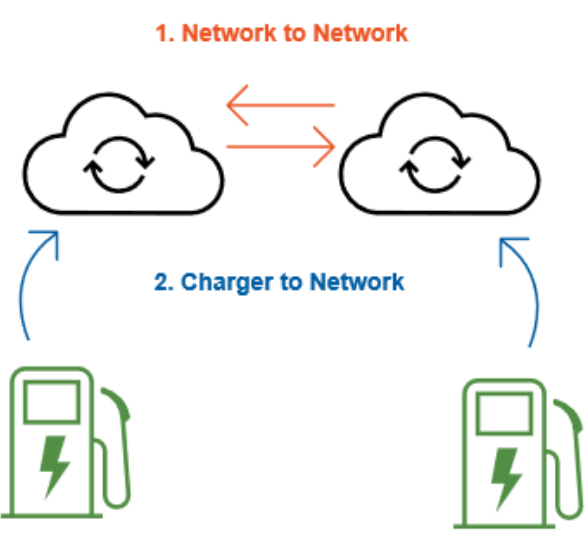

Figure 14. Interoperability protocols Illustration by Kaylyn Bopp. Adapted from (MJB\&A 2019). 


\section{Grid Planning and Management}

\section{New EV loads on the electric grid present both challenges and opportunities.}

EVs represent a large potential source of load growth for electric utilities, as the energy needed for transportation shifts from petroleum to electricity. At the same time, these new EV loads may create challenges to ensuring that the grid can reliably support every customer. Utilities are responsible for maintaining the grid, and so may need to implement new planning practices and dedicated EV programs to successfully meet the demands of increased EV deployment. The most relevant potential challenges, considerations, and opportunities within grid planning and management are described in this building block.

\section{Long-term preparation and planning by utilities can ensure timely and cost-effective deployment of EVSE networks.}

Widespread adoption of EVs will require a proportional buildout of EVSE to allow for convenient and accessible refueling options for EV owners. Depending on the type and volume of EV and EVSE deployed, investment in grid infrastructure may be required to accommodate the additional charging load. Distribution system upgrades are the most common requirement, but transmission systems are sometimes impacted as well. These grid upgrades can take months or years to complete, depending on the scale of improvement. Therefore, a key pathway for utilities to support EV deployment is through dedicated planning for EVSE projects. Furthermore, as an emerging technology, EVs will be mostly adopted by first-time users. This lack of familiarity with EVs introduces significant uncertainties into EV and EVSE deployment processes, with the potential for expensive consequences if such capital-intensive projects are mismanaged or designed with faulty information. Customer support will therefore be crucial to the success of utility EV programs.

Effective customer support for EVSE deployment can take multiple forms (Wilson 2019). Utility staff positions dedicated to EVs are often needed to help forecast EV demand, design specialized EV tariffs, and incorporate EVrelated investments into utility resource planning. For customers pursuing large projects, such as an original equipment manufacturer supporting EVSE deployment or a fleet of vehicles requiring major EVSE-related upgrades, technical support staff may be the optimal choice to streamline the permitting and procurement processes. For small installations or residential customers, simply having access to a brochure or online process guide can allow EVSE projects to proceed smoothly. For all customers, it is important for the utility to be transparent about the time required for grid upgrades.

The location, design, and power level of expected EVSE projects should also be considered by the utility and leaders of EVSE projects. Tracking and documenting projects is important for maintaining grid stability as EV deployment increases. For example, a neighborhood with a high concentration of Level 1 charging stations may strain the local distribution infrastructure in ways that each individual L1 installation plan does not consider. These tracking and documentation efforts are important for both utilities and private EVSE companies. Utilities have a responsibility to maintain grid stability, while private EVSE companies may suffer revenue losses and reputational damage if their installations cannot provide charging services due to grid outages.

Meanwhile, because high-power charging units often require much more intensive grid upgrades, communication with EVSE developers is crucial for utilities to avoid outsized expenditures. Adding electrical infrastructure that is sufficient for high-power DCFC systems may be a costly overbuild if it only ends up servicing Level 2 EVSE, for example. However, installing the capacity to handle expected load growth and future EV technologies may ultimately save money. New build infrastructure is far less expensive than retrofitting, so understanding the future charging needs of an EVSE installation is crucial for long-term project economics.

\section{Utilities should engage with EVSE projects of all types and ownership models.}

Broadly considered, there are two types of EVSE deployment: utility-led charging infrastructure programs and third-party charging infrastructure interconnection. In places where the utility has limited resources, a higher percentage of EVSE projects will be led by third parties, especially the private sector. In each case, the utility has a role in guiding projects to both enable EV deployment and minimize grid upgrade costs.

If the utility itself decides to fully support EVSE, it can significantly reduce common barriers to third-party EVSE deployment, such as uncertainty surrounding utility processes, access to financing, cost barriers, and interconnection timelines. Complete utility ownership, including funding, construction, and maintenance can thus 
streamline EVSE deployment, but there are often barriers. Utilities do not always own the land upon which they would like to build EVSE, nor are all utilities interested in providing the service and maintenance of charging stations. Furthermore, utilities will need to effectively justify the investment to their regulators, which may be difficult to do with the same level of certainty as traditional network investments.

In cases where third parties lead infrastructure programs, utilities still have an interest in assisting the process, as poor execution of an EVSE installation could lead to misallocated utility resources. Utilities have multiple options in this role (Bolduc 2020). If the utility prefers to support EVSE without assuming the burden of ownership, it can offer rebates to customers for all or part of the necessary equipment and construction. The utility also can design and install "make-ready" infrastructure, which includes all required components for EVSE except the charger, which can be added by the customer later. The revenues from these types of mixed-ownership EVSE can be difficult to negotiate, which is another reason for utilities to proactively create forecasts, processes, and standards for EVSE deployment in their territories.

\section{Altering the timing and power level of charging can reduce system costs and improve grid stability.}

\section{Potential Benefits of Managed Charging}

As described above, EVs comprise a load that can sometimes create technical challenges for utilities if unmanaged. At the same time, charging load is potentially flexible in ways that can aid grid management and increase utilization of existing assets to reduce system costs. Completely unmanaged EV refueling results in more extreme charging patterns and loads. Sometimes this demand can helpfully match with periods of excess generation, but it also may necessitate large and widespread upgrades to grid infrastructure. By spreading the EV charging over time, so that localized and systemwide demand peaks are avoided and the timing of EV charging coincides with times of abundant and low-cost electricity generation, utilities can reduce the need for generation, transmission, and especially distribution grid upgrades.

Figure 15 shows the potential difference in grid upgrade costs on a per-EV basis depending on whether charging load is unaltered ("nonoptimized") or optimized to match grid capabilities (Sahoo, Mistry, and Baker 2019). This type of optimization is a central goal of managed charging, which seeks to capture these savings while also ensuring that EV refueling occurs in a manner that is satisfactory to the customer. However, the benefits of managed charging are only proportional to the utility's EV load-without a sufficient level of EV deployment, the costs of managed charging may outweigh the benefits.

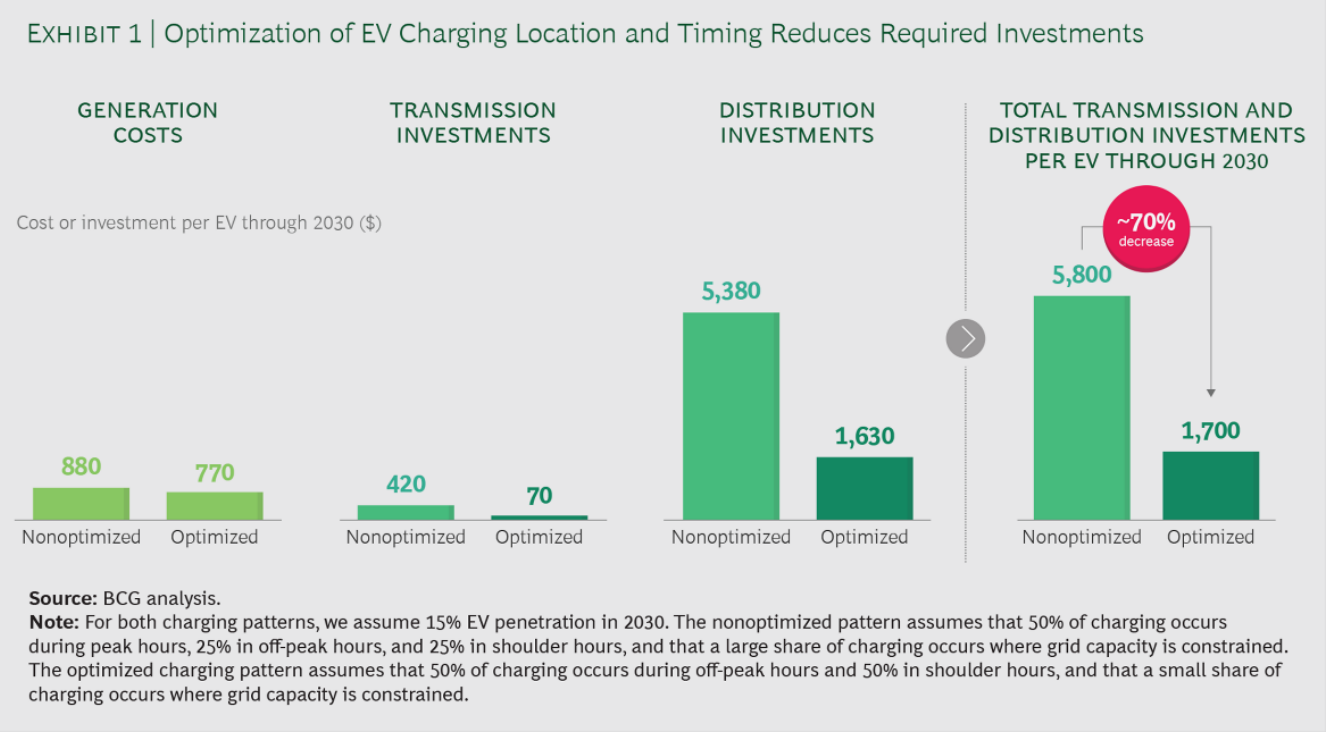

Figure 15. Potential cost savings of grid investments due to optimized EV charge timing

Source: (Sahoo, Mistry, and Baker 2019) 


\section{State of the Technology}

There are two broad categories of managed charging: passive and active. Passive managed charging provides incentives for time-shifted charging, but ultimately leaves decisions to customers. These incentives could involve the cost of electricity (e.g., time-of-use [TOU] rates), outreach to customers that requests specific charging behavior, or other incentives that influence customers without providing a mandate (See Tariff Design) (Electric Nation 2019). Active managed charging involves the physical control of electron flow, whether at the EV itself, the charging device (EVSE), or by controlling the circuits that connect to the EVSE. Passive strategies cannot provide precise demand response in the same way that active methods can, but active methods will require additional technological upgrades and more frequent monitoring by the utility.

When evaluating the potential for effective managed charging, it is also important to consider the owners of EVs and EVSE and if their interests are aligned. For example, it will be easier to coordinate managed charging priorities for vehicle fleets that are driven and refueled by the same entity. Situations where one party controls the EVSE and another controls the EV, such as workplace or public charging, may require extra effort in order to provide effective incentives to both parties for managed charging.

\section{Communications Protocols}

All active, and some passive, methods of managed charging have a common need for consistent communication standards and practices. Many different technologies and owners are involved in this chain of communication between EV, EVSE, and utilities, as a comprehensive managed charging system must function with devices for residential EVs, fleets, public charging, workplace charging, and charge aggregators. This complexity requires support for multiple types of signal, including Wi-Fi, cellular signals, ethernet connections, radio frequencies, and more. Multiple standards exist to govern reliable and effective communication protocols for managed charging, but industry has not yet united behind a single approach to standardize the entire complex network of managed charging communication (SEPA 2019). Utilities that embrace a managed charging strategy can monitor communication standards closely to ensure interoperability with as many EVs and EV customers as possible. See EVSE Communications and Interoperability Protocols for more information.

\section{Vehicle-to-Grid (V2G)}

Managed charging is a set of strategies to modulate the one-directional flow of electricity to EVs. V2G is a concept of complete vehicle-grid integration that additionally includes the flow of energy from plugged-in EVs back to the grid to provide a range of services. In this balancing act, fully charged EVs could help meet the demands of other EVs that need refueling. Major obstacles to V2G include expenses for current inversion and control, additional engineering requirements for interconnection, and, most importantly, battery warranties. V2G will inevitably result in additional charge/discharge cycles for vehicle batteries, leading to issues for vehicle manufacturers in terms of warranty adjustment and issues surrounding fair compensation for the EV's contributions to the grid.

The challenges associated with full, widespread V2G raise the question of the additional benefits provided by its bidirectional energy flows. In terms of demand response and grid balancing, experts estimate that managed charging alone (vehicle-grid integration) can provide substantial benefits with currently available technology (Coignard et al. 2018; Szinai et al. 2020). However, V2G also offers less-explored value streams such as the potential for resilience from EVs enabling home microgrids in the case of power outage. Before committing to full V2G, policymakers and grid operators should ensure that V2G's additional benefits can be captured and that the fundamental questions of implementation-both technical and regulatory-are answered.

\section{Equipment upgrade costs can be minimized through a variety of utility strategies.}

Vehicles are highly power-intensive assets that, when brought into the electricity sector, are both a promising source of revenue and potentially costly to accommodate and service. However, the magnitude of the expense can be drastically lowered through preparation. Hiring a dedicated EV team, supporting managed charging programs, creating customer-friendly products and services to ensure right-sized EVSE is installed successfully in desired locations, and matching utility resource plans to EV deployment projections are all practices that lead to lower grid upgrade costs for utilities. The opposite approach - handling EVSE projects and meeting EV loads on an individual basis, without strategic planning — can easily result in dissatisfied customers and expensive grid management costs. 


\section{Tariff Design}

\section{Electricity tariffs specify how electricity consumers are charged for electricity.}

Electricity tariffs constitute a variety of utility charges that are designed to collect revenue from customers to ensure cost recovery for the utility, fairly apportion the cost of service to different customers, and encourage energy conservation and other "grid-friendly" behavior (Figure 16). In principle, tariffs should be simple, understandable, stable, feasible to implement, and publicly acceptable.

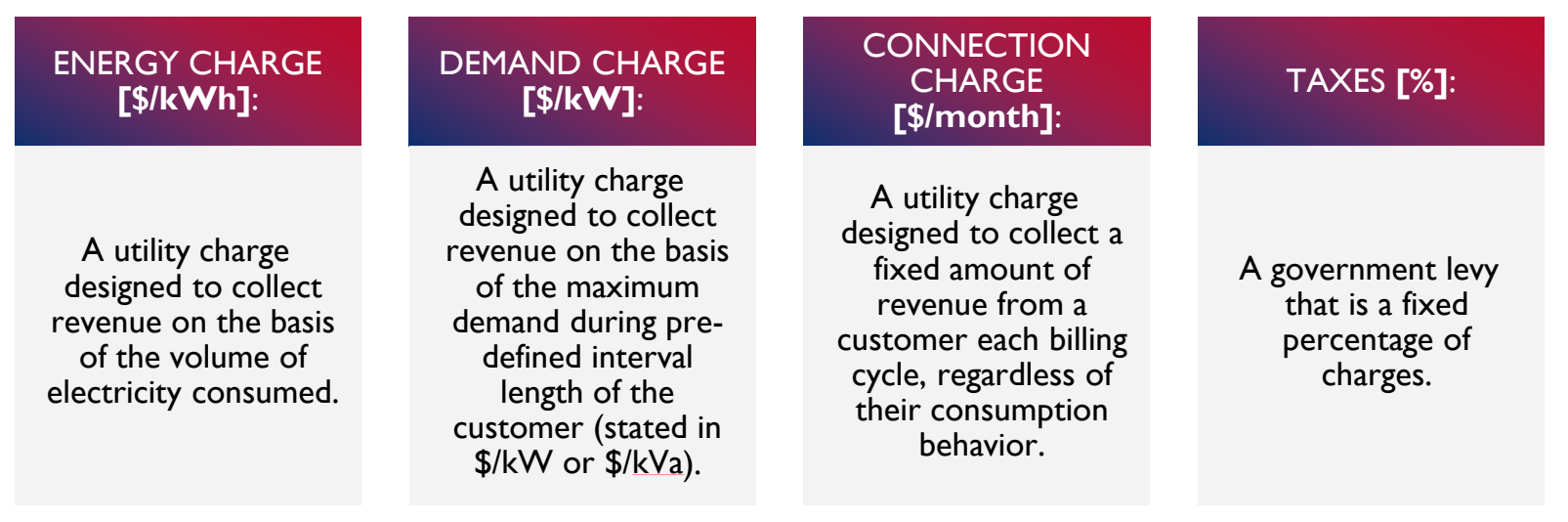

Figure 16. Typical tariff design components

Source: (Zinaman et al. 2020)

\section{Governments commonly intervene to set tariffs between electric utilities and EVSE owners.}

In the context of EVs and EVSE, tariffs are typically designed between an electric utility, which sells retail electricity, and owners of EVSE, ${ }^{25}$ including (but not limited to):

1. Residential Customers: Private EV owners who charge their EV at home using their own EVSE.

2. Fleets Owners: Private- or government-owned EV fleet customers who may own/operate their own EVSE, such as a taxi or bus fleet.

3. Private Charging Service Companies: For-profit commercial enterprises that offer charging services to customers in public spaces.

While certainly possible, it is less common for governments to set customer-facing charges for private charging service companies. Thus, this building block focuses on the design of utility tariffs for EVSE owners.

\footnotetext{
${ }^{25}$ It is also possible for utilities to be the owner of EVSE themselves. In this case, utilities (with government oversight) would directly set tariffs for EV owners charging in public at utility-owned EVSE.
} 


\section{Box 7. EVSE Tariff Design in Southeast Asia}

Policymakers around the world are grappling with how to appropriately design electricity tariffs for EVSE. In Southeast Asia, USAID and NREL are supporting regulators in Lao PDR and Thailand to build an understanding of EVSE tariff design best practices and locally appropriate electricity pricing approaches for both commercial EVSE developers and EV customers using grid electricity. Key factors to consider when designing effective EVSE tariffs include, among others: (1) the differentiated objectives of a new EVSE tariff structure for home versus public charging, (2) if and how EVSE tariffs should differ from other electricity tariffs, (3) the timing for and appropriate use of demand charges versus energy charges, (4) the pros and cons of introducing more system-friendly timevariant tariffs, and (5) what the role of the government should be in setting customer-facing tariffs for charging services for public EVSE.

For example, Thailand's Ministry of Energy aims to have 1.2 million EVs on the road by 2036. Additionally, in 2021 Thailand released a new energy sector master plan, which will prompt a new tariff design process led by Office of the Energy Regulatory Commission, with results due in the end of 2021 that will determine public EV charging tariffs. Under this new policy and resulting tariff design process, a new EV tariff structure for privatelyowned public charging stations will be designed and implemented. The Office of the Energy Regulatory Commission met with NREL staff to learn about the fundamentals of public EVSE tariffs, build an understanding of expected charging patterns for public EVSE at different locations and levels of market development, and design a new schedule of public EVSE tariffs for Thailand.

In Lao PDR, a multi-ministry Electric Vehicle Working Group is exploring locally appropriate EVSE tariff design as part of their recently passed "Strategy on Clean Energy Use and Promotion in the Transportation Sector, Development Plan 2025, Strategy 2030, and Vision 2050." The Working Group met with NREL staff for a series capacity-building workshops which aimed to provide foundational policy design information while also generating locally appropriate EVSE tariff design concepts. The Lao PDR government aims to promulgate a formal ministerial decree defining EVSE business models and specifying a series of EVSE tariffs by April 2021.

\section{Box 8. How Do Commercial EVSE Businesses Typically Charge Customers for Use?}

How private EVSE companies charge customers for services varies greatly. For example, in the United States, there are different private sector-owned and -managed EVSE networks (e.g., Blink, Tesla, EVgo, ChargePoint) that charge drivers/customers differently based on different pricing structures and payment models.

With respect to pricing structure, options include charging customers: a flat fee per session; for each kWh used; for each minute or hour of charging time; or combinations of time and kWh used. In many cases, charging services are actually made available for free (with some limitations) to EV owners, and EVSE companies instead collect costs from the hosting site (e.g., a large store or mall which wants to offer free charging as an incentive for customers to shop at their business). With respect to payment models, some private EVSE companies ask for payments to be made for each session, whereas others use a monthly subscription payment, or a combination or the two.

Source: (Zinaman et al. 2020)

\section{Tariff design for EV charging can support utility cost recovery associated with hosting EVSE.}

EVSE are typically larger sources of both peak power consumption and energy use in the power system. Thus, depending on the hosting capacity of the power system, and the exact utilization patterns of the EVSE, it is possible (though not inevitable) that EVSE will be a driver of new utility costs. Tariff design is a critically important tool for ensuring that any new utility infrastructure costs associated with hosting EVSE are fairly recovered. 


\section{Tariff subsidies for commercial EVSE developers may be appropriate in early-stage markets.}

In newer EV markets aiming to introduce public networks of commercial EVSE, decision-makers can consider using tariff subsidies as a tool to incentivize deployment. In general, tariff subsidies reduce the rates charged to customers for energy consumption in order to accomplish various social policy objectives. Subsidies are financed either by tariff increases on customer classes (this is referred to as a "cross-subsidy") or directly by a government. Tariff subsidies for EVSE (along with direct financial incentives - see Targets and Incentives for EV and EVSE Deployment) improve EVSE project economics and increase the likelihood of EVSE deployment. Especially in markets with little to no private EVSE deployment, tariff subsidies could be considered. However, subsidies of any kind should be approached with caution as they can be a strain on budgets and can create (or further exacerbate) social inequities. ${ }^{26}$ As well, tariff subsidies should be considered in light of other financial incentives that are made available to commercial EVSE developers in order to avoid inefficient use of government or ratepayer funds.

\section{Specialized EV tariffs can influence customer charging behavior and present significant opportunities to ensure "grid-friendly" charging patterns by EV owners.}

Why should decision-makers create specialized EV tariffs that differ from ordinary retail electricity tariffs? While in some cases it may be appropriate to use established retail tariffs to charge EV/EVSE owners, ${ }^{27}$ specialized EV electricity tariffs can be used to influence EV customer charging behavior to the benefit of the electricity system by:

1. Discouraging EV charging during critical peak times that stress grid infrastructure

2. Encouraging EV charging when electricity is less expensive to produce/procure and existing network infrastructure is not fully utilized, and/or when renewable energy resources are available.

With appropriate tariffs, utilities can better manage the new source of demand that originate from EV charging and avoid costly upgrades in network infrastructure associated with unmanaged growth in peak demand (Figure 17). For example, Figure 17 offers an example in which incremental peak electricity demand growth due to EV charging was significantly reduced due to the use of a TOU energy charge, in which electricity purchases become more expensive during "peak" hours and less expensive during "off-peak" hours. Notably, in this example, it is demonstrated that charging activities were also shifted to less expensive off-peak hours (i.e., midnight).

\footnotetext{
${ }^{26}$ Tariffs subsidies for public EVSE will inevitably benefit those who adopt EVs first, which is typically a wealthier segment of the general population.

${ }^{27}$ In some circumstances, existing tariffs may be sufficient for incentivizing desired EV charging behavior, ensuring utility network cost recovery, or promoting commercial EVSE profitability. This is largely dependent on the state of tariff design in each market and the availability of metering infrastructure to enable tariffs.
} 


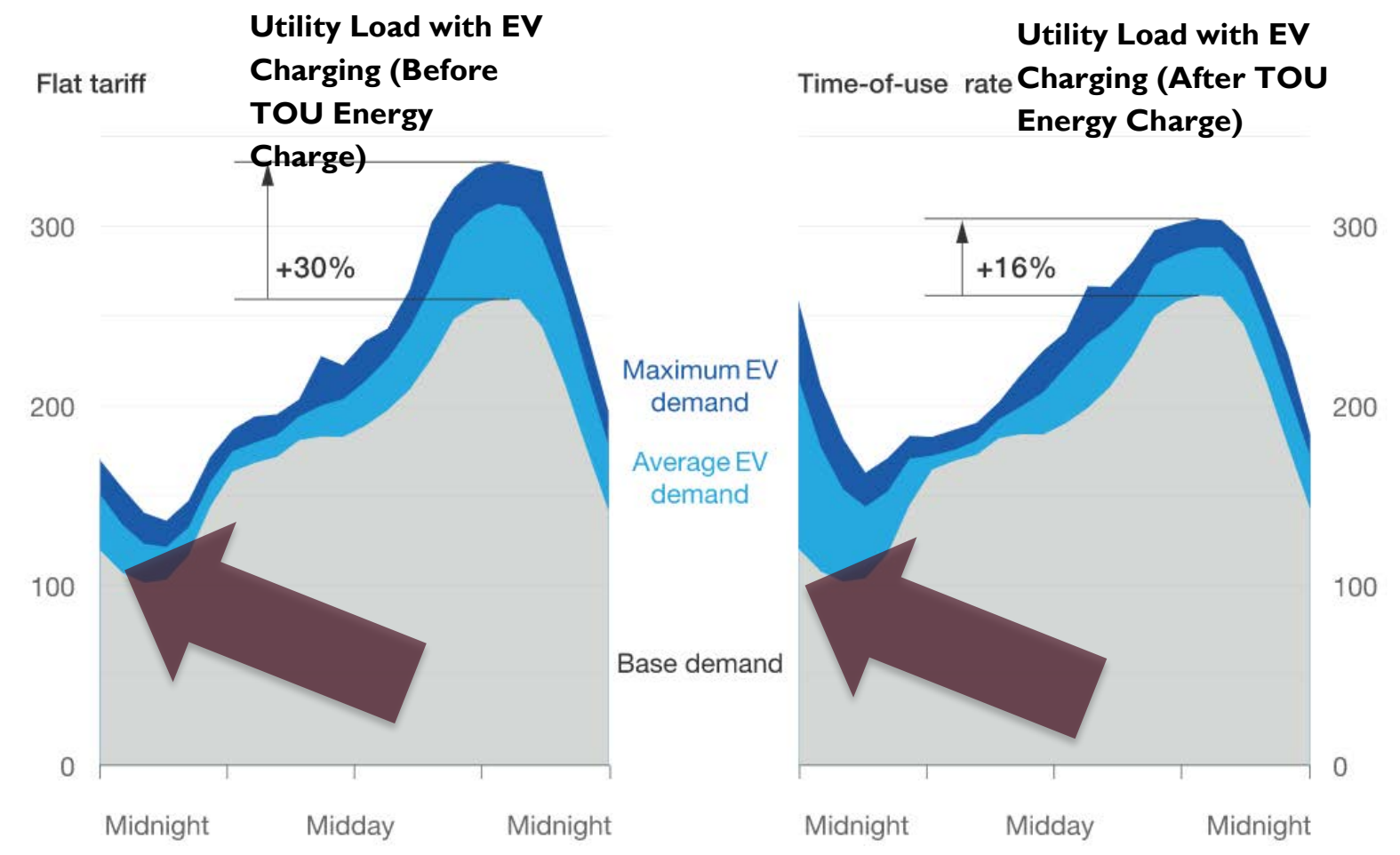

Figure 17. Utility load with EV charging before and after implementation of TOU energy charges

Source: (Open EI); (Engel et al. 2018)

\section{Design of TOU energy charges for EV charging can take into account a variety of factors.}

Utilities around the world are implementing TOU energy charges for EVs whereby the price of electricity differs throughout the day to incentivize the timing of EV charging. However, what factors can decision-makers account for when designing TOU energy charges for EVs? The following factors can be considered:

- System Electricity Demand Pattern: By understanding how electricity demand changes (e.g., on an hourly basis) for the bulk power system over time, decision-makers can identify expected periods of peak system demand (e.g., when network and/or generation infrastructure may be stressed) and discourage EV charging during these times. Instead, decision-makers can design tariffs to encourage charging during off-peak hours to help defer or avoid expensive peak-driven investments in network or generation infrastructure.

- Localized Electricity Demand Patterns: Related to system electricity demand shape, decision-makers can also consider how individual areas within areas of the distribution network are being utilized. If possible, tariffs can be designed to influence charging behavior such that existing distribution network infrastructure can be more fully utilized, and the extent to which new investments in local distribution networks must be made is reduced.

- Resource Availability and Energy Prices: By understanding how the electricity supply mix changes over time (e.g., on an hourly basis), decision-makers can identify when lower-cost resources (e.g., solar) are available and design tariffs that encourage charging during those times. Tariffs could also feasibly account for seasonal resource availability, so it is important to understand when abundant, low-cost seasonal resources (e.g., hydropower) are available as well.

While the design of TOU energy charges can in principle consider these aspects, in practice each utility system has unique conditions that warrant different TOU tariff structures to best-manage demand. Figure 18 illustrates this by depicting a range of potential TOU periods and tariff magnitudes for nine U.S. utilities offering TOU tariffs for EVs. 


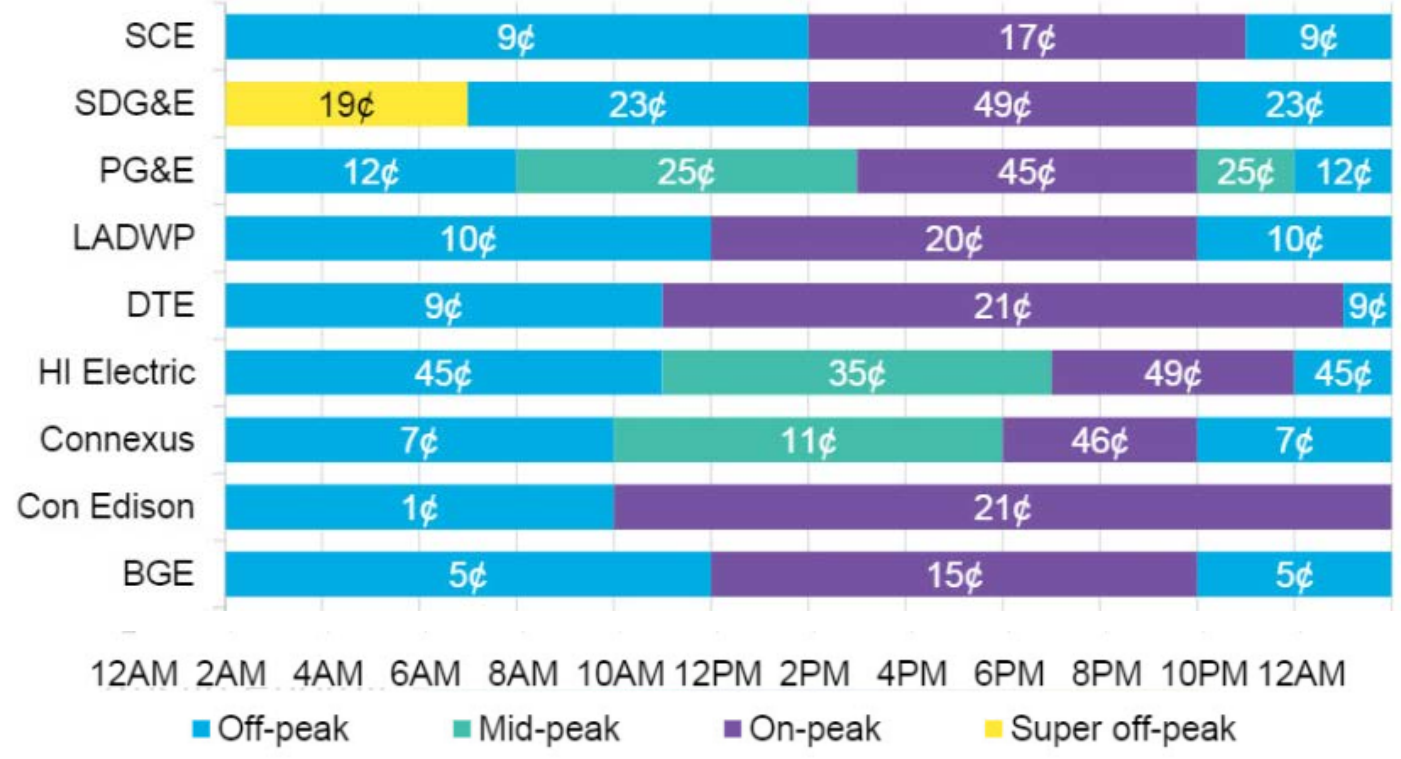

Figure 18. Examples of TOU EV energy charge at select U.S. utilities

Source: (Bloomberg New Energy Finance 2017)

Based on their own conditions surrounding energy availability, expected network utilization levels, and the structure of electricity demand, decision-makers can consider the following design-related questions as they explore specialized EV TOU energy charges for their unique contexts:

- How many TOU periods should be offered?

- What is the timing of each TOU period, and how does this map to both local power system conditions (e.g., expected local network utilization levels) and broader power system conditions (e.g., expected timing of system peak demand, expected diurnal changes in electricity availability)?

- What will the price level for each TOU period be? Will the relative difference between each TOU period be sufficient to influence changes in charging behavior?

- How will customers be notified and educated with respect to changing tariffs? Will customers be able to understand and effectively respond to proposed TOU energy charges?

- Will these rates be blended with inclining block energy charges that increase with the volume of energy used?

Demand charges can help recover fixed network costs associated with hosting an EVSE, but may not be appropriate in all circumstances, especially in early-stage markets and for residential customers.

Demand charges - a \$ per kW charge for a customer's peak demand during a billing cycle — can also be considered by decision-makers seeking to ensure that their utility is able to recover local network costs associated with hosting an EVSE. Demand charges are typically paid by commercial and industrial customers based on their highest power consumption in a given time interval (e.g., 15 minutes or 1 hour) during the billing period. They are not typically implemented for residential customers, as these customers do not tend to have the same level of understanding, visibility, or control over their electricity consumption patterns as commercial and industrial customers; without the ability to understand or respond to price signals offered by demand charges, there is a higher potential for undue cost burdens.

For private EVSE developers, demand charges may be useful to support utility network cost recovery associated with the high instantaneous consumption levels of EVSE. However, especially in earlier stage markets where EVSE utilization levels for EVSE are low, this may be an overly burdensome approach that could hamper EVSE development. In practice, infrequently used EVSE that incur demand charges can lead to significantly higher 
levelized charging costs than frequently used EVSE that face the same demand charge. Table 7 offers a highly simplified example of effective charging costs (to the EVSE developer) with a low-utilization and high-utilization DC fast charger subject to a demand charge. ${ }^{28}$

Table 7. Comparison of Cost Implications for Low and High Utilization Rate 50-kW DCFC Subject to Demand Charge in a Billing Cycle

\begin{tabular}{|l|l|l|}
\hline & Low-Utilization DCFC & High-Utilization DCFC \\
\hline \# of 30-minute charges per month & 2 & 200 \\
\hline Total charging time [minutes] & 60 & 6,000 \\
\hline Peak 15-minute average demand [kW] & 50 & 50 \\
\hline Total energy use [kWh] & 50 & 5,000 \\
\hline Energy rate & $\$ 0.10 / \mathrm{kWh}(\$ 10)$ & $\$ 0.10 / \mathrm{kWh}(\$ 500)$ \\
\hline Demand charge & $\$ 4$ per $\mathrm{kW}(\$ 200)$ & $\$ 4$ per $\mathrm{kW}(\$ 200)$ \\
\hline Total monthly bill & $\$ 210$ & $\$ 700$ \\
\hline Equivalent price per $\mathbf{k W h}$ & $\$ 4.20$ & $\$ \mathbf{0 . 1 2}$ \\
\hline
\end{tabular}

Thus, the implementation of demand charges may create nontrivial cost burdens for EVSE owners in earlier-stage EV markets when EVSE are not being significantly utilized. In these cases, energy charges and fixed charges may be a more appropriate tool to recover utility costs. However, as EV markets mature, phasing demand charges in while reducing energy charges may be a more financially sustainable means of ensuring utility cost recovery from commercial EVSE owners in the long term.

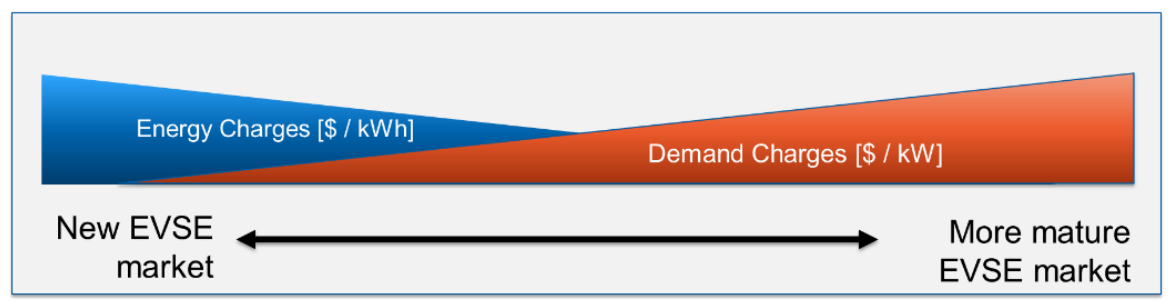

Figure 19. Maturity of EVSE market and use of energy vs. demand charges

Source: (Nelder 2018)

\section{EV tariffs often require new meters to implement.}

Depending on the metering infrastructure that is already in place, as well as the type of EV tariff being considered, an upgrade to metering infrastructure may be required if a specialized EV charging tariff is to be implemented. In general, upgrades to metering infrastructure may be required in three non-mutually exclusive circumstances:

1. If existing meters for a particular customer $\operatorname{class}^{29}$ do not have the required technical functionalities to implement a desired EV tariff (e.g., if a meter does not have time stamping and/or the ability to measure peak power consumption), then a new meter might be required.

2. If utilities wish to ensure that only customer electricity consumption associated with EV charging activities is subject to the new EV tariff, then an additional meter may be required to exclusively measure EV-related consumption.

\footnotetext{
${ }^{28}$ For a significantly more analytically detailed comparative exercise, see EVgo Fleet and Tariff Analysis - Phase 1: California, available at: https://rmi.org/wp-content/uploads/2017/04/eLab EVgo Fleet and Tariff Analysis 2017.pdf

${ }^{29}$ Notably, different customer types (e.g., residential, commercial, industrial) typically use different types of meters, which reflect their distinct tariffs. For instance, a large industrial customer may be subject to a demand charge and require a meter that can measure peak 15-minute demand, whereas a residential customer may be subject to a flat, time-invariant energy charge that requires only a simple meter that measures and reports total energy consumption.
} 
3. If utilities wish to have increased visibility into charging behavior through separate metering of non-EV and EV loads, then an additional would be required to achieve that.

A rollout of new metering infrastructure can come with an additional cost burden to install the meter (which may be borne by either the EVSE owner or the utility), as well as an administrative burden to coordinate installation and ensure that utility billing systems are updated to receive and process oftentimes more complex metering data. In general, decision-makers can weigh these burdens against the potential utility and system benefits and can customize their approach to both EV tariff design and EVSE metering requirements by customer class. For instance, requiring new metering infrastructure may be overly burdensome for residential customers with a single $\mathrm{EV}$, but might make up a significantly smaller and more reasonable portion of EVSE installation costs for a commercial EVSE business or EV fleet owner.

\section{Tariff design approaches for home charging and public may have different objectives and considerations.}

Considerations surrounding desired customer charging behavior, metering infrastructure requirements and costs, utility cost recovery, customer price sensitivity, and expected EVSE utilization levels may drive distinct outcomes for the design of home charging versus public charging tariffs.

Home charging tariff design primarily aims to influence customer charging behavior, steering customers through TOU price signals to charge at more/less desired times to reduce power system operational costs and investment requirements. Charging demand in home environments is more flexible with respect to timing, as drivers may park overnight or for significant periods of time. These longer "dwell times" suggest that residential customers may be more responsive to TOU EV energy charges. However, an upgrade of metering infrastructure for residential customers, either because the existing customer meter cannot collect data on the timing of energy consumption, or because the utility wants to separately meter and track EV charging activities, or both. Additional metering can be costly as a proportion of total EVSE installation/operation costs for smaller-scale applications like home charging, so it is important for decision-makers to weigh these costs relative to the benefit they provide to customers, utilities and the power system. It is also important to consider whether residential customers can be reasonably expected to voluntarily register for an EV tariff, or if incentives for registration are needed.

Tariff design for public charging (e.g., for commercial EVSE owners offering charging services to the public) is typically attempting to balance:

1. Utility cost recovery for hosting the EVSE: tariffs must be sufficient to ensure energy and network costs associated with the presence of EVSE are recovered by the utility.

2. Equity concerns for nonparticipating owners: tariffs should ideally not result in an undue cost-shift to ratepayers who do not use or own EVSE.

3. Profitability of the commercial EVSE sector ${ }^{30}$ : tariffs should ideally not serve as a barrier to commercial EVSE deployment and should enable commercial EVSE to charge reasonable rates to customers. $^{31}$

Charging demand in public applications tends to be less flexible and responsive to time-variant tariffs, as EV drivers typically want to charge immediately, have shorter dwell times, and are not responsible for paying utility tariffs directly if the EVSE is owned by a commercial enterprise. Shorter dwell times and a relative inelasticity of customers to time-variant tariffs suggests that, in the long run, demand charges may be a more effective way to support utility cost recovery. However, as discussed earlier, demand charges may not always be appropriate for

\footnotetext{
${ }^{30}$ When utilities directly own/operate public EVSE as a commercial enterprise, ratepayers are typically absorbing the infrastructure costs associated with building, operating, and hosting EVSE on the grid. Thus, profitability of individual public EVSE may be less of a concern, and tariff design is more focused on customer-facing tariffs for charging services rather than for the EVSE (see Box 9).

${ }^{31}$ Of particular note during tariff design processes for public EVSE is the issue of the profitability of EVSE expected to have a low utilization. Some low utilization EVSE, such as an EVSE fleet on a national highway corridor, may be necessary for the public good and for EV market development, but may not be profitable on their own. In these applications, it is common for decision-makers in early-stage EV markets to consider direct subsidies, "make-ready" investments, and more generous tariff offerings, among other financial incentives.
} 
early-stage markets, and a combination of energy charges and fixed charges may be suitable until the EVSE market matures, with demand charges phasing in over time. With respect to metering, public EVSE can either be installed in "greenfield" applications where no metering is in place, or at an existing site where a meter already exists. For greenfield applications, commercial customers such as EVSE developers may already be subject to time-variant or demand-based tariffs and thus current metering requirements may already be sufficient. Otherwise, the incremental cost of installing a smart meter that enables more advanced tariffs is likely to be minimal in a greenfield application. If the EVSE is being installed on a site with an existing meter that does not have the required capabilities to implement more advanced tariffs, then decision-makers must weigh the incremental cost of a meter upgrade relative to the overall expected EVSE project costs and the expected system and utility benefit of using a more complex tariff.

\section{Box 9. Can Governments Set Customer-Facing Prices for Private EVSE Businesses?}

In theory, governments can play a role in setting private EVSE retail customer charges in one of three ways:

- Allow private sector to set customer charges. Private sector competition may reduce costs.

- Set maximum customer charges. Private sector can compete to reduce charges below the maximum.

- Set customer charges so that all private EVSE charges the same price.

If pursuing options 2 or 3 (above), a government may consider socially acceptable charge levels for a jurisdiction, the extent to which private EVSE owners need to recover costs, how much the private EVSE owners should be allowed to profit from reselling electricity, and if different EVSE types and locations with different expected utilization levels have different cost structures. 


\section{Workforce Development}

Holistic workforce development strategies lay the groundwork for thriving EV markets.

New technologies such as EVs struggle to become mainstream without a larger ecosystem of trained, skilled professionals who provide services that keep EVs operational and safe (Table 8). Workforce development, therefore, is a critical but often overlooked building block of EV market development.

Workforce development aims to ensure that a workforce has the skills, training, and experience needed to support EV deployment and fully take advantage of its economic benefits. It encompasses myriad strategies, common across other relatively new renewable energy industries (e.g., solar, wind), including (Baring-Gould 2011; Friedman, Jordan, and Carrese 2011; NREL n.d.):

1. Standardized education and training at all levels of education (e.g., primary school through higher education)

2. Industry-based training, certification, and apprenticeships that build professional capacity on an ongoing basis

3. Understanding labor market dynamics over time to ensure programs and policies match labor supply with job demand. 
Table 8. EV and EVSE Workforce Needs and Considerations

\begin{tabular}{|c|c|c|}
\hline Category & Requirements & Key Actions and Considerations \\
\hline $\begin{array}{l}\text { Vehicle service } \\
\text { and repair }\end{array}$ & $\begin{array}{l}\text { Mechanics, } \\
\text { technicians }\end{array}$ & $\begin{array}{l}\text { Jurisdictions that deploy battery electric buses can leverage } \\
\text { technician assistance provided by fleet vehicle manufacturers who } \\
\text { typically include training hours in the purchasing contract. Transit } \\
\text { agency staff, local repair shop staff, and even technicians in training } \\
\text { from local schools could participate in these trainings. For passenger } \\
\text { vehicles, vehicle dealership could request technician training from } \\
\text { their manufacturers, if available. Jurisdictions can also sponsor } \\
\text { technicians to attend certification programs. Technicians will need to } \\
\text { be trained to certify EVs for secondary used EV markets and other } \\
\text { second-life markets for batteries. }\end{array}$ \\
\hline $\begin{array}{l}\text { EVSE } \\
\text { installation and } \\
\text { repair }\end{array}$ & $\begin{array}{l}\text { EVSE installers } \\
\text { (i.e., certified } \\
\text { electrician), } \\
\text { technicians }\end{array}$ & $\begin{array}{l}\text { In the United States, some EVSE networks offer installer certification } \\
\text { programs, while equipment manufacturers are often responsible for } \\
\text { installing and maintaining DCFC per the purchase contract. All EVSE } \\
\text { should be installed by certified electricians if possible. }\end{array}$ \\
\hline $\begin{array}{l}\text { Marketing and } \\
\text { sales }\end{array}$ & Salespeople & $\begin{array}{l}\text { Sales and marketing industries play an influential role in consumer } \\
\text { decision-making. Their unfamiliarity (or even bias against) with EVs } \\
\text { may discourage sales staff from promoting EVs accurately and } \\
\text { convincingly to consumers. Proper sales training from manufacturers, } \\
\text { therefore, is essential. }\end{array}$ \\
\hline $\begin{array}{l}\text { First response } \\
\text { and } \\
\text { emergencies }\end{array}$ & First responders & $\begin{array}{l}\text { First responders should be trained to safely manage the unique } \\
\text { dimensions and risks of EV accidents and emergencies because EVs } \\
\text { have high internal voltages and electrochemical batteries than can } \\
\text { pose unique safety risks. In the United States, the National Fire } \\
\text { Protection Association offers training and resources on this topic } \\
\text { (National Fire Protection Association n.d.). }\end{array}$ \\
\hline Education & Educators & $\begin{array}{l}\text { Educators of all levels of education (e.g., primary, secondary, } \\
\text { university) are needed to educate, train, and prepare an EV } \\
\text { workforce. Dedicated funding to train teachers on EV technology that } \\
\text { is changing at rapid pace is needed to sustain EV deployment. } \\
\text { Partnerships between educational institutions and industry may also } \\
\text { benefit teachers, students, and the EV industry overall. For example, } \\
\text { the Michigan Alliance for Greater Mobility Advancement is a } \\
\text { consortium made of equipment manufacturers, suppliers, educational } \\
\text { institutions, workforce development organizations, and government } \\
\text { that addresses the automotive industry's evolving workforce needs } \\
\text { with the emergence of connected, automated, and electrified mobility. } \\
\text { Consortium partners work together to assess skills and training gaps } \\
\text { and develop education and training programs to fill those needs } \\
\text { (Michigan Alliance for Greater Mobility Advancement 2020). }\end{array}$ \\
\hline
\end{tabular}

Source: (Johnson et al. 2020; Rojko and Španer 2013; Yeh, Liao, and Petrosky 2013)

\section{Tracking the EV labor market as it evolves can ensure that policies and programs meet current and evolving industry needs.}

EV workforce development policies and programs, like their counterparts in the solar and wind industries, must understand and be responsive to labor market (i.e., supply-demand) dynamics in order to prepare a sufficient number of skilled workers for jobs that exist now and will exist in the future. As Friedman et al. (2011) point out (with reference to solar, but applicable to EVs), labor intensity changes over time, because as an industry matures, labor productivity typically improves. Key labor market factors that decision-makers should regularly consider to build and expand EVs include:

- Types of occupations needed: What types of occupations are needed to build and sustain EVs in a local, regional, national market? Are there existing occupations that could expand into this space (with additional training) or are entirely new jobs and skill sets needed? 
- Anticipated growth rate for jobs: How many jobs will be needed to support EV deployment and when? How can one ensure that labor supply and demand match? How will job growth change as the industry expands?

- Current challenges facing firms: How difficult is it for firms to find qualified labor? What skillsets do firms need?

- Size of local job markets and regional distribution of jobs: How can one discourage the training workers into non-existent or declining job markets? What kind of firms hire for specific types of roles in the EV market? Where are they located?

- Typical wages: What are employers willing to pay for services? What kind of wages can workers expect in this industry? How do these wages compare with the cost of education required to perform in these jobs?

- Equity concerns: How can representation of women and other minorities in EV workforce development be best increased?

\section{EV deployment may create new jobs across multiple sectors.}

Anticipated growth in EV deployment raises questions about if, how, and when jobs may be affected. In particular, established automotive industries in Europe and the United States have voiced concern about the potential effects of electromobility on manufacturing jobs, largely because production of battery electric cars is expected to be less complex and labor intensive ${ }^{32}$ than ICEs (Fraunhofer IAO 2018; Dawson, Naughton, and Coppola 2019; Harrison 2018; Perk et al. 2018). A Fraunhofer report commissioned by the German automotive industry estimates that from 2017-2030, 75,000 of the current 210,000 car manufacturing jobs in Germany will be lost, with $27 \%$ of these job losses attributable to electromobility and the remaining majority due to productivity gains (Fraunhofer IAO 2018). Other European-focused reports estimate that: (1) the European automotive industry will remain stable until 2030 (Harrison 2018); and (2) on net, electromobility creates permanent jobs across the new "electromobility value chain" (Harrison 2018; Perk et al. 2018). Perk et al. (2018) categorize electromobility jobs by:

- Production of batteries and chargers

- Sales of electrical equipment

- Installation, connection to grid, operation and maintenance of chargers

- Associated grid reinforcements

- Civil and road work

- Production of additional electricity.

These study results are sensitive to key assumptions, notably EV market share and location of battery manufacturing. ${ }^{33}$ On the other hand, several countries in the developing world with notable traditional automotive industries such as Thailand, see great opportunity to become regional hubs for EV production and are aligning national policies to support this objective (Thanthong-Knight 2021). Similarly, Vietnam's existing EV automaker, VinFast, has ambitions plans to expand its research, development, and manufacturing capacity, which are bolstered by supportive government policies to incentivize purchase of VinFast vehicles (Deloitte 2021).

Importantly, research to date notes that electromobility will transform employment as we know it, as jobs are expected to shift "downstream" away from manufacturing to installation, operation, and maintenance of charging points (Figure 20) (Perk et al. 2018; Harrison 2018; Deloitte 2021). Understanding how EV deployment may affect traditional auto manufacturing and job development more broadly can help decision-makers determine if and how some types of workers will be displaced and prepare retraining programs in response.

\footnotetext{
${ }^{32}$ Although hybrid vehicle manufacturing may be more complex and labor-intensive.

${ }^{33}$ Most expect battery manufacturing to take place outside of Europe.
} 

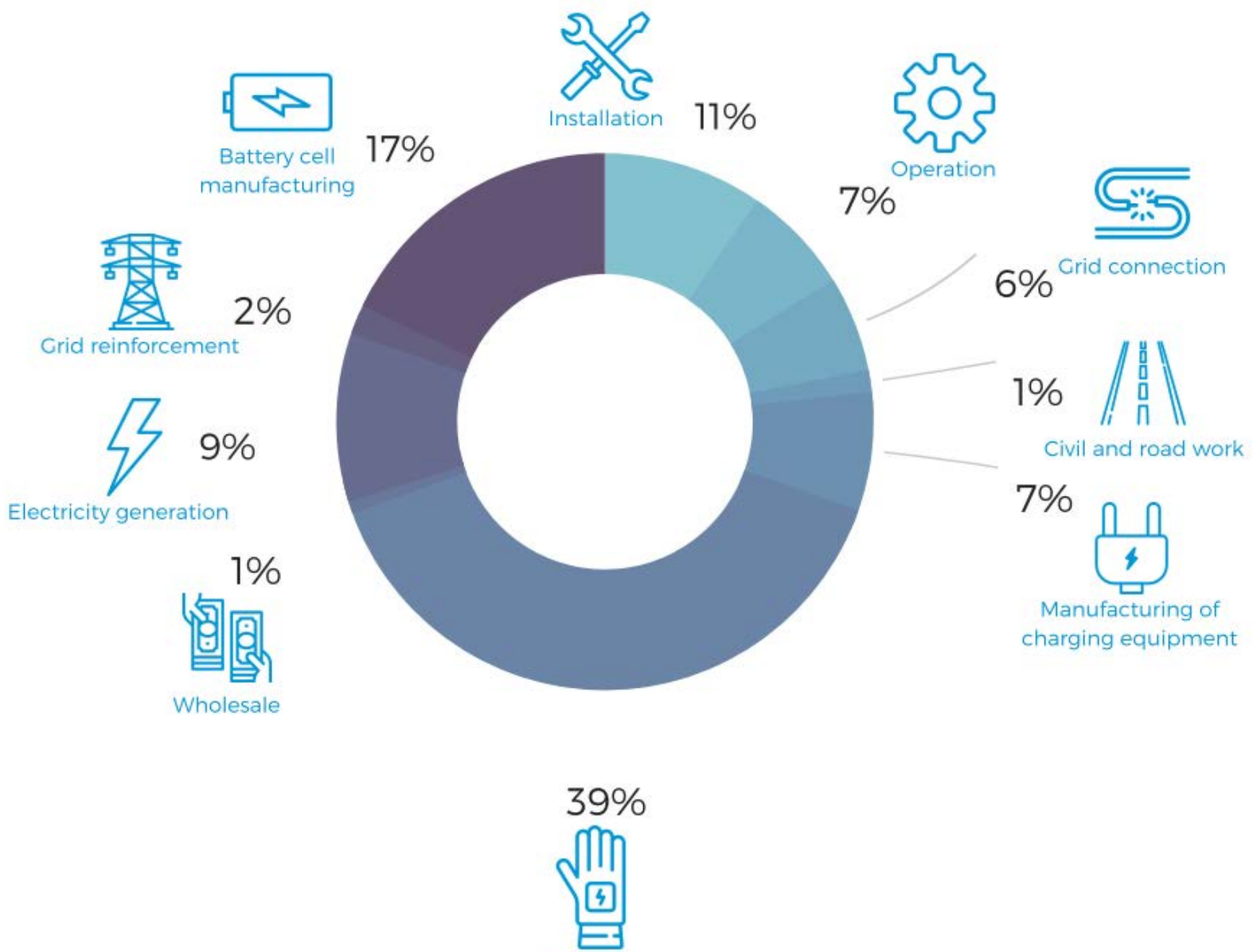

Maintenance

Figure 20. Anticipated types of jobs in "electromobility value chain"

Source: (Perk et al. 2018)

For developing countries, these study results shed light on where across the EV value chain job opportunities may lie and thus suggest key workforce areas for reinforcement, development, or expansion. Even if countries do not have established automotive or battery manufacturing industries (or anticipate them developing), as is the case in much of the world, EV deployment still holds the promise of job creation across other important sectors. 


\section{Conclusion}

Political leadership, private and public sector investments, battery technology innovations, industry commitments, and the decarbonization of the power sector are paving the way for a wholesale transformation of the transport sector. Stakeholders across the previously siloed transport and power sectors must interact in unprecedented ways as their sectors converge. While there is still much to learn from EV deployment in developed countries, developing countries face unique challenges as they face the task of deploying EVs quickly, intentionally, and at scale. USAID and NREL have seen firsthand the many motivations of developing countries for pursuing EVs and the key challenges and questions they face during this process.

The seven building blocks for vehicle electrification outlined in this report can guide decision-makers through the exciting but challenging task of preparing their communities for safe, effective, and clean EVs and their corresponding infrastructure. High upfront costs mean that EVs and EVSE typically require several complementary targets and incentives to catalyze a robust EV market. Data management helps identify the potential benefits of vehicle electrification and enables well-designed strategies to scale EV deployment in a targeted manner. Establishing charging infrastructure can be done in a variety of ways and is paramount to spurring EV adoption. Experience shows waiting for "sufficient" EV deployment to justify charging infrastructure development results in a much slower uptake of EVs by consumers. Private sector engagement to finance and build EV charging structure will be crucial for most countries. Charging infrastructure and EVs require standards and communications protocols to guarantee a compatible, reliable, and safe operating environment for EVs that meets customer expectations. New EV loads on the electric grid present both challenges and opportunities for utilities, so grid planning and management is essential for timely and cost-effective deployment of EVSE networks. The electricity required to charge EVs has a cost and requires appropriate pricing, which is why thoughtful electricity tariff design for $\mathbf{E V}$ charging is critical to supporting utility cost recovery associated with hosting EVSE and influencing grid-optimal customer charging behavior. And as with any emerging technology, EVs promise new job opportunities, but must be met with useful and timely workforce development strategies to support EV markets. By executing on these building blocks in parallel, developing countries can unleash the promises that EVs hold in terms of decarbonization, improved local air quality, enhanced mobility, resilience, and economic development.

These building blocks provide a framework for understanding key pillars of electrifying vehicles, but additional technical information may be necessary to design programming around EV deployment. We suggest the following resources for further reading, as well as Greening the Grid's Electric Vehicle Toolkit, which is regularly updated with new, curated EV resources. 
Table 9. Additional Resources

\begin{tabular}{|c|c|}
\hline Topic & Additional Reading \\
\hline EV and EVSE Basics & Electric Vehicle Outlook 2020 (BNEF 2020) \\
\hline $\begin{array}{l}\text { Targets and Incentives for EV } \\
\text { and EVSE Deployment }\end{array}$ & $\begin{array}{l}\text { Effectiveness of Electric Vehicle Policies and Implications for } \\
\text { Pakistan (Hodge, O'Neill, Coney 2020) } \\
\text { Comparison of Leading Electric Vehicle Policy and Deployment in } \\
\text { Europe (Tietge et al. 2016) }\end{array}$ \\
\hline $\begin{array}{l}\text { Establishing a Network of } \\
\text { Charging Infrastructure }\end{array}$ & $\begin{array}{l}\text { Utility Best Practices for EV Infrastructure Deployment (SEPA } \\
\text { 2020) } \\
\text { Plug-in Electric Vehicle Handbook for Public Charging Station } \\
\underline{\text { Hosts (DOE 2012) }}\end{array}$ \\
\hline Grid Planning and Management & $\begin{array}{l}\text { A Comprehensive Guide to Electric Vehicle Managed Charging } \\
\text { (SEPA 2019) } \\
\text { Preparing for an Electric Vehicle Future: How Utilities can } \\
\underline{\text { Succeed (SEPA 2019) }}\end{array}$ \\
\hline Tariff Design & $\begin{array}{l}\text { Electric Vehicle Supply Equipment: Tariff Design Support to the } \\
\text { Lao PDR (Zinaman et al. 2020) } \\
\text { Residential Electric Vehicle Time-Varying Rates that Work: } \\
\text { Attributes that Increase Enrollment (SEPA 2019) }\end{array}$ \\
\hline $\begin{array}{l}\text { Workforce Development } \\
\text { Strategies }\end{array}$ & $\begin{array}{l}\text { Powering a New Value Chain in the Automotive Sector: The Job } \\
\text { Potential of Transport Electrification (Pek et al. 2018) }\end{array}$ \\
\hline
\end{tabular}




\section{References}

Aleatica. 2017. "Relevant events: Launched the EcoTag Toll." June 12, 2017. https://inversionistasmx.aleatica.com/ecotag-toll-service/.

AFDC (Alternative Fuels Data Center). 2018. Electric Vehicle Charger Selection Guide. https://afdc.energy.gov/files/u/publication/EV_Charger_Selection_Guide_2018-01-112.pdf.

AFDC. 2020. "Home Page." https://afdc.energy.gov/.

Amir, Jamal. 2019. "New Vehicle Sales in Malaysia Surge in January, Production Plunges." IHS Markit. February 27, 2019. https://ihsmarkit.com/research-analysis/new-vehicle-sales-in-malaysia-surge-injanuary-production-plun.html.

Baring-Gould, Ian. 2011. "Wind Energy Workforce Development: A Roadmap to a Wind Energy Educational Infrastructure.” NREL/PR-7A20-51599. May 25, 2011. https://www.nrel.gov/docs/fy11osti/51599.pdf.

Bedir, Abdulkadir, Noel Crisostomo, Jennifer Allen, Eric Wood, and Clément Rames. 2018. California Energy Commission STAFF REPORT California Plug-In Electric Vehicle Infrastructure Projections: 2017- 2025 Future Infrastructure Needs for Reaching the State's ZeroEmission-Vehicle Deployment Goals. Sacramento, CA: California Energy Commission. CEC-600-2018-001. https://www.nrel.gov/docs/fy18osti/70893.pdf.

Bennett, Jesse C, Cabell Hodge, Charles W Kurnik, Kosol Kiatreungwattana, Lauren Lynch, and James A Salasovich. 2019. Electric Vehicle Supply Equipment Tiger Team Site Assessment Findings from Army Facilities. Golden, CO: NREL. NREL/TP-5400-74538. https://doi.org/10.2172/1573461.

Bloomberg New Energy Finance. 2017. “U.S. Utilities Offer Multiple Electric Car Charging Rates | BloombergNEF.” July 2017. https://about.bnef.com/blog/u-s-utilities-offer-multiple-electric-carcharging-rates/.

Bolduc, April. 2020. Utility Best Practices for EV Infrastructure Deployment. Smart Electric Power Association (SEPA). https://sepapower.org/resource/best-practices-for-utility-ev-infrastructure-deployment/.

Brooker, Aaron, Jeffrey Gonder, Lijuan Wang, Eric Wood, Sean Lopp, and Laurie Ramroth. 2015. "FASTSim: A Model to Estimate Vehicle Efficiency, Cost and Performance." In SAE International, 2015-01-0973. https://doi.org/10.4271/2015-01-0973.

Chaudhary, Vikram. 2020. "Turn your car into a hybrid for just Rs 1-2 lakh, here's how!" Express Drives. April 11, 2020. https://www.financialexpress.com/auto/car-news/turn-your-car-into-a-hybrid-for-just-rs-1-2lakh-heres-how-retrofit-manual-gearbox-petrol-diesel/1925575/.

Climate Technology Centre and Network. 2018. Government of Tonga Energy Efficiency Master Plan. The United Nations. https://www.ctc-n.org/system/files/dossier/3b/deliverable_3.3._final_teemp.pdf.

Coignard, Jonathan, Samveg Saxena, Jeffrey Greenblatt, and Dai Wang. 2018. "Clean Vehicles as an Enabler for a Clean Electricity Grid." Environmental Research Letters (May).

https://iopscience.iop.org/article/10.1088/1748-9326/aabe97/meta.

Cui, Hongyang, Dale Hall, and Nic Lutsey. 2020. Update on the Global Transition to Electric Vehicles through 2019. International Council on Clean Transportation (ICCT).

https:/theicct.org/sites/default/files/publications/update-global-EV-stats-20200713-EN.pdf.

Dawson, Chester, Keith Naughton, and Gabrielle Coppola. 2019. “'They Don’t Need Us Anymore': Auto Workers Fear Electric Unrest.” September 27, 2019. https://finance.yahoo.com/news/don-t-us-anymoreauto-090000918.html. 
Deloitte. 2021. "Full Speed Ahead: Supercharging Electric Mobility in Southeast Asia." Future of Mobility Solution Centre. https://www2.deloitte.com/content/dam/Deloitte/sg/Documents/strategy/sea-strategyoperations-full-speed-ahead-report.pdf.

Ecola, Liisa, Charlene Rohr, Johanna Zmud, Tobias Kuhnimhof, and Peter Phleps. 2014. The Future of Driving in Developing Countries. https://www.rand.org/pubs/research_reports/RR636.html.

EERE. 2021. "Charging at Home.” Electric Vehicles. https://www.energy.gov/eere/electricvehicles/charginghome.

Electric Nation. 2019. Summary of the Findings of the Electric Nationa Smart Charging Trial. https://www.electricnation.org.uk/wp-content/uploads/2019/07/Electric-Nation-Trial-Summary-A4.pdf.

Engel, Hauke, Russell Hensley, Stefan Knupfer, and Shivika Sahdev. 2018. "The Basics of Electric-Vehicle Charging Infrastructure | McKinsey \& Company.” August 16, 2018. https://www.mckinsey.com/industries/automotive-and-assembly/our-insights/charging-aheadunderstanding-the-electric-vehicle-infrastructure-challenge.

Fitzgerald, Garrett, Chris Nelder, and James Newcomb. 2017. Electric Vehicles as Distributed Energy Resources. Boulder, CO: Rocky Mountain Institute. https://rmi.org/wpcontent/uploads/2017/04/RMI_Electric_Vehicles_as_DERs_Final_V2.pdf.

Fraunhofer IAO. 2018. ELAB 2.0 Wirkungen Der Frahrzeugelektrifizierung Auf Die Beschäftigung Am Standort Deutschland. https://www.iao.fraunhofer.de/lang-de/images/iao-news/elab20.pdf.

Friedman, B, P Jordan, and J Carrese. 2011. Solar Installation Labor Market Analysis. Golden, CO: NREL. NREL/TP-6A20-49339. https://doi.org/10.2172/1031395.

Funke, Simon Árpád, Frances Sprei, Till Gnann, and Patrick Plötz. 2019. "How Much Charging Infrastructure Do Electric Vehicles Need? A Review of the Evidence and International Comparison." Transportation Research Part D: Transport and Environment 77 (December): 224-42. https://doi.org/10.1016/j.trd.2019.10.024.

Government of India. 2012. National Electric Mobility Mission 2020. https://dhi.nic.in/writereaddata/content/nemmp2020.pdf.

Government of India. 2019. Publication of Notification in Gazette of India Regarding Phase-II of FAME India Scheme. https://dhi.nic.in/writereaddata/UploadFile/publicationNotificationFAME\%20II\%208 March2019.pdf.

Hardman, Scott, Alan Jenn, Jonn Axsen, George Beard, Erik Figenbaum, Sten Karlsson, Daniel Sperling, Tom Turrentine, and Bert Witkamp. 2018. Driving the Market for Plug-in Vehicles: Understanding ZEV Mandates. https://phev.ucdavis.edu/wp-content/uploads/zev-mandates-policy-guide.pdf.

Hardman, Scott, Alan Jenn, Gil Tal, Jonn Axsen, George Beard, Nicolo Daina, Erik Figenbaum et al. 2018. "A Review of Consumer Preferences of and Interactions with Electric Vehicle Charging Infrastructure." Transportation Research Part D: Transport and Environment 62 (July): 508-23. https://doi.org/10.1016/j.trd.2018.04.002.

Harrison, Pete. 2018. Fuelling Europe's Future: How the Transition from Oil Strengthens the Economy. Cambridge Econometrics. http://www.camecon.com/wp-content/uploads/2018/02/ECF-FuellingEurope_EN_web.pdf.

IEA. 2020a. “Energy Prices 2020.” IEA. https://www.iea.org/reports/energy-prices-2020.

. 2020b. “Global EV Outlook 2020.” IEA. https://www.iea.org/reports/global-ev-outlook-2020. 
IEA. 2021. "Electric Vehicles Initiative: Accelerating the introduction and adoption of electric vehicles worldwide." Programmes and partnerships. https://www.iea.org/areas-of-work/programmes-andpartnerships/electric-vehicles-initiative.

Johnson, C. 2013. Guam Transportation Petroleum-Use Reduction Plan. Golden, CO: NREL. NREL/TP-7A3057191. https://doi.org/10.2172/1078064.

Johnson, Caley. 2011. U.S. Virgin Islands Transportation Petroleum Reduction Plan. Golden, CO: NREL. NREL/TP-7A40-52565. https://doi.org/10.2172/1024056.

Johnson, Caley, Sanjini Nanayakkara, Jeff Cappellucci, and Matthew Moniot. 2020. Foundations of an Electric Mobility Strategy for the City of Mexicali. Golden, CO: NREL. NREL/TP-5400-75690. https://afdc.energy.gov/files/u/publication/electric_mobility_strategy_mexicali.pdf.

Johnson, Caley R, Samuel Koebrich, and Mark R Singer. 2019. Jamaica Transportation Greenhouse Gas Reduction Plan. Golden, CO: NREL. NREL/TP-5400-73380, 1507689. https://doi.org/10.2172/1507689.

Kodjak, Drew. 2017. "China Publishes Updated Fuel Economy Standards with Mandate for EVs." GFEI| Global Fuel Economy Initiative (blog). October 11, 2017. https://www.globalfueleconomy.org/blog/2017/october/china-publishes-updated-fuel-economy-standardswith-mandate-for-evs.

Kundi, Imran Ali. 2020. "Gov't to consult all stakeholders for revising Electric Vehicle Policy." The Nation. April 7, 2020. https://nation.com.pk/07-Apr-2020/govt-to-consult-all-stakeholders-for-devising-electricvehicle-policy?version=amp.

Lars Kamer. 2019. "South Africa: Modes of Transport to Get to Work.” Statista. May 2019. https://www.statista.com/statistics/1116074/distribution-of-transportation-used-to-get-to-work-in-southafrica/.

Lutsey, Nic. 2017. Integrating Electric Vehicles within U.S. and European Efficiency Regulations. International Council on Clean Transportation (ICCT). https://theicct.org/sites/default/files/publications/IntegratingEVs-US-EU_ICCT_Working-Paper_22062017_vF.pdf.

Michigan Alliance for Greater Mobility Advancement. 2020. "MAGMA - Michigan Alliance for Greater Mobility Advancement." https://miautomobility.org/.

MJB\&A. 2019. "Electric Vehicle Charging Interoperability." MJB\&A Issue Brief. https://mjbradley.com/sites/default/files/MJB\%26A\%20Interoperability\%20Issue\%20Brief\%20May\%202 019.pdf.

Nelder, Chris. 2018. "Rate Design Considerations for EV Charging." Presented at the ACEEE National Convening on Utilities and Electric Vehicles, Atlanta, GA, November 14, 2018. https://www.aceee.org/sites/default/files/pdf/conferences/ev/nelder.pdf.

Narassimhan, Easwaran, and Caley Johnson. 2018. "The Role of Demand-Side Incentives and Charging Infrastructure on Plug-in Electric Vehicle Adoption: Analysis of US States." Environmental Research Letters 13 (7): 074032. https://doi.org/10.1088/1748-9326/aad0f8.

National Fire Protection Association. n.d. "NFPA - Alternative Fuel Vehicles Safety Training Program." Accessed August 31, 2020. https://www.nfpa.org/Training-and-Events/By-topic/Alternative-FuelVehicle-Safety-Training.

New Zealand Ministry of Transport. 2018. "New Zealand Household Travel Survey." https://www.transport.govt.nz/area-of-interest/public-transport/new-zealand-household-travel-survey/. 
Newman, Peter, and Jeffery Kenworthy. 2015. The End of Automobile Dependence: How Cities Are Moving Beyond Car-Based Planning. Island Press: Washington, D.C. https://islandpress.org/books/endautomobile-dependence.

Nicholas, Michael, and Dale Hall. 2018. Lessons Learned on Early Electric Vehicle Fast-Charging Deployments. ICCT. https://theicct.org/sites/default/files/publications/ZEV_fast_charging_white_paper_final.pdf.

Noel, Lance, and Benjamin K. Savacool. 2016. "Why Did Better Place Fail?: Range anxiety, interpretive flexibility, and electric vehicle promotion in Denmark and Israel." Energy Policy 94 (July): 377-386. https://www.sciencedirect.com/science/article/pii/S0301421516301987?via\%3Dihub.

NREL. 2019. "Fleet DNA: Commercial Fleet Vehicle Operating Data | Transportation Research | NREL.” 2019. https://www.nrel.gov/transportation/fleettest-fleet-dna.html.

.n.d. "Workforce Development Analysis." Accessed August 31, 2020.

https://www.nrel.gov/analysis/workforce-development.html.

Perk, Alyssa, Giorgia Concas, Janne Skogberg, Lucien Mathieu, and Oddvin Breiteig. 2018. Powering a New Value Chain in the Automotive Sector: The Job Potential of Transport Electrification. The European Association of Electrical Contractors. https://download.dalicloud.com/fis/download/66a8abe211271 fa0ec3e2b07/c572c686-f52f-4c0d-88fc51f9061126c5/Powering_a_new_value_chain_in_the_automotive_sector__the_job_potential_of_transport_electrification.pdf.

Pillai, Reji Kumar, Reena Suri, Suddhasatta Kundu, Harpreet Singh, Shuvam Sarkar Roy, and Shreekant Dhuri. 2018. Electric Vehicle Charging Stations Business Models for India. India Smart Grid Forum. https://indiasmartgrid.org/reports/ISGF\%20White\%20Paper\%20\%20EVSE\%20Business\%20Models\%20for\%20India.pdf.

P\&S Intelligence. 2020. "Insights on Battery Swapping Market for Electric Two and Three Wheeler Industry: P\&S Intelligence." October 15, 2020. https://www.prnewswire.com/news-releases/insights-on-batteryswapping-market-for-electric-two-and-three-wheeler-industry-ps-intelligence-301153091.html.

Randall, Chris. 2019. "Korea aims for 33\% of new vehicles electrified by 2030." Electrive.com. October 15, 2019. https://www.electrive.com/2019/10/15/south-korea-aims-for-33-of-vehicles-electrified-by-2030/.

Rogge, Matthias, Sebastian Wollny, and Dirk Uwe Sauer. 2015. "Fast Charging Battery Buses for the Electrification of Urban Public Transport-A Feasibility Study Focusing on Charging Infrastructure and Energy Storage Requirements.” Energies 8 (5): 4587-4606. https://doi.org/10.3390/en8054587.

Rojko, Andreja, and Marijan Španer. 2013. "Education in Sustainable Energy for Professionals from Industry and Teachers." In 2013 7th IEEE International Conference on E-Learning in Industrial Electronics (ICELIE), 108-13. https://doi.org/10.1109/ICELIE.2013.6701282.

Rokadiya, Shikha, and Zifei Yang. 2019. Overview of Global Zero-Emission Vehicle Mandate Programs. International Council on Clean Transportation (ICCT). https:/theicct.org/sites/default/files/publications/Zero\%20Emission\%20Vehicle\%20Mandate\%20Briefing \%20v2.pdf.

Sahoo, Anshuman, Karan Mistry, and Thomas Baker. 2019. "The Costs of Revving Up the Grid for Electric Vehicles.” December 20, 2019. https:/www.bcg.com/publications/2019/costs-revving-up-the-grid-forelectric-vehicles.

Salas, Erick Burgueño. 2018. "Most Frequently Used Transport Modes in Chile 2018.” Statista. February 2018. https://www.statista.com/statistics/909952/chile-most-used-transport-mode/.

Sawatch Labs. 2020. “EzEV Analytics.” https://sawatchgroup.com/ezev.html. 
SEPA (Smart Electric Power Alliance). 2019. A Comprehensive Guide to Electric Vehicle Managed Charging.

Shirk, Matthew, and Jeffrey Wishart. 2015. "Effects of Electric Vehicle Fast Charging on Battery Life and Vehicle Performance.” SAE International 2015-01-1190. https://doi.org/10.4271/2015-01-1190.

Smith, Margaret, and Jonathan Castellano. 2015. Costs Associated With Non-Residential Electric Vehicle Supply Equipment: Factors to consider in the implementation of electric vehicle charging stations. Washington, D.C.: DOE. DOE/EE-1289. https://afdc.energy.gov/files/u/publication/evse_cost_report_2015.pdf.

Szinai, Julia K., Colin J. R. Sheppard, Nikit Abhyankar, and Anand R. Gopal. 2020. "Reduced Grid Operating Costs and Renewable Energy Curtailment with Electric Vehicle Charge Management." Energy Policy 136 (January): 111051. https://doi.org/10.1016/j.enpol.2019.111051.

Thanthong-Knight, Randy. 2021. "Thailand Lays Out Bold EV Plan, Wants All Electric Cars by 2035." Bloomberg.Com, April 22, 2021. https://www.bloomberg.com/news/articles/2021-04-22/thailand-laysout-bold-ev-plan-wants-all-electric-cars-by-2035.

Uddin, Moaz. 2020. "Pakistan's National Electric Vehicle Policy: Charging toward the future." ICCT. January 10, 2020. https://theicct.org/blog/staff/pakistan\%E2\%80\%99s-national-electric-vehicle-policy-chargingtowards-future.

U.S. Department of Energy. 2020. "Federal Tax Credits for All-Electric and Plug-in Hybrid Vehicles." Fueleconomy. November 2020. https://www.fueleconomy.gov/feg/taxevb.shtml.

U.S. Department of Energy. 2012. Plug-In Electric Vehicle Handbook for Public Charging Station Hosts. Golden, CO: NREL. DOE/GO-102012-3275. https://afdc.energy.gov/files/pdfs/51227.pdf.

Wilson, Dan. 2019. "Preparing for an Electric Vehicle Future: How Utilities Can Succeed.” SEPA. https://sepapower.org/resource/preparing-for-an-electric-vehicle-future-how-utilities-can-succeed/.

Wood, Eric, Clément Rames, Matteo Muratori, Sesha Raghavan, and Marc Melaina. 2017. National Plug-In Electric Vehicle Infrastructure Analysis. Washington, D.C.: DOE. DOE/GO-102017-5040. https://www.nrel.gov/docs/fy17osti/69031.pdf.

Yeh, C.-P., G.Y.-J. Liao, and J.L. Petrosky. 2013. "A University and Community College Partnership to Meet Industry Needs for Future Workers in Advanced Automotive Technology." Presented at the ASEE Annual Conference and Exposition, Atlanta, GA, June 23, 2013. https://peer.asee.org/a-university-andcommunity-college-partnership-to-meet-industry-needs-for-future-workers-in-advanced-automotivetechnology.

Zinaman, Owen, Kaylyn Bopp, Nathan Lee, and Laura Beshilas. 2020. "Electric Vehicle Supply Equipment: Tariff Design Support to the Lao PDR.” Presented at virtual meeting, July 22, 2020. NREL/PR-7A4077747. https://www.nrel.gov/docs/fy20osti/77747.pdf. 
